NBER WORKING PAPER SERIES

\title{
FROM IMMEDIATE ACCEPTANCE TO DEFERRED ACCEPTANCE: EFFECTS ON SCHOOL ADMISSIONS AND ACHIEVEMENT IN ENGLAND
}

\author{
Camille Terrier \\ Parag A. Pathak \\ Kevin Ren \\ Working Paper 29600 \\ http://www.nber.org/papers/w29600 \\ NATIONAL BUREAU OF ECONOMIC RESEARCH \\ 1050 Massachusetts Avenue \\ Cambridge, MA 02138 \\ December 2021
}

We thank John Coldron and Anne West for sharing data on schools. Simon Burgess, Julien Combe, Ellen Greaves, Rustamdjan Hakimov, Adam Kapor, Sandra McNally, Jonathan de Quidt, Olmo Silva, and Olivier Tercieux and seminar participants at the London School of Economics, ASSA 2020 meetings, Barcelona GSE, CESifo Area conference on economics of education, CREST Polytechnique, Bristol, Berlin, and Lausanne provided helpful feedback. We're especially grateful to Kate Bradley and Tiernan Evans for research assistance and Eryn Heying for invaluable administrative support. We are very grateful for the research assistance provided by the Centre for Economic Performance (LSE). We gratefully acknowledge funding from the Walton Foundation. The views expressed herein are those of the authors and do not necessarily reflect the views of the National Bureau of Economic Research.

At least one co-author has disclosed additional relationships of potential relevance for this research. Further information is available online at http://www.nber.org/papers/w29600.ack

NBER working papers are circulated for discussion and comment purposes. They have not been peer-reviewed or been subject to the review by the NBER Board of Directors that accompanies official NBER publications.

(C) 2021 by Camille Terrier, Parag A. Pathak, and Kevin Ren. All rights reserved. Short sections of text, not to exceed two paragraphs, may be quoted without explicit permission provided that full credit, including $\odot$ notice, is given to the source. 
From Immediate Acceptance to Deferred Acceptance: Effects on School Admissions and Achievement in England

Camille Terrier, Parag A. Pathak, and Kevin Ren

NBER Working Paper No. 29600

December 2021

JEL No. D47,I20

\section{ABSTRACT}

Countries and cities around the world increasingly rely on centralized systems to assign students to schools. Two algorithms, deferred acceptance (DA) and immediate acceptance (IA), are widespread. The latter is often criticized for harming disadvantaged families who fail to get access to popular schools. This paper investigates the effect of the national ban of the IA mechanism in England in 2008. Before the ban, 49 English local authorities used DA and 16 used IA. All IA local authorities switched to DA afterwards, giving rise to a cross-market differencein-differences research design. Our results show that the elimination of IA reduces measures of school quality for low-SES students more than high-SES students. After the ban, low-SES students attend schools with lower value-added and more disadvantaged and low-achieving peers. This effect is primarily driven by a decrease in low-SES admissions at selective schools. Our findings point to an unintended consequence of the IA to DA transition: by encouraging highSES parents to report their preferences truthfully, DA increases competition for top schools, which crowds out low-SES students.

Camille Terrier

Faculty of Business and Economics

University of Lausanne

Internef 553

CH-1015 Lausanne-Dorigny

Switzerland

camille.terrier@unil.ch

Parag A. Pathak

Department of Economics, E52-426

MIT

77 Massachusetts Avenue

Cambridge, MA 02139

and NBER

ppathak@mit.edu
Kevin Ren

2211 Campus Dr

Kellogg School of Management

Northwestern University

Evanston, IL 60208

USA

kevin.ren@ kellogg.northwestern.edu 


\section{Introduction}

The use of centralized assignment systems in education markets has risen sharply in recent years. Between 1970 and 2020, more than 90 countries have adopted centralized systems to assign students to schools or universities (CCAS Project, 2021). These systems have three common features: (i) students submit preferences over schools, (ii) schools use admission criteria to prioritize students, and (iii) a central administration uses an algorithm to determine admission offers. When facing this last choice, more than thirty countries have adopted deferred acceptance (DA) and a dozen have chosen immediate acceptance (IA). The widespread adoption of these two schemes has led to active discussions on their benefits and costs.

DA is strategy-proof, meaning that participants do not gain from reporting their preferences untruthfully. Under IA, participants could gain from reporting preferences dishonestly (Abdulkadiroğlu and Sönmez, 2003). The scope for preference manipulation in IA has given rise to two main concerns. First, IA is criticized for harming families who may be less sophisticated about admissions procedures (Abdulkadiroğlu et al., 2006; Pathak and Sönmez, 2008). ${ }^{1}$ Second, growing evidence from cities using IA shows that low-SES families are usually those who do not understand how to strategize (Dur, Hammond and Morrill, 2018; Abdulkadiroğlu et al., 2006; Calsamiglia and Güell, 2018; Agarwal and Somaini, 2018). The type of mechanism used and its vulnerability to parent strategies could therefore contribute to socioeconomic gaps in school access and educational outcomes.

Concerns about the harm of IA for low-SES families motivated several authorities, including in Amsterdam, Boston, and China, to replace IA by variants of DA (Pathak, 2016; Chen and Kesten, 2017; de Haan et al., 2018). Our study focuses on England, which banned IA throughout the country in 2008 through an Act of Parliament, in part because "those who get it wrong or don't understand, lose out" (Carter, 2006). We study how the transition from IA to DA in England affected school admissions and achievement for low and high-SES students. We use evidence of an SES gradient in parent strategies to motivate our assumption that socioeconomic status proxies for levels of sophistication.

Theoretically, whether low-SES students benefit from moving to DA is unclear. On one hand, survey evidence shows that parents have incorrect beliefs about admission chances (Kapor, Neilson and Zimmerman, 2020). This leads sophisticated parents to strategically avoid ranking overdemanded schools in which they could sometimes have been accepted. ${ }^{2}$ These costly mistakes reduce the competition faced by low-SES students and allows them to access sought-after schools.

\footnotetext{
${ }^{1}$ Immediate acceptance is also known as the Boston mechanism.

${ }^{2}$ Several lab experiments show high levels of preference manipulation under immediate acceptance (Chen and Sönmez, 2006; Pais and Pintér, 2008; Calsamiglia, Haeringer and Klijn, 2011), a finding which has been confirmed in various cities that use the IA mechanism or a variant, such as Barcelona, Beijing, Cambridge MA, or New Haven (Agarwal and Somaini, 2018; He, 2017; Calsamiglia and Güell, 2018; Kapor, Neilson and Zimmerman, 2020).
} 
We refer to this as the competition-for-top-schools effect. ${ }^{3}$ At the same time, low-SES students who rank schools truthfully under IA may have lower admissions chances at second or third choices because they obtain admissions offers only after other students who rank those schools first. We term this the trickle-down effect. Ultimately, how much low-SES students benefit (or lose) from IA depends on whether the competition-for-top-schools effect dominates the trickle-down effect. That balance depends on the uncertainty on admission chances, the level of competition for top schools, and the extent of oversubscription on second and third choices.

Empirically, whether low-SES students benefit from moving to a strategy-proof mechanism is also unclear. Substantial progress has been made in estimating welfare effects of the IA-to-DA transition using data on applicant rankings under the IA mechanism and variants (Agarwal and Somaini, 2018; Calsamiglia, Fu and Güell, 2020; de Haan et al., 2018; He, 2017; Hwang, 2017; Kapor, Neilson and Zimmerman, 2020). By combining choice models, new methods to recover preferences from untruthful mechanisms, and within-market counterfactual analysis, these studies compare allocations and welfare under DA and IA. Research finds mixed evidence on whether unsophisticated parents benefit more than sophisticated parents. ${ }^{4}$ An alternative approach compares outcomes across IA and DA markets that change mechanisms. However, evidence based on such cross-market comparisons is scant, primarily due to the lack of comparison markets that change mechanisms. ${ }^{5}$

A nationwide reform that banned IA in England provides an opportunity to fill this gap. In 2008, a portion of English local authorities (entities similar to US school districts) switched from IA to DA. Before the reform, 49 local authorities used DA and 16 used IA. ${ }^{6}$ After the ban, all IA local authorities switched to DA. Using a difference-in-differences research design, we compare the evolution of outcomes in the local authorities that went from IA to DA (the treated group) and those that used DA during the entire period (the control group). Our outcomes are students' access to their stated first choice school, school value-added, school peer composition, access to selective schools, and between-group achievement inequality three years after school assignment. ${ }^{7}$

We also study how the level of competition for students' top choices influences the effect of the IA-to-DA transition. The competition-for-top-schools effect suggests that the larger the competition for top-ranked schools, the more low-SES students gain from IA relative to DA when high-SES

\footnotetext{
${ }^{3}$ Dur, Hammond and Morrill (2018) and Pathak and Sönmez (2013) find suggestive evidence of this effect in Charlotte-Mecklenburg and Chicago.

${ }^{4}$ While many papers find that sophisticated parents lose more from the IA-to-DA transition than sincere parents (Agarwal and Somaini, 2018; He, 2017; Hwang, 2017), Calsamiglia, Fu and Güell (2020) find the opposite. Kapor, Neilson and Zimmerman (2020) show that students can benefit from DA over IA when parents have incorrect beliefs about admission chances.

${ }^{5}$ Chen, Jiang and Kesten (2020) and Song, Tomoeda and Xia (2020) are the only other studies, as far as we know, that study the effect of the transition from IA to DA in China. We discuss these papers further at the end of the introduction.

${ }^{6}$ There are 152 local authorities in England. Aside from the 16 IA and 49 DA authorities, the other local authorities use a mechanism that is hybrid between IA and DA, as explained in Section 3.

${ }^{7}$ We do not have individual data on parents' reported preferences. Data on students' access to their stated first choice school is aggregated at the local authority level.
} 
parents strategically avoid applying to top-ranked schools. Fortunately, England offers a rich environment to test this hypothesis because some local authorities have more heterogeneity in school performance and, as a result, greater levels of oversubscription at schools. ${ }^{8}$ Our hypothesis is that the effect of the IA ban is amplified in these competitive local authorities.

Before the reform, we find that the IA mechanism increased parents' access to their stated first choice by 26 percentage points ( $\mathrm{pp}$ ) compared to DA. This boost is only present in competitive local authorities. This fact supports our claim that the type of mechanism used is more likely to affect assignments in environments with significant competition over schools. Next, we find that access to stated first choice dropped by eight pp in competitive IA local authorities (compared to DA local authorities) in the two years that followed the ban of the IA mechanism. ${ }^{9}$ This effect size is on the lower end of those found by Chen, Jiang and Kesten (2020) after the IA-to-DA transition in China and may reflect differences in the competitive environment across the settings. ${ }^{10}$

We next examine whether high- and low-SES students were differentially affected by the ban. The first outcome we consider is the value-added of the school students attend, which we measure as the school's contribution to students success at the national GCSE exams, a high-stakes standardized assessment taken by all pupils in England at age $15{ }^{11}$ Value-added is an important outcome as low-SES students attend schools whose value-added is 10.4 pp lower than high-SES students before the 2008 reform. We find that the transition from IA to DA led to a $7.7 \%$ increase in this gap. In local authorities using IA (compared to DA), the value-added of the schools that low-SES students attended dropped by $0.8 \mathrm{pp}$ after the ban compared to the school value-added of high-SES students.

Reduced access to high value-added schools suggests that eliminating IA may not increase lowSES student achievement, but a school's value-added need not affect measures of student welfare if low-SES parents do not value school effectiveness (see, e.g., Abdulkadiroğlu et al. (2020)). We therefore also examine effects of the IA-to-DA transition on students' peers' characteristics. Research shows that parents prefer schools with high-achieving peers and high-SES peers (Black, 1999; Bayer, Ferreira and McMillan, 2007; Hastings and Weinstein, 2008; Burgess et al., 2015; Abdulkadiroğlu et al., 2020). We again find that the IA ban affected low-SES students more negatively than high-SES students: due to the ban, low-SES students became $1.6 \mathrm{pp}$ more likely to have

\footnotetext{
${ }^{8}$ Overall, about $31 \%$ of schools were oversubscribed in 2006 (Coldron et al., 2008).

${ }^{9} \mathrm{~A}$ gap in first choice access persists after 2008, but it shrinks when we control for differences in number of preferences reported by parents in IA and DA local authorities.

${ }^{10}$ In Chen, Jiang and Kesten (2020), ten million high school seniors compete for seven million seats in Chinese universities. $74 \%$ of students were assigned to their top-ranked choice under the IA mechanism. In contrast, only $31 \%$ of the schools were oversubscribed in England in 2006 and $93 \%$ of students were assigned their first choice in IA local authorities.

${ }^{11}$ A school value-added measures the school's contribution to a standard performance metric: earning a level 2 qualification in at least five of the General Certificate of Education (GCSE) exams including English and Mathematics. GCSE performance is part of the English school accountability system, and success is a requirement for secondary students to gain entry to sixth form, which are the final two years of secondary education.
} 
low-SES peers and peers with 0.03 standard deviations (SD) lower baseline test scores compared to high-SES students. ${ }^{12}$ This detrimental effect suggests that the benefit that low-SES parents obtain from lower competition for top schools under IA offsets the cost of not receiving their second or third choices, an effect previously observed by Agarwal and Somaini (2018) in Cambridge MA.

To further explore the competition-for-top-schools effect, we show that the effect on low-SES students is partly driven by a reduction in their chances of admission to selective schools. These schools admit pupils using admissions tests and are some of the most sought-after English schools. ${ }^{13}$ We consider the sample of competitive local authorities, and find that the effect of the IA ban is significantly larger in these local authorities. The negative effects for low-SES students on schools' value-added move from $-0.8 \mathrm{pp}$ to $-1.3 \mathrm{pp}$ in competitive local authorities. Similarly, the negative effects on peers' test scores moves from -0.029 SD to $-0.072 \mathrm{SD}$, the effect on the share of low-SES peers moves from $+1.6 \mathrm{pp}$ to $+3.1 \mathrm{pp}$, and the effect on access to selective schools moves from -1.1 pp to $-2.6 \mathrm{pp}$. The level of competition for students' top schools amplifies the effect of the IA ban.

Our research design leverages cross-market variation across 65 local authorities in the type of assignment mechanism. Although this setting is unique and the local authority is the natural unit of observation to study the effects of the mechanism change, relying on variation between local authorities might fail to capture effects of the ban within a local authority. Our results so far show that the competition-for-top-schools effect is larger in competitive local authorities, i.e., in local authorities that host a selective school. Yet, even in these competitive local authorities, selective schools might only affect competition locally. Many students who reside further away from selective schools and thus do not consider attendance may be unaffected by the ban. In that case, our estimates underestimate the effect that an IA ban would have in highly competitive environments. We therefore next examine local effects of the 2008 reform by analyzing school-level effects of the reform.

To study local competition effects, our school-level analysis takes advantage of a special feature of the British system: some schools (35\%) are free to choose their admission criteria. In 2007, $32 \%$ of these schools adopted an admissions criteria called first preference first (FPF) which gives higher priority to students who rank a school first. Using an FPF admissions criteria is a strategic device for schools: when faced with competition from neighboring selective schools, the FPF criterion encourages high-SES parents, who are worried that their admission chances for neighboring selective schools are too low, to rank the FPF school as their first choice. The FPF criterion was banned in 2008 and that allows us to directly examine the competition-for-top-schools effect at a local level. We document the effect of the ban on the composition of the schools that strategically adopted the FPF criterion in response to local competition.

\footnotetext{
${ }^{12}$ We find no evidence that the IA ban increased achievement inequalities between high- and low-SES students three years after enrolling in secondary school.

${ }^{13}$ In selective schools students' test scores are 0.4 SD higher, the share of low-SES students is 8 pp lower, and value-added is $7.8 \mathrm{pp}$ higher than non-selective schools.
} 
We use a difference-in-differences research design that compares the changes in school enrollment before and after the 2008 ban between schools that were forced to abandon the FPF criterion and schools that used the alternative equal preference (EP) criterion during the entire period. EP schools do not modify priorities based on how the school is ranked. We find that preventing schools from using the FPF admissions criteria had a large effect on enrollment. Compared to EP schools, FPF schools became less likely to enroll high-achieving students and more likely to enroll lowachievers and low-SES students. After the ban, former FPF schools enrolled 1.5 pp fewer students from the top decile of baseline achievement, $1.4 \mathrm{pp}$ more students from the bottom decile of baseline achievement, and $3.9 \mathrm{pp}$ more low-SES students. This reallocation of low-SES students to FPF schools provides additional support for the competition-for-top-schools-effect.

Our paper contributes to the literature on the effects of strategy-proof student assignment mechanisms. Several theoretical papers compare the welfare properties of the IA and DA mechanisms concluding that, in environments with complete information, assignments under DA are more efficient than under IA (Chen and Sönmez, 2006; Ergin and Sönmez, 2006) while the opposite can hold with imperfect information due to IA's ability to extract information on preference intensity (Abdulkadiroğlu, Che and Yasuda, 2011; Featherstone and Niederle, 2016; Miralles, 2009; Troyan, 2012). Papers using estimates of parents' preferences for schools and counterfactual analysis of assignments have found some support for IA in the aggregate and mixed findings across levels of sophistication (Kapor, Neilson and Zimmerman, 2020; Agarwal and Somaini, 2018; He, 2017; Calsamiglia, Fu and Güell, 2020; de Haan et al., 2018; Hwang, 2017). ${ }^{14}$ Accounting for parents' incorrect beliefs about admission chances leads to a reversal of the welfare results found by several papers: the IA-to-DA transition becomes welfare-improving, and welfare gains are larger for low-SES students (Kapor, Neilson and Zimmerman, 2020).

We complement this prior literature in several ways. First, in contrast to the approach based on choice models and counterfactual simulations, we examine a real-life change of mechanism, spanning more than 60 markets in England. Second, rather than focusing on school allocations as the main outcome, we study the effect of the IA ban on several policy-relevant outcomes following assignment, such as school value-added, peer composition, and student achievement. Examining these outcomes is important as the value of school assignments as estimated from revealed preferences need not be related to productive dimensions of school assignment (e.g., Abdulkadiroğlu et al. (2020)). Third, our data covers the universe of students in England for ten years and allows us to document the effect of a transition from IA to DA over time. Fourth, while papers based on simulation approaches model parents' behavior based on a number of behavioral assumptions, our reduced form approach

\footnotetext{
${ }^{14}$ Agarwal and Somaini (2018) and He (2017) found that high-SES (paid-lunch) students lose more than low-SES (free-lunch) students from an IA-to-DA switch in Cambridge and Beijing respectively. Calsamiglia, Fu and Güell (2020), on the other hand, report that welfare decreases more for non-strategic parents than for strategic ones when IA is replaced by DA. He (2017) finds that sincere parents suffer an $8 \%$ increase in the home-to-school distance when IA is replaced by DA, a cost which jumps to $40 \%$ for sophisticated parents.
} 
measures the overall effect of the IA-to-DA transition, giving outcomes that combine the direct effect of the algorithm change and any changes in applicant strategies. ${ }^{15}$ Finally, variation in level of competition for schools across British local authorities allows us to examine how competitiveness mediates the effects of the IA-to-DA transition.

Our paper is most closely related to Chen, Jiang and Kesten (2020) and Song, Tomoeda and Xia (2020). All three papers provide evidence on the IA-to-DA transition based on a real-life reform. Chen, Jiang and Kesten (2020) and Song, Tomoeda and Xia (2020) study college admission in China, while we consider secondary school admissions in England. This difference matters because Chinese college admissions are more competitive than secondary schools' admissions in England, and our analysis illustrates the importance of the competitive environment. ${ }^{16}$ Our paper also differs by covering more than 10 years of data (which allows us to examine pre-trends and study longerterm effects), considering a large set of outcomes (spanning access to first choice, school admissions, school value-added, and student achievement), focusing on the differential effect of the reform for high- and low-SES students, and investigating the role of the level of competition for top schools.

The next section describes the first preference first mechanism and discusses unequal levels of sophistication between applicants. Sections 3 and 4 provide details on the British institutional context and the data used to estimate the effect of the ban of the immediate acceptance mechanism. After outlining the research design in Section 5, we discuss the findings in Section 6, and we report robustness checks in Section 7. Section 8 turns to our school-level analysis and to investigate the role played by local competition. We conclude in Section 9 .

\section{First Preference First: A Hybrid Between DA and IA}

\subsection{The First Preference First Mechanism}

Until 2008, several local authorities in England used the first preference first (FPF) mechanism. As defined by Pathak and Sönmez (2013), under the FPF mechanism, a school either uses a first preference first admission criterion or the equal preference (EP) criterion. FPF schools give a higher priority to parents who rank the school higher whereas EP schools do not account for parents' rankings. More formally, the priorities of the students are defined as follows:

\footnotetext{
${ }^{15}$ When switching from a manipulable to a strategy-proof mechanism, the total effect of the transition stems from two combined effects: (i) the mechanical effect of the algorithm change and (ii) the potential change in parents' strategies, i.e the behavioral response. In the absence of data on parents' reported preferences and on their true preferences before and after the change of mechanism, quantifying the behavioral response requires to model and estimate parents' preferences, which necessitates a number of assumptions (for instance on the level of information that parents have). We do not have data on parents' preferences. Our approach has the advantage of not relying on any behavioral assumptions, but it comes at the cost of not being able to disentangle the mechanical and behavioral channels.

${ }^{16}$ When there is no competition for schools - i.e when none of the schools are oversubscribed — schools do not need to apply admission criteria, and every student will be assigned his favorite school, irrespective of the algorithm used.
} 
- (i) for each EP school, the base priorities for each student are used

- (ii) for each FPF school, the base priorities of students are adjusted so that

- any student who ranks school $s$ as his first choice has higher priority than any student who ranks school $s$ as his second choice,

- any student who ranks school $s$ as his second choice has higher priority than any student who ranks school $s$ as his third choice,

Schools rank students with these priorities. Given these rankings, a matching is determined by the student-proposing deferred acceptance algorithm. Thus, the FPF mechanism is a hybrid between DA and IA. When all schools use the EP admission criterion, the allocation coincides with the DA outcome. In contrast, when all schools use the FPF admission criterion, the outcome coincides with the IA outcome. To examine the effect of the IA-to-DA transition in England, our analysis begins by considering the $49 \mathrm{DA}$ local authorities in which all the schools were using the EP criterion before 2008, and the 16 IA local authorities in which all the schools were using the FPF criterion.

\subsection{Application Behavior}

Since IA is not strategy-proof, parents have incentives to misreport their preferences, especially when the schools they prefer are oversubscribed and their perceived priority is not high enough (Abdulkadiroğlu and Sönmez, 2003). Several papers have used lab experiments to show high levels of preference manipulation under IA (Chen and Sönmez, 2006; Pais and Pintér, 2008; Calsamiglia, Haeringer and Klijn, 2011). ${ }^{17}$ This finding has been confirmed in various cities that use the IA mechanism, such as Barcelona (Calsamiglia and Güell, 2018), Beijing (He, 2017), Cambridge MA (Agarwal and Somaini, 2018), and New Haven (Kapor, Neilson and Zimmerman, 2020).

In England, a survey of parents' preferences conducted two years before the ban of immediate acceptance shows preference manipulation among parents (Coldron et al., 2008). $5 \%$ of parents said that there was a school that they favoured but chose not to apply to. Another $5 \%$ of parents admitted that they did not list schools in the order they really prefer. These strategic behaviors are partly driven by the level of competition for good schools. In fact, the reason that $43 \%$ of parents chose not to apply to their favourite school was that the school was oversubscribed and their child did not meet the oversubscription criteria. Among parents who actively considered oversubscribed schools, $25 \%$ said the oversubscription criteria influenced their choice of which schools to apply to.

\footnotetext{
${ }^{17}$ Between 72 and $86 \%$ of students misreport their true preferences in Chen and Sönmez (2006), a result which has been confirmed when the students have access to more information (Pais and Pintér, 2008), and when the number of schools that can be ranked is limited (Calsamiglia, Haeringer and Klijn, 2011).
} 
When asked about the characteristics of the school they did not apply to, the most common answer was "Good exam results" (52\%). Finding that $10 \%$ of parents openly admit strategic behavior may hide large differences between IA and DA local authorities, as well as between parents.

\subsection{Heterogeneous Levels of Sophistication}

Manipulable mechanisms are often criticized for being unfair because parents might not all be equally able to strategize. Parents may differ in their information about the competitiveness of various schools or may vary in their understanding of the mechanism. Pathak and Sönmez (2008) formalized these differences with a model where "sincere" parents report their preferences truthfully by ranking the schools in order of their true preferences. In contrast, "sophisticated" parents understand that truthful reporting is not optimal when competition for some schools is high and parents lose their priority in a school unless they rank it first. In that model, sincere students can prefer IA in some circumstances. ${ }^{18}$

Growing evidence from cities using a manipulable mechanism shows that low-SES families are more likely to be sincere (Dur, Hammond and Morrill, 2018; Abdulkadiroğlu et al., 2006; Calsamiglia and Güell, 2018; Agarwal and Somaini, 2018). ${ }^{19}$ Evidence from England is similar (Coldron et al., 2008). In 2006, parents with higher levels of education were more likely to know the admission criterion of school to which they applied. Mothers who had an undergraduate degree or higher were three times as likely to use formal sources of information on schools' admission criteria and oversubscription status as mothers without qualifications. Parents who were homeowners were nearly twice as likely to search for data on school achievement as parents who rented.

These differences in access to information are partly due to a lack of official information. British local authorities publish booklets that contain information about schools such as their admission criteria and oversubscription status. However, Coldron et al. (2008) reports that only $44 \%$ of parents reported having access to the booklet in $2006 .{ }^{20}$ To compensate for lack of information, $59 \%$ of parents turned to individual secondary school prospectuses and $44 \%$ to school achievement and attainment data, two sources of information that are difficult to obtain as they need to be accessed school by school. In the rest of the paper, we use this evidence of an SES gradient in parent strategies to motivate our assumption that socioeconomic status proxies for levels of sophistication.

\footnotetext{
${ }^{18}$ In particular, a sincere student can out compete another sincere students when she ranks a school higher, but has lower priority.

${ }^{19}$ In Charlotte-Mecklenburg, Dur, Hammond and Morrill (2018) find that Asian students are significantly more likely to be sophisticated, while Black students are significantly more likely to be sincere. In New York City, many households made obvious mistakes in their schools' applications. $80 \%$ of the students unassigned due to these mistakes received subsidized lunch. 62\% were Black (Abdulkadiroğlu et al., 2006). In Barcelona, the fraction of strategic parents increases with their level of education (Calsamiglia and Güell, 2018), and in Cambridge MA free lunch students are less strategic than paid lunch students, a difference that partially reflects the lower competition they face for schools due to reserved seats (Agarwal and Somaini, 2018).

${ }^{20}$ Among parents using the booklet, only $36 \%$ reported that the booklet was sent by the local authority. $46 \%$ reported that a copy was circulated by the primary school, and $11 \%$ by a secondary school.
} 


\subsection{Competition-for-Top-Schools vs. Trickle-Down}

The belief that strategy-proofness leads to a more equal access to schools is relatively widespread among policy makers both in the U.S. and in Europe. Yet, whether low-SES students would fare better under DA than under IA is not clear. Under perfect information, the IA mechanism gives a clear advantage to sophisticated students who always weakly prefer their IA assignment to their DA one (Pathak and Sönmez, 2008). ${ }^{21}$ Imperfect information alters the welfare benefit of IA compared to DA (Kapor, Neilson and Zimmerman, 2020). Parents may not know the preferences of other parents, priorities, or tie-breaker realizations. Inaccurate beliefs about admission chances lead sophisticated parents to avoid ranking over-demanded schools, even when they could have been admitted.

These mistakes have two main effects, which we illustrate in Figure 1. They reduce the benefits that sophisticated parents get from IA (compared to a full information environment) and they increase the benefit for sincere parents who face less competition and gain priority at top-choice over-demanded schools. We refer to the latter effect as the competition-for-top-schools effect. ${ }^{22}$ This beneficial effect of IA for sincere parents might be partially offset by a negative effect on their chances of being assigned their second or third choice (Pathak and Sönmez, 2008; Agarwal and Somaini, 2018). Sincere students' lack of strategizing implies that those who fail to gain access to their top choice are also less likely to be assigned their second or third choice as they lose priority at these schools (Abdulkadiroğlu et al., 2006). We refer to this as the trickle-down effect. ${ }^{23}$ The aggregate welfare effects for sincere students depends on whether the benefits of an increased likelihood of assignment at the top choice (competition-for-top-schools effect) outweigh the lost priority at less preferred options (trickle-down effect).

Several factors influence these two effects: (i) parents' access to information determines the accuracy of their beliefs, (ii) the level of correlation in parents' preferences - the more parents agree on a unique ranking of schools, the more likely it is that sincere parents benefit from sophisticated parents' strategic decision not to rank top over-demanded schools, (iii) the level of competition for top-choice schools — which determines the incentives that parents have to strategize -, (iv) the level

\footnotetext{
${ }^{21}$ With perfect information, parents know other parents' preferences, schools' priorities and potential tie-breaker rules used. This information allows parents to form accurate expectations about their admission chances in each school. Using this information, sophisticated parents optimally respond to incentives under the IA mechanism by not ranking schools in which their priority is too low to be admitted.

${ }^{22}$ Dur, Hammond and Morrill (2018) identified this effect in Charlotte-Mecklenburg showing that sophisticated students systematically avoid over-demanded schools. Similarly, in Chicago high-scoring kids were being rejected from the city's elite college preps because of the order in which they listed their college prep preferences (Pathak and Sönmez, 2013). In China, Song, Tomoeda and Xia (2020) report that more than 10\% of students are cautious when applying to colleges under IA.

${ }^{23}$ Evidence exists for the harmful effect of losing priority in second or third choice. When Boston was using the IA mechanism, nearly $20 \%$ of students listed two over-demanded schools as their top two choices, which was a clear mistake. $27 \%$ of these students were unassigned by the mechanism (Abdulkadiroğlu et al., 2006). Similarly, in Germany, high performing students who truth-tell due to a lack of understanding of the mechanism used for college admission received suboptimal placements (Braun, Dwenger and Kübler, 2010).
} 
of competition for second and third choice schools - which determines the size of the trickle-down effect. Our analysis brings empirical evidence on these effects.

\section{Institutional Background}

The British education system is divided into primary education (from ages 5 to 10) and secondary education (from ages 11 to 16). We provide an illustration in Figure A.1. In this paper, we focus on admissions to secondary schools in England at age 11, which corresponds to the transition between Key Stage 2 and Key Stage 3. There are 152 local authorities in England that are responsible for education policies within their jurisdiction, in particular for the assignment of students to one of the 3,963 secondary schools across the country. In 2007, England counted 3,122 public (state-funded) schools and 841 private schools (21.2\%). State-funded schools may be selective schools (called grammar schools, they represent $11.7 \%$ of the schools) - meaning that they use student test scores as an admission criterion - or non-selective schools (called comprehensive schools). Comprehensive schools are further subdivided into five categories: community $(60.8 \%)$, voluntary controlled $(2.2 \%)$, voluntary aided $(17.1 \%)$, foundation $(18.1 \%)$, and academies $(0.9 \%)$.

Admission authorities. We group these five categories into two subsets. The first subset consists of foundation schools, voluntary aided schools, and academies. These schools are their own admission authority, so they determine the admission criteria used and they rank applications under the chosen criteria. As illustrated in Figure 2, we call these schools active adopters (of the EP or FPF criterion). In contrast, community and voluntary controlled schools, which represent $63.1 \%$ of the schools in 2007, are not their own admission authority: they follow the admission criteria decided by their local authority. We call them passive adopters of the EP or FPF criterion.

IA and DA local authorities. As a result of schools' freedom, in some local authorities, schools using the FPF criterion can coexist with schools using the EP criterion. In other local authorities, all the schools are using the EP criterion - we call these pure DA local authorities - or the FPF criterion-we call these pure IA local authorities. For the rest of the paper we focus on these local authorities so for brevity we use DA local authority and IA local authority interchangeably with pure DA local authority and pure IA local authority, respectively. We define a mixed DA (respectively IA) local authority as a local authority that has chosen the EP (resp. FPF) criterion but there may be some schools using FFP (resp. EP). Thus a DA (resp. IA) local authority is a special case of a mixed DA (resp. IA) local authority in which all schools utilize EP (resp. FPF). Figure 3 shows a map of all local authorities and their type. ${ }^{24}$

\footnotetext{
${ }^{24}$ We are missing school level data for 6 local authorities that are colored white in the map in Figure 3.
} 
Admission criteria. Aside from choosing the FPF admission criterion, local authorities/schools decide on a number of other admission criteria, such as a sibling criterion or whether the student is living within the catchment area of the school. Table 1 reports the frequency of each criterion for IA and DA local authorities (columns 1 and 2) and schools (columns 3 to 6). Figure A.2 in the Appendix provides a detailed description of each oversubscription criterion. Note that schools do not reserve seats for low-SES students in England, nor do they use admission criteria that explicitly target them. This implies that competition for schools does not directly vary by socio-economic background.

Coordinated system. The 2003 School Admissions Code led to the introduction of a coordinated admission scheme for secondary schools. The reform introduced a single application form on which parents can rank a minimum of three schools and receive a single offer from a school. Local authorities are in charge of collecting parents' applications and schools' priorities. They run the algorithm and send the offers to parents. ${ }^{25}$ Local authorities also determine the number of schools parents' can list in the application. In 2007, most local authorities (64\%) invited just 3 preferences, $8 \%$ invited 4 or 5 preferences, and $28 \%$ invited 6 or 7 preferences $(28 \%) .{ }^{26}$ The limit on the number of preferences that parents can report is an important feature of the British system that is likely to alter the effect of the IA-to-DA transition. With truncated preference lists, DA is not strategyproof (Haeringer and Klijn, 2009). However, it is less manipulable than the IA mechanism (Pathak and Sönmez, 2013). The expected effect of the IA-to-DA transition and the underlying mechanisms presented earlier prevail, but they might be weakened. ${ }^{27}$

Ban of the FPF criterion. The FPF mechanism raised widespread concerns in England regarding its vulnerability to manipulation by parents and the strategic adoption of the FPF admission criterion by schools (see Section 8). On the parents' side, policy makers warned against the strategic complexity of the FPF system which could harm less sophisticated parents who were not able to strategize well, as illustrated by these quotes from the chair of the London Inter-Authority Admissions Group (Carter, 2006):

"FPF forces parents to make tactical, rather than genuine preferences"

"Those who get it wrong or don't understand, lose out"

"Parents have to identify school most likely to offer a place - often impossible"

"Parents cannot be sure whether they will meet criteria for schools they might wish to put as first preference."

\footnotetext{
${ }^{25}$ Carter, Pathak and Terrier (2020) provides additional information on the assignment process in England.

${ }^{26}$ All London authorities invited 6 preferences as part of the pan-London scheme. No IA local authorities offered 6 preferences, which prevents us from considering heterogenous effects of the IA ban by number of preferences.

${ }^{27}$ It is easy to modify the example shown in Section 2.4 when there are constraints on how many schools can be ranked and generate the same forces.
} 
These concerns on the potential harm of the mechanism for disadvantaged parents led to the ban of the FPF admission criterion in England for admission to schools in September 2008. ${ }^{28}$ From 2008 onward, all schools in England used the equal preference criterion, hence transitioning to the DA mechanism in which incentives to misreport preferences were lower.

\section{Data and Descriptive Statistics}

Student-level data. We use data from the National Pupil Database (NPD), an administrative panel dataset on the census of students attending state-funded secondary schools in England between the academic years 2002-2003 and 2013-2014. In addition to information on the school attended by each student and their local authority, this dataset contains demographic information on gender, ethnicity, and free school meal eligibility. We define students who are eligible for a free school meal (FSM) as low-SES and students who do not qualify as high-SES. We link data on educational attainment at the end of KS2 (at age 11) - i.e just before students enroll in secondary school - and at the end of KS3 (at age 14) - i.e at the end of the 3rd year in secondary school. We also link students' General Certificate of Secondary Education (GCSE) exam results, which are taken at the end of KS4 (at age 16). The KS2 test scores come from national standardized evaluations that all students take at the end of primary school before students move to their secondary school. The KS3 test scores are based on teacher assessments, with results for each school being published in performance tables. We standardize KS2 test scores at the cohort level, with mean of zero and standard deviation of one. For KS3 test scores, we create indicators of whether the student scored at least a six or higher, which indicates that the student is meeting minimum academic expectations in a subject. Finally, for the GCSE results we create indicators for whether a student obtained level 2 qualifications in at least five subjects including English and Mathematics.

School and local authority level data. We complement NPD data with two sources of information on schools. First, we use the school census for academic years 2002-2003 to 2013-2014, which provides information on schools' address, postcode, and school type. We link information on schools' admission criteria from Coldron et al. (2008). This dataset contains information on each admission criterion used by schools, including criteria related to siblings, catchment area, medical or social needs, special education needs, feeder schools, or faith. Most importantly, this dataset indicates which school was using EP and FPF in 2007, the year before the FPF criterion was banned. Finally, we use local authority level data on the share of students who received their first, second, and third choices in England. This information is only available for one year before the reform.

\footnotetext{
${ }^{28}$ The 2007 School Admissions Code openly refers to the "prohibition of unfair oversubscription criterion" and states that "in setting oversubscription criteria the admission authorities for all maintained schools must not give priority to children according to the order of other schools named as preferences by their parents, including 'first preference first' arrangements".
} 
IA and DA local authorities before the ban. Our sample contains 146 local authorities, 2,770 schools and 9,302,625 students in England between 2002-2003 and 2013-2014. Columns 3 and 4 of Table 2 report descriptive statistics for the 16 IA and 49 DA local authorities in 2007, just before the IA mechanism was banned. IA local authorities are $17 \mathrm{pp}$ more likely to be in rural areas. This is partly due to the fact that all London local authorities jointly decided to use DA from the beginning (Carter, Pathak and Terrier, 2020). In line with this suburban location, the share of White students is $17 \mathrm{pp}$ larger in IA local authorities, and the share of students who receive free school meals is $4 \mathrm{pp}$ lower. In terms of schools' characteristics, the share of schools that are managed by the local authority, i.e community and voluntary controlled schools, is also $14 \mathrm{pp}$ larger in IA local authorities (79\%) than in DA local authorities $(65 \%)$.

Finally, a noticeable difference exists between DA and IA local authorities in the number of preferences they allow students to express. All IA local authorities ask students to rank three preferences, and only $45 \%$ ask for three in DA local authorities. $43 \%$ of DA local authorities let students rank six preferences. This difference matters as parents face stronger strategic incentives when the number of schools to be ranked is shorter. This difference motivates us to account for list length in our analysis. Overall, these descriptive statistics clearly show that EP and FPF local authorities differed in a number of ways before the 2008 reform. Local authorities and schools might have chosen to use the FPF admission criterion for reasons we do not observe. Since we compare outcomes in local authorities over time, our identification strategy adjusts for any fixed differences that may have led to these choices.

Competitive local authorities. As we discussed above, the level of competition for top-choice schools drives how much the IA ban will change students sorting across schools. To test this hypothesis, we exploit the fact that $32 \%$ of the local authorities in England contain selective schools that have more positively selected students than other non-selective schools. As explained in section 3 , selective schools use students test scores as an admisison criterion. We distinguish between "competitive local authorities" that have at least one selective school, and "non-competitive local authorities" that do not have selective schools. ${ }^{29}$

This distinction is meaningful because there is a stronger vertical differentiation between schools in competitive local authorities. Students' test scores are on average $0.4 \mathrm{SD}$ higher in selective schools than in non-selective schools (Table 2). As a result, the between-school variance of students' test scores is significantly larger in competitive local authorities than in non-competitive ones (Figure 4). Numerous papers have shown that school performance is a major factor parents consider when ranking schools. ${ }^{30}$ Parents' preferences are therefore more aligned in competitive

\footnotetext{
${ }^{29}$ We discard two local authorities from the competitive set because, despite having a selective school, these local authorities have a very low share of students enrolled in a selective school, due to their very large size.

${ }^{30}$ See, for instance, Black (1999); Bayer, Ferreira and McMillan (2007); Hastings and Weinstein (2008); Burgess et al. (2015).
} 
local authorities, which results in greater levels of competition for the best schools. As reported by Coldron et al. (2008), the percentage of oversubscribed schools is higher in the 14 most selective local authorities (median=47\%) compared with other LAs $\left(\right.$ median=20\%). ${ }^{31}$ Table 3 shows this fact and other descriptive statistics for competitive and non-competitive local authorities.

\section{$5 \quad$ Research Design}

Identification challenge. Identifying the causal effect of replacing IA with DA is challenging because local authorities that used IA differ from local authorities that used DA in a number of observable and unobservable dimensions. Local authorities could use either IA or DA before 2008, but the 2008 reform forced all IA local authorities to switch to DA. We therefore compare changes in outcomes before and after this ban between local authorities that were forced to abandon the IA mechanism (our treated group) and in local authorities that used the DA mechanism from the beginning and were unaffected by the ban (our control group).

Difference-in-differences specification (DiD). We estimate difference-in-differences regressions, where the outcome of student $i$ in local authority $l$ in year $t\left(Y_{i l t}\right)$ depends on a dummy variable indicating whether the local authority is using the IA mechanism before the ban $\left(I A_{l}\right)$, a dummy variable equal to one for the post-reform years $\left(\right.$ Post $\left._{t}\right)$, and the interaction between IA and post-reform years. While the estimates from this $\mathrm{DiD}$ specification document the effect of the IA ban for all students, irrespective of social background, we are particularly interested in the differential effect of the ban for high- and low-SES students. To estimate this heterogenous effect (in a triple difference spirit), the specification contains a dummy variable equal to one for students qualifying for a free school meal $\left(\operatorname{LowSES}_{i}\right)$, and an interaction between $L o w S E S_{i}$ and $I A_{l} \cdot$ Post $_{t}$ :

$$
Y_{i l t}=\mu+\alpha \cdot I A_{l}+\beta \cdot \text { Post }_{t}+\phi \cdot \text { LowSES }_{i}+\gamma \cdot I A_{l} \cdot \text { Post }_{t}+\eta \cdot I A_{l} \cdot \text { Post }_{t} \cdot \text { LowSES }_{i}+\delta \cdot X_{l t}+\varepsilon_{i l t} \text {. }
$$

$X_{l t}$ is a vector of LA-level control variables for the average share of each school type, the share of schools that use each admission criterion, and the number of schools that students can rank on their list. $X_{l t}$ also includes the following interaction terms: Post $t_{t} \cdot$ LowSES $_{i}$ and $I A_{i} \cdot$ LowSES $_{i}$. We cluster standard errors at the local authority level.

The coefficient $\gamma$ captures the change in outcome in IA local authorities compared to the change in DA local authorities for high-SES students. We are particularly interested in $\eta$. It indicates whether the change in outcome (such as school value-added) in IA local authorities compared to the change in DA local authorities was different for low-SES students than for high-SES students.

\footnotetext{
${ }^{31}$ We do not have direct information on whether a school is oversubscribed. This is why we use references from the report on schools' admissions in England published in 2008 (Coldron et al., 2008).
} 
Identifying assumptions. Our identification relies on the assumption that the difference in outcome between high- and low-SES students would have evolved in the same way in DA and IA local authorities without the ban. Another important assumption is that the ban of the IA mechanism was the only change that affected IA local authorities in 2008, i.e that no other policy was adopted at the same time. We discuss and test the validity of both assumptions in Section 7 .

\section{Effects of Transitioning from IA to DA}

We start by showing that the number of local authorities that used the IA mechanically dropped after the Ministry for Education banned this mechanism in 2008. Figure 5 shows that more than $30 \%$ of the local authorities were using IA pre-ban, which dropped to $0 \%$ after the ban.

Effect on first choice accommodation. We first examine the share of students who are assigned the school ranked as their first choice. This outcome is only available for one year before the ban (in 2007) which prevents us from using the full history of the outcome. Moreover, we do not know whether a school ranked first is actually a student's top choice given the incentives of IA. The results should therefore be interpreted with caution. IA is mechanically designed to maximize access to first choice, so its replacement with DA is expected to reduce first choice accommodation. Figure 6 confirms this by reporting the difference between IA and DA local authorities in the probability that a student is assigned his first choice.

Before the reform, IA increased parents' access to their first choice by $25 \mathrm{pp}$ compared to DA. Interestingly, that boost in admission chances to a preferred school is more pronounced in competitive local authorities (see Figure 6). In non-competitive local authorities, parents in IA local authorities are only 8 pp more likely to be assigned their first choice than in DA local authorities. These results confirm that, in environments where competition for schools is fiercer, the type of mechanism used (IA versus DA) does affect the schools that parents are assigned to. IA was effective at giving parents access to their reported first choice, a finding which is consistent with the first preference prioritization that the mechanism imposes.

We then look at the effect of the reform in competitive local authorities. Access to first choice dropped by $8 \mathrm{pp}$ in IA local authorities, compared to DA local authorities, in the year that followed the ban of the IA mechanism. In contrast, the reform had a limited effect on first choice accommodation in non-competitive local authorities. ${ }^{32} 33$

\footnotetext{
${ }^{32}$ Although differences in first choice accommodation shrink after the ban, a gap persists. This is because all IA local authorities limit the preference list to 3 schools (hence encouraging strategic reports which boost first choice satisfaction), whereas DA local authorities offer between 3 and 6 choices (see Table 2). Figure A.3 shows that the remaining gap in first choice access shrinks when we control for list length.

${ }^{33}$ The drop in first choice accommodation in IA local authorities could be driven by (i) students reporting their preferences more truthfully — behavioral change - or by (ii) students having lower chances of getting the school they truly prefer-mechanism change. We cannot disentangle both effects without information on parents' preferences.
} 
Putting our findings in perspective, England shows a high rate of first choice satisfaction in IA local authorities (93\%) compared to other cities that are using the IA mechanism. This statistic is $74 \%$ in Beijing (Chen, Jiang and Kesten, 2020), 84\% in Cambridge (Agarwal and Somaini, 2018), and 93\% in Barcelona (Calsamiglia, Fu and Güell, 2020). This suggests that overall competition for schools in England is lower than in these cities, a difference which also explains why the effect we find on first choice accommodation ( $8 \mathrm{pp}$ drop) is on the lower end of the estimated effects found by other papers. Chen, Jiang and Kesten (2020) for instance find that the proportion of students admitted to their top choices drops by $24 \mathrm{pp}$ in Beijing.

The ban of the FPF mechanism might also have a limited overall effect on first choice satisfaction if the average effect hides a negative effect for low-SES students but a positive effect for high-SES students. This might happen if low-SES students benefit from lower competition in their preferred school under IA. Although our data on first choice satisfaction is not decomposed by students' social background, we investigate heterogeneous effects by social origin below.

Effect on access to a high value-added school. We start by analyzing whether low-SES students (compared to high-SES students) attend a school with a higher value-added (VA) under DA than under IA. Our VA measure captures the contribution of a school to a standard high-stakes performance metric: a student's likelihood of obtaining level 2 qualifications in at least five GCSE exams including English and Mathematics. ${ }^{34}$ Using school value-added as an outcome is partly motivated by equity considerations. Before the IA ban, low-SES students in England attended schools whose value-added was $10.4 \mathrm{pp}$ lower than high-SES students. Because this difference contributes to achievement inequalities, it is important to understand if a change of mechanism increases low-SES students' access to high value-added schools.

We measure school effectiveness using value-added regression models commonly used to measure causal effects of teachers and schools (Koedel, Mihaly and Rockoff, 2015). Appendix B details the methodology. We regress student GCSE test scores (five years after enrollment in secondary school) on KS2 test scores (taken just before secondary school), a vector of other student characteristics, a vector of time-varying school characteristics, and school fixed effects. Our value-added estimates rely on a standard selection-on-observables assumption. Recent work has shown that conventional VAM models, which control for lagged achievement, are reliable estimates of the causal effects of school attendance based on lottery estimates (Angrist et al., 2020).

The results reported in column (1) of Table 4 shows that the IA ban led to a decline of the value-added of the school that low-SES students attended compared to high-SES students. In IA local authorities (compared to DA ones), the ban led to a 0.8 pp drop in low-SES students' school value-added relative to high-SES students' school value-added. As a benchmark, pre-reform in IA

\footnotetext{
${ }^{34}$ GCSE test scores are from national standardized evaluations taken at the end of secondary school. Performance on this test is reported in schools performance tables published by the Department for Education. We compute schools VA in 2007 and use this time-invariant measure as our outcome.
} 
local authorities low-SES students enrolled in schools whose value-added was 10.4 pp lower than high-SES students. The IA ban led to a $7.7 \%$ increase of this gap. After the reform low-SES students had reduced access to high-quality schools, a first sign that competition for these schools might have increased under DA. We bring additional evidence on the competition effect in the rest of the analysis. Although reduced access to high value-added schools is worrisome for equity reasons, it need not affect low-SES parents' welfare if these parents do not value school effectiveness.

Effect on access to high-achieving peers. We next analyze whether low-SES students attend a school they like more under DA than under IA, i.e., a school they would rank higher in their preference list. Welfare considerations motivate looking at students' access to a school they like. A common approach of the structural literature is to estimate parents' preferences for schools and to compute the welfare associated with the assigned school (Kapor, Neilson and Zimmerman, 2020; Calsamiglia, Fu and Güell, 2020; Agarwal and Somaini, 2018; de Haan et al., 2018). Having no information on parents' submitted list, we cannot follow this route. Instead, we take advantage of the information we have on schools' characteristics that have been shown to determine parents' preferences, such as peer test scores, share of low-SES peers in the school, and school value-added. Several papers document that parents prefer schools with high-achieving peers and high-SES peers (Black, 1999; Bayer, Ferreira and McMillan, 2007; Hastings and Weinstein, 2008; Burgess et al., 2015; Abdulkadiroğlu et al., 2020). ${ }^{35}$ Finding that low-SES students enroll in schools with better peers after the IA ban would suggest that these students are assigned to a school they like more. ${ }^{36}$

For each student, we use as outcomes two measures of peer characteristics in the first year of secondary school: (i) peers' KS2 test scores, and (ii) the share of low-SES peers. Our results show that the IA-to-DA transition reduced peer quality more for low-SES students than for high-SES students. After the ban, in IA local authorities (compared to DA ones), the average test scores of low-SES students' peers drop by 0.03 SD compared to the test score of high-SES students' peers. At the same time, low-SES students become 1.6 pp more likely than high-SES students to have other low-SES students (in IA LAs compared to DA LAs).

This detrimental welfare effect suggests that the benefit that low-SES parents get from lower competition in their preferred school under IA (the competition for top-school effect) might be larger than the cost of not receiving their second or third choices (the trickle-down effect), an effect that has been observed previously in Cambridge (Agarwal and Somaini, 2018). ${ }^{37}$

\footnotetext{
${ }^{35}$ Studies have found that high-SES parents tend to value schools' peers and performance more than low-SES parents (e.g. Bayer, Ferreira and McMillan, 2007; Hastings and Weinstein, 2008; Deming et al., 2014; Hofflinger, Gelber and Tellez Cañas, 2020). This social gradient implies that the welfare effect of enrolling in a school with better peers would be larger for high-SES students than for low-SES students. It does not invalidate the association between peer quality and student welfare.

${ }^{36}$ Access to good peers is also related to the equity motivation presented earlier. Table B.1 shows that more effective schools enroll more higher-ability students and fewer low-SES students, a correlation that has been observed in other environments (Abdulkadiroğlu et al., 2020).

${ }^{37}$ In Cambridge, the probability of a student assigned to her top choice under IA is larger for naïve agents than
} 
Competition for top schools effect. To further explore the competition-for-top-schools and the trickle-down effects, we check whether the negative effect of the IA-to-DA transition for lowSES students is driven by a reduction in admission chances to selective schools and an increase in admission chances to low-performing schools. The theory suggests that low-SES students might face more competition for their preferred school under DA than IA due to sophisticated parents becoming more likely to rank these schools after the IA ban.

Based on evidence that parents prefer high-achieving peers, high-SES peers, and schools with higher test scores, selective schools in England are likely to be ranked first by parents. Selective schools have on average 0.4 SD higher student test scores, 8 pp lower share of low-SES students, and value-added that is $7.8 \mathrm{pp}$ higher than non-selective schools. ${ }^{38}$ As a result, selective schools are more likely to be oversubscribed. ${ }^{39}$ Thus, we expect the competition-for-top-schools effect to apply to selective schools. After the ban, in IA local authorities (compared to DA local authorities), low-SES students become 1.1 pp less likely than high-SES students to enroll in selective schools. ${ }^{40}$

Finally, note that the results reported in the first row of Panel A in Table 4 document the effect of the IA ban for high-SES students. We find that the average test scores of high-SES students' peers dropped by $0.02 \mathrm{SD}$ after the ban, and their access to selective schools dropped by 2.2 pp. This surprising result - the competition-for-top-schools effect suggests that high-SES students gain higher access to selective schools under DA, and therefore to better peers - is explained by a post-ban reduction in selective schools' capacities in IA local authorities compared to DA local authorities. ${ }^{41}$ In other words, all students had lower access to selective schools after the ban, but low-SES students were more severely affected than high-SES students, which is in line with the competition-for-top-schools effect.

Trickle-down effect. Under IA, low-SES students who fail to gain access to their first choice might fall down their ranking when the schools they rank as their second or third choice are oversubscribed and give priority to students who rank the school as their first choice. This trickledown effect does not happen under DA, as low-SES students who are rejected from their preferred school do not lose priority in their second or third choice to students who rank it first. DA is therefore expected to reduce how often low-SES students are assigned a school they dislike and rank low. We examine if low-SES students are less likely to enroll in a low-performing school following the ban, i.e., a school whose KS2 test score is in the bottom 25th percentile of the distribution in

for sophisticated agents who have identical preferences $(78.4 \%$ vs. $76.2 \%)$. This comes at the cost of a significantly lower probability of assignment at the second choice (6.5\% for naifs and $12.3 \%$ for sophisticates).

${ }^{38}$ See Tables 2 and B.1.

${ }^{39}$ The percentage of oversubscribed schools is strikingly higher in the 14 most selective local authorities (median $=47 \%$ ) compared with other LAs (median=20\%) (Coldron et al., 2008).

${ }^{40}$ Although this effect (measured in all local authorities) is not statistically significant, we show in the next section that the effect in competitive local authorities is larger in magnitude and statistically significant.

${ }^{41}$ While the average number of seats in selective schools increased by $38(3.7 \%)$ in DA local authorities after the ban, they went down by $23(-1.7 \%)$ in IA local authorities, which represents a differential evolution of $5.4 \%$. 
local authority. These schools are less likely to be ranked as a first choice by parents, which makes them good candidates to explore the trickle-down effect.

We find no sign of lower enrollment in low-performing schools. This last result is not necessarily surprising in the British context where only the most attractive schools are over-demanded. In 2006, only $31 \%$ of the schools in England were reported as oversubscribed by Coldron et al. (2008). LowSES students who are rejected from their preferred school under IA would not be rejected from their second or third choice when these schools are not over-demanded. ${ }^{42}$

An amplifying effect: The level of competition for top schools. The larger the competition for schools, in particular for top-ranked schools, the more likely it is that low-SES parents benefit from high-SES parents' strategic decision not to rank their over-demanded top choice. To test this hypothesis, we check if our results differ in competitive local authorities and in non-competitive local authorities. As explained in Section 4, due to the presence of a selective school, competitive local authorities have a stronger vertical differentiation between schools, greater variance of students' test scores between schools, and greater rates of oversubscription. Panel B of Table 4 presents results for competitive local authorities, while panel A reports results for all IA and DA local authorities.

In line with our hypothesis, we find that the effect of the IA ban is significantly stronger in competitive local authorities. The negative effect of the IA ban on low-SES students' access to high-VA schools is almost twice as large in competitive local authorities than in non-competitive local authorities. In the former, the ban led to a $1.3 \mathrm{pp}$ drop in low-SES students' school valueadded relative to high-SES students' school value-added (in IA local authorities compared to DA ones). That drop was $0.8 \mathrm{pp}$ when considering all local authorities. Similarly, the effect on peers test scores moves from $-0.029 \mathrm{SD}$ to $-0.072 \mathrm{SD}$, the effect on share of low-SES peers moves from $+1.6 \mathrm{pp}$ to $+3.1 \mathrm{pp}$, and the effect on access to selective schools moves from $-1.1 \mathrm{pp}$ to $-2.6 \mathrm{pp}$. These results confirm that, under a manipulable mechanism like IA, the competition level influences how much low-SES students can gain from a manipulable mechanism, and as a result how much they lose from the transition to a less manipulable mechanism.

Effect on achievement inequalities. Finally, we look at the effect of the ban on students' test scores three years after they enter secondary school, i.e by age 13 at the end of Key Stage 3. We find a precisely estimated null effect. The ban of the IA mechanism did not lead to an increase in the achievement gap between high- and low-SES students. This result is may be surprising given that all other results point to a detrimental effect for low-SES students.

\footnotetext{
${ }^{42}$ The fact that second or third choices are not over-subscribed questions the motivation that high-SES parents have to strategize. If their second or third choice is not oversubscribed, ranking their preferred school first is not risky, which limits incentives to strategize. However, it is likely that high- and low-SES parents have different preferences. High-SES parents tend to value schools' performance more than low-SES parents (e.g. Bayer, Ferreira and McMillan, 2007; Hastings and Weinstein, 2008; Deming et al., 2014; Hofflinger, Gelber and Tellez Cañas, 2020), and high-performing schools are more likely to be oversubscribed.
} 
To explain this discrepancy, we show that low-SES students benefit significantly less from attending a high-value-added school than high-SES students in England. For each school, we decompose our school value-added measure into a value-added for high-SES students and a value-added for low-SES students. ${ }^{43}$ Figure 8 shows that the low-SES students' VA distribution has a left-ward shift compared to high-SES students' VA distribution. Figure 9 further shows that this lower VA for low-SES students tends to be larger in high-VA schools than in low-VA schools, an important fact since our competition-for-top-schools effect plays through low-SES students' access to high value-added selective schools. These two combined findings suggest that, under immediate acceptance, low-SES students' access to high-VA schools might not have reduced the achievement gap as much as expected. ${ }^{44}$

Similar evidence of heterogenous peer effects exists. When enrolling in a school with better peers, low-SES students have been shown to befriend students that are similar to them which limits the room for positive peer effects from higher-achieving peers (Carrell, Sacerdote and West, 2013). This kind of selective friendship formation may be particularly relevant in our context as students move to a new school.

Dynamic effect of the ban. We find that the transition from IA to DA has a progressive effect on the outcomes we consider. Whether we consider the effect on peers' characteristics or on school value-added, the effect of the IA ban increases over time (see Figure 7). This dynamic effect is not a threat for our identification strategy because the reform was not staggered. ${ }^{45}$ However, it raises the interesting question of the underlying dynamic channels. A likely explanation is that it takes time for strategic parents to update their behavior. In other related studies, parents learn about mechanisms and adjust their strategies over time (Hakimov and Kubler, 2021; Chen and Kesten, 2019; Ding and Schotter, 2019; Bo and Hakimov, 2020; Hastings, Kane and Staiger, 2009). ${ }^{46}$

\section{Robustness Checks}

Parallel trends in outcomes. Our identification relies on the assumption that the difference in outcome between high- and low-SES students would have evolved in the same way in DA and

\footnotetext{
${ }^{43}$ As explained in greater details in Appendix B, we modify the standard value-added regression by interacting the school fixed effects with a low-SES binary variable, which gives us two value-added estimates for each school.

${ }^{44}$ When looking at the effect of the IA ban on the VA of the schools students attend, we use a homogeneous VA measure that does not differ between high- and low-SES students. Using a VA measure that differs for these two groups leads to similar conclusions. The coefficients of the triple interaction term (post-reform-by-IA-by-lowSES) move from $-0.013^{* *}$ to $-0.012^{*}$ in competitive local authorities and from $-0.008^{*}$ to $-0.009 *$ in the full sample.

${ }^{45}$ Numerous papers have stressed the potential bias of difference-in-difference estimators when treatment effects are heterogenous over time (e.g. de Chaisemartin and D'Haultfœuille, 2020; Athey and Imbens, Forthcoming; GoodmanBacon, Forthcoming; Sun and Abraham, Forthcoming). The bias is only a concern when treatment adoption is staggered over time, which is not the case in our setting; all treated local authorities transitioned from IA to DA in the same year.

${ }^{46}$ Hakimov and Kubler (2021) reviews the literature on learning under DA and IA.
} 
IA local authorities, had the IA mechanism not been banned. To test this assumption, we run an event-study regression which is identical to Equation (1), except that we replace the post-reform dummy variable by a dummy for each year (excluding 2008, the reference year). Figure 7 plots the coefficients over time and provides a graphical visualization of our parallel pre-trends. To further rule out suspicions that our estimates capture pre-trends in outcomes, we show below that our results are robust to the inclusion of time trends in oversubscription criterion.

Ruling out other policy changes. An important assumption of our research design is that the ban of the IA mechanism was the only change that affected IA local authorities in 2008, i.e that no other policy was adopted at the same time that might have had a differential effect on IA local authorities than on DA local authorities. To support this assumption, it is important to account for oversubscription criteria (others than the FPF criterion) that were affected by the 2007 school admissions code. Two criteria were banned (parental commitment and children of associated adults) and one became mandatory (children in care). ${ }^{47}$ Figure A.2 provides a detailed summary of the admission criteria discussed in the 2003 and the 2007 schools' admissions code. We have information on the admission criteria used by schools in 2007, which allows us to check how frequently they were used pre-reform and how their usage differs in DA and IA local authorities. ${ }^{48}$

Three reasons make us confident that our estimates do not capture changes in these criteria. First, the three criteria that were affected by the 2007 school admissions code were rarely in effect before the reform. Children of associated adults was used by $4 \%$ of the schools, parental commitment by $9 \%$, and children in care by $77 \%$ of the schools, although this criterion only applies to less than $1 \%$ of the students. ${ }^{49}$ In addition, although differences existed in 2007 between IA and DA local authorities in their probability of using these criteria, the differences were small in magnitude compared to the $100 \mathrm{pp}$ difference in the probability of using the FPF criterion. ${ }^{50}$ To adjust for this potential confound, we systematically control for the share of schools that use each admission criterion. We also show in the next section that our results are not sensitive to this set of controls and to the addition of time trends for each admission criterion.

We run a number of robustness checks, which we present in Figure 10 (for all IA and DA local

\footnotetext{
${ }^{47}$ Parental commitment was used to give priority to parents willing to support the school's ethos in a financial manner or any other way, while children of associated adults was used to give priority to children who have associated parents such as current or former staff. From 2007 onward, children in care must be given the highest priority, while the previous school admissions code only recommended to give these children top priority. Children in public care are a disadvantaged group who have very low average levels of attainment, often related to frequent changes of school because their care placements change. Local authorities are legally responsible for looked after children.

${ }^{48}$ We do not have information on oversubscription criteria for post-reform years as this information is not centrally collected by the British department of education. The 2007 data was collected for a 2008 report on policy admissions in England by Coldron et al. (2008), and afterwards generously shared with us.

${ }^{49}$ In 2010 , there were 24,900 children in public care aged 10 to 15 (i.e., about 4,150 in each age group). The same year, we had 507,620 year 7 students so children in care would represent less than $1 \%$ of all year 7 students.

${ }^{50}$ As reported in Table 1, in 2007, DA local authorities were 8.2 and 8 pp more likely to use the parental commitment and the children of associated adults criterion. In contrast, they were $2.3 \mathrm{pp}$ less likely to use the children in care criterion.
} 
authorities) and in Figure 11 (for competitive local authorities). Each outcome is separated by a vertical bar. The bottom of the Figure shows which regression we run, i.e., whether the regression includes (i) a set of controls for school types, (ii) a set of controls for schools' admission criteria, (iii) time-trends for schools' oversubscription criteria, and (iv) controls for the preference list size.

Controls for list length, school type, and admission criteria. We test the robustness of our results to removing control variables for the number of schools that students can report on their preference list. Checking sensitivity to preference list size is important because IA local authorities limit the number of reported preferences to three, whereas $43 \%$ of DA local authorities let students rank six preferences (and $45 \%$ let students rank three preferences). The results are not sensitive to this control. We further show our results are not sensitive to the inclusion of control variables for the share of each school type in a local authority, and for the share of schools using each admission criterion in a local authority.

Time trends in admission criteria. Finally, a standard concern with our difference-in-differences approach is that the change in outcome we observe after the reform was already happening prior to the reform. A way to mitigate this concern is to account for existing time trends that are specific to treated/control units or to account for time trends in variables that determine the outcome. We prefer not to include local authority-specific time trends, following evidence from Borusyak and Jaravel (2018) that group-specific trends introduce under-identification problems. ${ }^{51}$ We control, however, for time trends associated with each admission criterion as changes in these criteria constitutes the most likely reason for why our outcomes (access to good peers and schools) might vary over time. ${ }^{52}$ Again, overall our results are very robust to the inclusion of these time trends. ${ }^{53}$

\section{Further Evidence on the Role of Local Competition}

Our research design leverages cross-market variation across 65 local authorities in the type of assignment mechanism. Although the local authority is the natural unit of observation to look at the effect of mechanism change, relying on variation between local authorities might fail to

\footnotetext{
${ }^{51}$ Borusyak and Jaravel (2018) show that including a group-specific trend is an inappropriate solution to nonparallel trends because the group-specific trend is collinear with the (time) distance to the treatment. Difference-in-difference specifications that include group-specific trends estimate an average of the dynamic treatment effects that severely overweighs short-run effects and weighs long-run effects negatively. This is a particular concern in our setting because the long-run effects are often larger than the short-run effects.

${ }^{52}$ For each oversubscription criterion we create an indicator of whether the proportion of schools that use this criterion in a local authority is above the median among all local authorities. Then we interact this term with a continuous measure of time to generate the time trends.

${ }^{53}$ In the sample of competitive local authorities, Figure 11 shows that one coefficient on school value-added (out of 16) and two coefficients on enrollment in selective school (out of 16) are not significantly different from zero and have large standard errors. In both cases, the outlying coefficients correspond to specifications that do not control for school admission criteria. This is not a specification we favor for the reasons discussed in this section. All results discussed in the paper come from regressions that control for schools' admission criteria.
} 
capture effects of the ban within a local authority. Our results so far show that the competitionfor-top-schools effect is larger in competitive local authorities, i.e., in local authorities that host a selective school. Yet, even in these competitive local authorities, selective schools might only affect competition locally. There are on average 18.8 schools in a local authority, so many students who reside further away from selective schools may be unaffected. In that case, our estimates, by considering all the students in a competitive local authority irrespective of whether they face high competition for schools, might underestimate the effect that an IA ban would have in competitive environments (like college admission in China as in Chen, Jiang and Kesten (2020)). We therefore also examine local effects of the reform by analyzing school-level effects of the reform.

\subsection{Schools' Strategic Adoption of the FPF Admission Criterion}

We turn to a unique feature of the British system that allows us to investigate local competition effects: Some schools are free to choose their admission criteria. We exploit this feature to explore the effect of the 2008 reform on the composition of schools which, as a defense against the local competition they faced from a neighboring selective school, had strategically adopted the first preference first admission (FPF) criterion. The ban of this criterion in 2008 provides a clean natural experiment to explore its effect on the composition of the students who enroll in FPF schools. We detail the institutional context and the identification strategy below.

Schools' strategies and incentives. As explained in Section 3, 35\% of the schools in England are free to choose their admission criteria. We call them "active adopters." Taking advantage of this freedom, in 2007, 32\% of the active schools used the first preference first admission criterion which gives a higher priority to parents who rank the school as their first choice, and therefore encourages parents to act strategically. Crucially, schools faced strong strategic incentives to use the FPF criterion, and the incentives differed across schools.

Selective schools whose objective was to admit the highest achieving students using test scores had little incentives to adopt the FPF criterion. FPF could only reduce the achievement levels of incoming students by giving priority to first choice (potentially low achieving) students over second choice (potentially higher achieving) students. This is illustrated by Graham Carter's (Chair of the London Inter-Authority Admissions Group) following statement: "FPF [was] less likely to be agreed by admission authorities wishing to apply ability/aptitude, religious commitment to all applicants."

In contrast, non-selective schools that were competing with selective schools had large incentives to adopt the FPF criterion, as the latter would discourage strategic parents from applying to overdemanded selective schools, perceived as too risky when their second choice is using FPF. Again, numerous quotes from policy makers illustrate the non-selective schools' strategic incentives:

"FPF can deter parents from applying for a selective school", Carter (2006) 
"EP risks a reduction in ability profile of non-selective schools, as parents can put a grammar [selective] school first", Carter (2006)

"In areas like Kent or Calderdale where wholly selective grammars attract a majority of the highest attaining children, nonselective schools may wish to use the first preference first criterion so that parents who are not sure whether their children will gain a place at their preferred grammar school will be encouraged to put their preferred comprehensive as their first expressed preference. In this way the non-selective schools hope to gain a better balanced intake which evidence shows [...] would benefit all of the children in their school. Similar issues arise in non-selective areas where there are very popular and very unpopular comprehensive schools.", Coldron et al. (2008).

"Basically, what those [FPF] schools were doing was sort of blackmailing parents, saying, 'If you don't put us down first, you'll lose your place in the queue.' I do not think that that is fair.", House of common testimony

These quotes indicate schools' strategic use of the FPF criterion to encourage strategic parents to rank the school as their first choice. This is consistent with evidence by Bergman and McFarlin (2018) that frictions in the choice process allows schools to influence who applies, notably because many families lack information about schools' quality and admissions processes (DeArmond, Jochim and Lake, 2014; Hastings and Weinstein, 2008; Kapor, Neilson and Zimmerman, 2020).

Schools' strategic play with admission criteria in England is driven by the strong incentives they have to attract and enroll high achieving students. The Department for Education publishes performance tables every year that are based on test results and reports from the inspection authority (called OFSTED), two indicators that capture the absolute performance of a school rather than its value-added. A very high profile is given to these 'league tables' and high stakes are associated with a good or poor performance, notably because parents chose schools based on their performance on league tables (Burgess et al., 2015; Hussain, 2020). ${ }^{54}$

Expected effect of the FPF ban. The manipulable environment we just presented encourages parents to rank FPF schools as their first choice instead of a school they prefer (most likely the nearby selective school) but whose admission might be uncertain. These strategies from sophisticated parents are expected to have two effects. First, they should lower the competition that sincere low-SES parents face for their preferred schools. This competition-for-top-schools effect has

\footnotetext{
${ }^{54}$ Hussain (2020) shows that parents' school choice and house prices react to changes in inspection ratings. A unit increase in the nearest school's rating leads to a $5 \mathrm{pp}$ rise in the probability of listing that school as the first choice, and a 0.5 percent increase in prices (equivalent to around £800) of properties located near the school, an effect that jumps to 1.3 percent for top performing schools. Other papers have stressed that failing to get a good evaluation discourages principals from staying in the school (Hussain, 2009), and affects teaching practices (Hussain, 2015) and the time that parents devote to their children's academic studies (Greaves et al., 2021).
} 
the same roots as the one we illustrated in the previous section when local authorities use IA. This makes active FPF schools particularly relevant to bring additional evidence on this competition effect. Second, high-SES parents' strategies are expected to boost the baseline achievement of students attending FPF schools. The reform was therefore expected to prevent FPF schools from attracting high-SES parents. The aim of this section is to verify whether the reform made FPF schools worse off, compared to schools that used the alternative less manipulable "equal preference" criterion (EP) during the entire period.

\subsection{Research Design}

Difference-in-Differences. The challenge we face when analyzing the effect of the FPF ban on schools' composition is the fact that schools that adopted the FPF criterion in the first place might differ from schools that used the EP criterion. Table 2 shows that FPF schools enrolled fewer low-SES students and students with higher test scores. To address this selection, we rely on a difference-in-differences approach that compares the evolution of students' characteristics in active FPF schools (our treatment group) and in a group of schools, presented below, that used the EP criterion during the entire period (our control group). Said differently, we measure the post-reform change in the characteristics of the students who enroll in a former FPF school, using changes in EP schools' student composition to control for natural year-to-year variation in school composition. Under the assumption that, absent the ban, student characteristics would have evolved in the same way in EP and FPF schools, the double difference provides a set of estimates of the effect of the FPF ban on schools' composition.

Let school-level outcome $\left(Y_{s t}\right)$ be a function of a dummy variable indicating whether it was a school actively using $\mathrm{FPF}\left(F P F_{s}\right)$, a dummy variable equal to one for the post-reform years $\left(\right.$ Post $\left._{t}\right)$, and the interaction between FPF and post-reform years as follows:

$$
Y_{s t}=\mu+\alpha \cdot F P F_{s}+\beta \cdot \text { Post }_{t}+\gamma \cdot F P F_{s} \cdot \text { Post }_{t}+\delta \cdot X_{s t}+\varepsilon_{s t},
$$

$X_{s t}$ controls for school-level characteristics including school type, and each admission criterion used by schools. The coefficient of interest $\gamma$ captures the change in outcome in active FPF schools compared to the change in the control group of EP schools. In all regressions, we cluster standard errors at the local authority level. In this analysis we only consider non-selective schools since these schools are more likely to employ the FPF criterion.

Outcomes. We use five outcome variables: in each school, we compute the share of low-SES students, as well as the share whose KS2 test score is below the 10th and 25th percentiles of their cohorts' distribution, and the share of students whose KS2 test score is above the 75th and 90th percentiles. Looking at the effect of the ban on the enrollment of the very top performers 
is particularly important because schools' selection strategies might affect the enrollment of highperforming kids whose parents are more sophisticated.

Control group. The control group of EP schools has to be carefully chosen because there is a risk of spillover between the FPF and EP schools that are located in the same local authority. After the ban, any change in the enrollment at FPF schools should almost mechanically be compensated by the opposite change in EP schools, which means that the control group would also be affected by the reform. To avoid spillover effects between schools, we use EP schools in DA local authorities as the control group, i.e EP schools that are in local authorities in which zero schools were using the FPF criterion before its ban. By design, these schools cannot be affected by the FPF ban.

Identifying assumptions. The key identifying assumption of our method is that student outcomes would have evolved in the same way in EP and FPF schools had the FPF admission criterion not been banned. We test that assumption in two ways. First, we test if outcome trends were parallel before the ban. Using a standard event-study specification, we regress the outcome variable on a dummy variable indicating whether a school is using the FPF admission criteria before the ban, year fixed-effects, the interaction between FPF and each year, and the set of controls included in Equation (2). Figure 12 shows that each of our five outcomes evolved very similarly in EP and FPF schools before 2008. Each Figure also reports the p-values from a formal F-test of whether the coefficients of the FPF-by-year effects are jointly equal to zero in the pre-reform years. We obtain large p-values for all outcomes, confirming parallel pre-trends. To completely rule out suspicions that our estimates capture pre-trends, we also show in Section 8.4 that our results are robust to the inclusion of time trends in oversubscription criterion. We rule out in Section 8.4 that our results are driven by contemporaneous changes or reforms that happened in (or around) 2008, such as changes in other admission criteria and the expansion of the academy sector.

\subsection{Results}

Table 5 reports estimates of (2). A first result is the difference in the composition of EP and FPF schools before the first preference first criterion was banned (captured by the coefficient of the FPF variable). Active FPF schools were 1.4 pp more likely (14\%) than EP schools to enroll top achieving students (i.e students whose test score is in the top 10th percentile of the KS2 scores distribution). We do not find significant differences in the composition of EP and FPF schools along the rest of the achievement distribution, a finding which is not surprising if the FPF criterion was primarily used to attract top students.

After the ban, however, active FPF schools largely lost their advantage. Their higher probability of enrolling students in the top 10th percentile dropped by $1.5 \mathrm{pp}$ relative to EP schools (which represents a $14.4 \%$ relative drop). We find consistent results along the rest of the distribution: 
active FPF schools became $2.2 \mathrm{pp}(-8.7 \%)$ less likely to enroll students who score in the top 25th percentile (compared to EP schools). In contrast, their relative chances of enrolling low performing students (in the bottom 10th and 25th percentile) rose by $1.4 \mathrm{pp}(+13.3 \%)$ and $2.5 \mathrm{pp}(+9.8 \%)$. Consistent with these changes in FPF schools' composition in terms of student achievement, FPF schools also became $3.9 \mathrm{pp}(+21.5 \%)$ more likely to enroll low-SES students than EP schools.

These large effects of the reform suggest that, under the old FPF regime, FPF schools were attracting high-SES parents by discouraging them from applying to better, yet oversubscribed, schools. The large reallocation of low-SES students to FPF schools after the IA ban brings additional support for the competition for top schools effect. After 2008, low-SES students might have faced larger competition for their top choice school because high-SES parents stopped strategically listing FPF schools as their first choice and instead ranked the selective school.

\subsection{Robustness Checks}

We run a number of robustness checks that are similar to the ones we ran in the previous section, when looking at the effect of IA-to-DA transition. We therefore refer the reader to that section for a detailed justification of the alternative specifications. We present the results in Figure 13.

Sample variations. In addition to the original sample (labeled as "Base Sample" in Figure 13), we run our regressions on (i) a sample that excludes students from the local authorities in London and (ii) a sample that discards academy schools. ${ }^{55}$ With this last test, we want to check that our results are not driven by the rapid expansion of the academy sector between 2010 and 2020. Originally introduced in 2002 under the Labour Government to replace poorly performing secondary schools, academies massively expanded after the change of government in May 2010 and the Academies Act of that year (Eyles, Machin and McNally, 2017; Eyles and Machin, 2019). Almost $60 \%$ of state-funded secondary schools are academies in 2020, up from $6 \%$ in 2010 .

Yet, our results do not differ when we discard academy schools from our sample, a reassuring finding that might be explained by two features of academies. First, the bulk of the academy expansion took place at the very end of the period we consider. Second, in almost all cases, academies are conversions of existing schools that inherit currently enrolled pupils and existing admission criteria. Changes in admission criteria and students' composition might take time. ${ }^{56}$

Additional control variables. We also test the robustness of our results to removing control variables for school type and admission criteria. The results are not sensitive to it, nor are they sensitive to the addition of a time trend specific to each admission criterion.

\footnotetext{
${ }^{55}$ More precisely, we discard any schools that will become an academy school at some point in the sample.

${ }^{56}$ Finding that our results are not driven by academies is reassuring since Eyles and Machin (2019) show that post-conversion, academies became less likely to admit free school meal eligible pupils and more likely to admit pupils with higher KS2 scores. They mostly attribute these changes to a post-conversion change in parents' preferences.
} 


\section{Conclusion}

A few years after the Boston school committee replaced IA with DA in 2005, English officials enacted a nationwide ban on IA. An Act of Parliament forced all local authorities to use DA from 2008 onward. We exploit this natural experiment in market organization to investigate whether a strategy-proof mechanism like DA affects access to school quality for disadvantaged pupils. A common motivation for replacing IA with DA is that unsophisticated families, who are more likely to be low-SES, may be better off under a strategy-proof mechanism because sophisticated parents' strategic advantage is nullified.

We compare the changes in outcomes for students in IA and DA local authorities in the years before and after the ban. Our results suggest that low-SES students were harmed by the IA-to-DA transition relative to high-SES students. Low-SES students attended schools with lower valueadded and a greater fraction of low-SES peers and low-achieving peers. This unintended effect of DA partly stems from low-SES students losing access to selective schools. Under IA, high-SES parents did not compete for these schools as vigorously for fear of wasting a top choice, but they were free to under DA. Supporting this competition-for-top-schools effect, we further show that the detrimental effect for low-SES students is significantly larger in competitive local authorities. We also analyze schools that used the FPF admission criterion before its ban to compete with neighboring selective schools for a granular look at competition. The 2008 reform led to a large increase in the share of low-SES students in formerly FPF schools, which is a direct consequence of their displacement from selective schools, consistent with the competition-for-top-schools-effect.

Our findings represent novel evidence on the debate on the benefits and costs of strategyproof mechanisms for school assignment. More than a dozen countries and cities - among which Belgium, Germany, Spain, Cambridge MA and Seattle - still use IA to allocate students to schools or universities. Yet, opposition to manipulable mechanisms is still widespread due to the harm they might incur for unsophisticated families. Our results highlight the importance of the competitive environment and fallback options for measuring effects on unsophisticated families.

Several aspects of the British environment are unique, and extrapolation of our findings to other environments requires special care. The main mechanism we identify suggests that lowSES students face lower competition for their preferred schools under manipulable mechanisms because sophisticated high-SES parents might strategically avoid ranking these schools under IA. This effect is more likely in environments in which parents' preferences are aligned, leading to more competition for top schools that also use admission criteria that favor sophisticated parents. In Boston, no selective schools participate in the main choice process, and geography plays a large role in preference heterogeneity. In a such a situation, the trickle-down effect may dominate the competition-for-top-schools effect. In England, selective schools pick students based on test scores, which favors high-SES parents. After the transition to DA, high-SES parents enroll at these schools 
at higher rates. Selective admissions are widespread throughout education, so our results provide an important caution to equity rationales for DA over IA in settings where selective schools have large market share. 


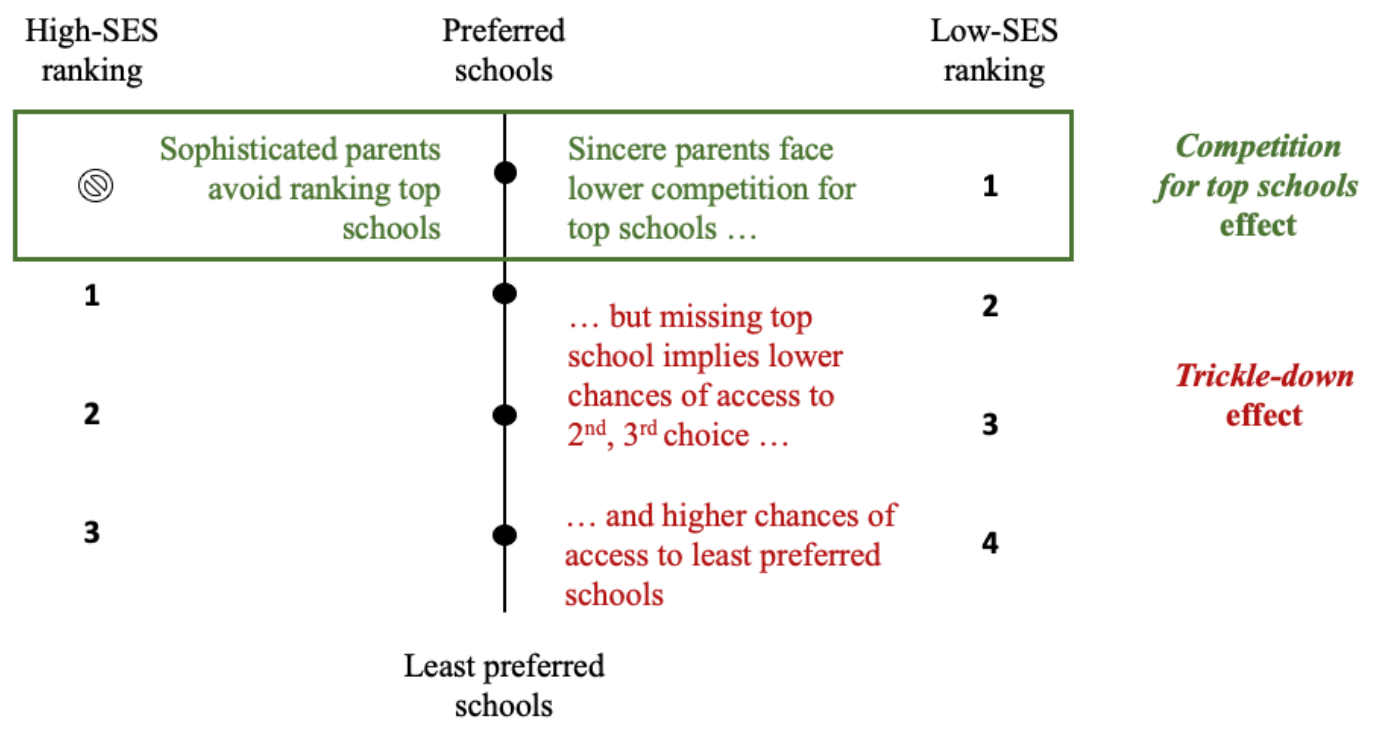

Figure 1: Illustration of the Competition-for-Top-Schools and Trickle-Down Effects

Notes: This figure illustrates the competition-for-top-schools and trickle-down effects. Inaccurate beliefs about admission chances lead sophisticated parents to avoid ranking over-demanded schools, even when they could have been admitted. Due to these mistakes sincere parents face less competition and gain priority at top-choice over-demanded schools. We refer to the latter effect as the competition-for-top-school effect. This beneficial effect of IA for sincere parents might be partially offset by a negative effect on their chances of being assigned their second or third choice. Sincere students' lack of strategizing implies that those who fail to gain access to their top choice are also less likely to be assigned their second or third choice as they lose priority at these schools to parents who ranked it as their first choice. We refer to this as the trickle-down effect. 


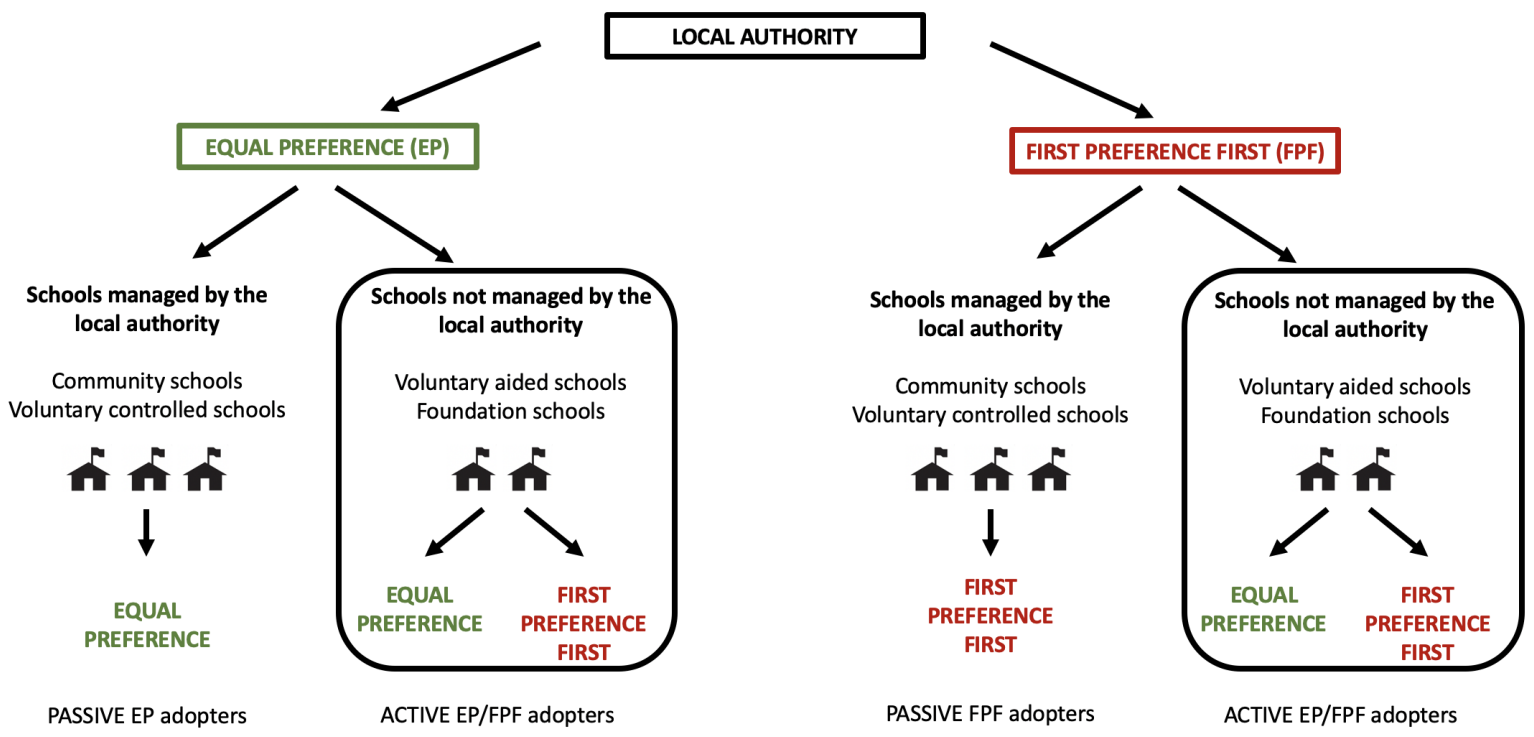

Figure 2: School-level Active and Passive Adopters of the FPF Admission Criterion

Notes: This figure illustrates the two levels of decisions on admission criteria: the local authority and the school. Three types of schools in England are their own admission authority: foundation schools, voluntary aided schools, and academies. We call these schools "active" adopters (of the EP or FPF criterion). In contrast, community and voluntary controlled schools, which represent $63.1 \%$ of the schools in 2007, are not their own admission authority: they follow the admission criteria decided by their local authority. We call them "passive" adopters of the EP or FPF criterion. 
Table 1: Oversubscription Criteria Used Before the FPF Ban

\begin{tabular}{|c|c|c|c|c|c|c|c|c|}
\hline & \multirow{2}{*}{\multicolumn{2}{|c|}{$\begin{array}{c}\text { Local } \\
\text { Authorities }\end{array}$}} & \multicolumn{6}{|c|}{ Schools } \\
\hline & & & \multicolumn{3}{|c|}{ All Schools } & \multicolumn{3}{|c|}{ Active Schools } \\
\hline & IA & DA & FPF & $\mathrm{EP}$ & Selective & FPF & $\mathrm{EP}$ & Selective \\
\hline & $(1)$ & $(2)$ & $(3)$ & $(4)$ & $(5)$ & $(6)$ & $(7)$ & $(8)$ \\
\hline & \multicolumn{8}{|c|}{ Panel A. Criteria That Changed } \\
\hline First Preference First (FPF) & 1.000 & 0.000 & 1.000 & 0.000 & 0.219 & 1.000 & 0.000 & 0.119 \\
\hline Parental Commitment & 0.048 & 0.130 & 0.073 & 0.105 & 0.031 & 0.193 & 0.192 & 0.044 \\
\hline Children of Associated Adults & 0.004 & 0.084 & 0.016 & 0.049 & 0.034 & 0.046 & 0.068 & 0.050 \\
\hline \multirow[t]{2}{*}{ Children in Care } & 0.785 & 0.808 & 0.838 & 0.736 & 0.741 & 0.643 & 0.566 & 0.566 \\
\hline & \multicolumn{8}{|c|}{ Panel B. Other Unaffected Criteria } \\
\hline Siblings & 0.930 & 0.911 & 0.913 & 0.929 & 0.809 & 0.807 & 0.820 & 0.654 \\
\hline Catchment Area and Proximity & 0.952 & 0.911 & 0.904 & 0.919 & 0.852 & 0.750 & 0.792 & 0.742 \\
\hline Medical/Social Needs & 0.684 & 0.569 & 0.535 & 0.502 & 0.444 & 0.357 & 0.381 & 0.245 \\
\hline Special Educational Needs & 0.754 & 0.598 & 0.538 & 0.534 & 0.312 & 0.296 & 0.276 & 0.220 \\
\hline Feeder Schools & 0.544 & 0.231 & 0.276 & 0.366 & 0.077 & 0.357 & 0.373 & 0.088 \\
\hline Faith & 0.096 & 0.147 & 0.164 & 0.165 & 0.062 & 0.500 & 0.470 & 0.126 \\
\hline Other & 0.096 & 0.058 & 0.072 & 0.075 & 0.052 & 0.050 & 0.065 & 0.057 \\
\hline Number of Schools & 228 & 845 & 858 & 1659 & 324 & 280 & 557 & 159 \\
\hline
\end{tabular}

Notes: This table reports how frequently each admission criterion is used by IA and DA local authorities (columns 1 and 2), by FPF and EP schools (columns 3 and 4), and by active FPF and EP schools (columns 6 and 7). Columns 3, 4, 6, and 7 do not contain selective schools. Panel A reports statistics for the criteria that were affected by the 2007 Admission Code, while Panel B reports statistics for those that were not affected by the new code. Appendix A.2 provides a detailed description of each oversubscription criterion. 


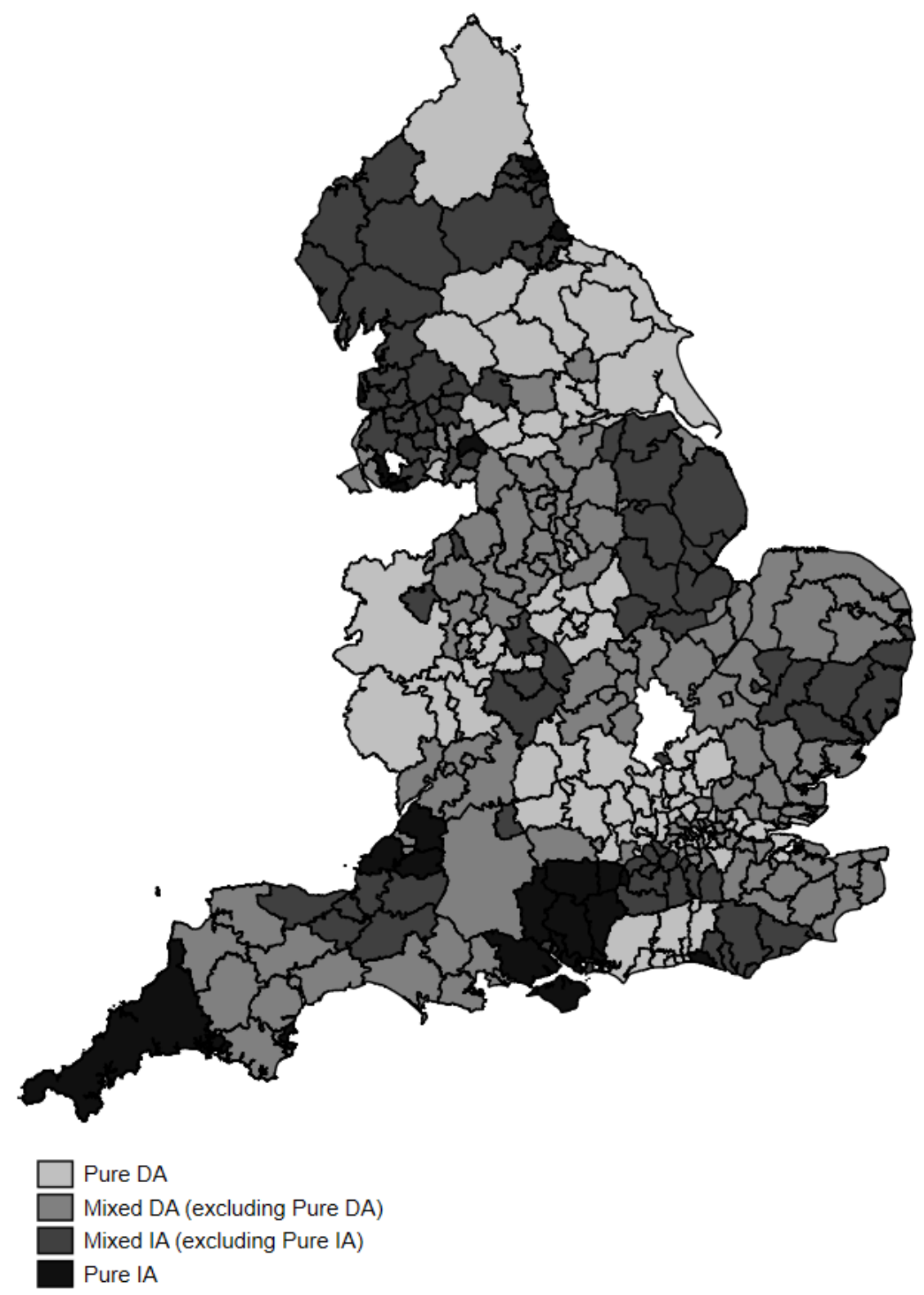

Figure 3: IA and DA Local Authorities in England in 2007

Notes: This map shows the location of deferred acceptence (DA) and immediate acceptence (IA) local authorities in England. 46 local authorities (31.5\%) use the IA criterion for the schools they control, and 100 use the DA criterion. Some schools are their own admission authority and do not have to follow the criteria guidelines of their local authority. As a result, schools using the FPF criterion can coexist with schools using the EP criterion within each local authority. We call local authorities in which all schools use the EP (or FPF) criterion "pure DA" and "pure IA". Throughout the paper we drop the word "pure" for brevity. We call "mixed DA" (resp "mixed IA") the local authorities in which the local authority has chosen the EP criterion (resp FPF) but there may be some schools using FFP (resp EP). As such a DA (resp. IA) local authority is a special case of a mixed DA (resp. IA) local authority in which all schools are using EP (resp. FPF). 
Table 2: Descriptive Statistics on Local Authorities and Schools (in 2007)

\begin{tabular}{|c|c|c|c|c|c|c|c|c|c|c|}
\hline & \multirow{2}{*}{\multicolumn{4}{|c|}{$\begin{array}{c}\text { Local } \\
\text { Authorities }\end{array}$}} & \multicolumn{6}{|c|}{ Schools } \\
\hline & & & & & \multicolumn{3}{|c|}{ All Schools } & \multicolumn{3}{|c|}{ Active Schools } \\
\hline & Mixed IA & Mixed DA & IA & DA & FPF & $\mathrm{EP}$ & Selective & FPF & $\mathrm{EP}$ & Selective \\
\hline & $(1)$ & $(2)$ & $(3)$ & $(4)$ & $(5)$ & $(6)$ & $(7)$ & $(8)$ & $(9)$ & $(10)$ \\
\hline & \multicolumn{10}{|c|}{ Panel A. Local Authorities Characteristics } \\
\hline Three preferences & 0.96 & 0.49 & 1.00 & 0.45 & - & - & - & - & - & - \\
\hline Six preferences & 0.00 & 0.40 & 0.00 & 0.43 & - & - & - & - & - & - \\
\hline Fraction of selective schools & 0.08 & 0.10 & 0.06 & 0.10 & - & - & - & - & - & - \\
\hline Fraction of private schools & 0.18 & 0.24 & 0.16 & 0.25 & - & - & - & - & - & - \\
\hline At least one selective school & 0.28 & 0.34 & 0.19 & 0.33 & - & - & - & - & - & - \\
\hline \multirow[t]{2}{*}{$\mathrm{N}$} & 46 & 100 & 16 & 49 & - & - & - & - & & \\
\hline & \multicolumn{10}{|c|}{ Panel B. School Characteristics } \\
\hline Number of Students & 187 & 185 & 201 & 181 & 191 & 187 & 163 & 192 & 183 & 155 \\
\hline Urban & 0.42 & 0.56 & 0.45 & 0.62 & 0.46 & 0.56 & 0.45 & 0.51 & 0.54 & 0.55 \\
\hline Greater London Area & 0.00 & 0.18 & 0.00 & 0.16 & 0.04 & 0.17 & 0.12 & 0.11 & 0.22 & 0.16 \\
\hline Community school & 0.66 & 0.58 & 0.78 & 0.63 & 0.64 & 0.62 & 0.46 & 0.00 & 0.00 & 0.00 \\
\hline Voluntary Controlled school & 0.02 & 0.02 & 0.01 & 0.02 & 0.02 & 0.02 & 0.04 & 0.00 & 0.00 & 0.00 \\
\hline Voluntary Aided school & 0.17 & 0.17 & 0.11 & 0.17 & 0.18 & 0.17 & 0.15 & 0.55 & 0.51 & 0.31 \\
\hline Foundation school & 0.14 & 0.20 & 0.10 & 0.15 & 0.15 & 0.17 & 0.34 & 0.45 & 0.49 & 0.69 \\
\hline Academy & 0.00 & 0.01 & 0.00 & 0.01 & 0.00 & 0.01 & 0.00 & 0.00 & 0.00 & 0.00 \\
\hline \multirow[t]{2}{*}{$\mathrm{N}$} & 837 & 1,933 & 228 & 845 & 787 & 1,659 & 324 & 261 & 557 & 159 \\
\hline & \multicolumn{10}{|c|}{ Panel C. Student Characteristics } \\
\hline Female & 0.49 & 0.49 & 0.49 & 0.49 & 0.50 & 0.49 & 0.50 & 0.51 & 0.48 & 0.47 \\
\hline Free School Meal & 0.15 & 0.17 & 0.14 & 0.18 & 0.15 & 0.18 & 0.10 & 0.12 & 0.15 & 0.07 \\
\hline White & 0.89 & 0.79 & 0.92 & 0.75 & 0.88 & 0.79 & 0.82 & 0.86 & 0.79 & 0.75 \\
\hline White British & 0.87 & 0.75 & 0.90 & 0.71 & 0.85 & 0.76 & 0.78 & 0.82 & 0.74 & 0.70 \\
\hline Special Education Needs & 0.40 & 0.41 & 0.40 & 0.40 & 0.41 & 0.42 & 0.33 & 0.38 & 0.39 & 0.21 \\
\hline Distance to School (km) & 1.80 & 1.79 & 1.63 & 1.73 & 1.72 & 1.68 & 2.66 & 2.13 & 2.06 & 3.29 \\
\hline KS2 Score & 0.01 & 0.02 & 0.02 & 0.02 & -0.02 & -0.03 & 0.37 & 0.07 & 0.04 & 0.72 \\
\hline KS3 Score & 0.38 & 0.38 & 0.37 & 0.39 & 0.37 & 0.36 & 0.56 & 0.41 & 0.39 & 0.72 \\
\hline $\mathrm{N}$ & 156,133 & 358,180 & 45,831 & 152,699 & 150,523 & 310,866 & 118,215 & 50,142 & 102,040 & 24,654 \\
\hline
\end{tabular}

Notes: This table reports descriptive statistics for the sample of 146 local authorities, 2,770 schools, and 461,389 students in 2007 . Column 1 and 2 report statistics for mixed IA and DA local authorities, columns 3 and 4 for IA and DA local authorities in which 100\% of the schools are using the EP (resp FPF) admission criterion. Columns 5 to 10 report statistics for all FPF and EP schools in columns 5 and 6 and for active FPF and EP schools in columns 8 and 9 . These columns only contain non-selective schools. Columns 7 and 10 contain the statistics for selective schools. 
Table 3: Competitive vs. Non-Competitive Local Authority Comparison

\begin{tabular}{|c|c|c|}
\hline & $\begin{array}{l}\text { High Competition } \\
\text { (1) }\end{array}$ & $\begin{array}{l}\text { Low Competition } \\
\qquad(2)\end{array}$ \\
\hline & \multicolumn{2}{|c|}{ Panel A. Local Authorities Characteristics } \\
\hline Fraction of Selective Schools & 0.346 & 0.002 \\
\hline Three Preferences & 0.294 & 0.681 \\
\hline Six Preferences & 0.529 & 0.255 \\
\hline SD of School KS2 & 0.526 & 0.233 \\
\hline SD of School KS3 & 0.272 & 0.140 \\
\hline Fraction of Private Schools & 0.194 & 0.225 \\
\hline \multirow[t]{2}{*}{ Number of IA and DA LAs } & 17 & 47 \\
\hline & \multicolumn{2}{|c|}{ Panel B. School Characteristics } \\
\hline Number of Students (mean) & 170 & 189 \\
\hline Urban & 0.720 & 0.511 \\
\hline Greater London Area & 0.152 & 0.113 \\
\hline Community School & 0.480 & 0.742 \\
\hline Voluntary Controlled School & 0.013 & 0.024 \\
\hline Voluntary Aided School & 0.197 & 0.135 \\
\hline Foundation School & 0.288 & 0.080 \\
\hline \multirow[t]{2}{*}{ Academy } & 0.019 & 0.017 \\
\hline & \multicolumn{2}{|c|}{ Panel C. Student Characteristics } \\
\hline Female & 0.492 & 0.489 \\
\hline Free School Meal & 0.184 & 0.160 \\
\hline White & 0.693 & 0.824 \\
\hline White British & 0.649 & 0.792 \\
\hline Ever Special Education Needs & 0.408 & 0.412 \\
\hline Distance to School (km) & 1.818 & 1.664 \\
\hline KS2 Score & 0.071 & -0.002 \\
\hline KS3 Score & 0.428 & 0.383 \\
\hline
\end{tabular}

Notes: This table shows the conditional means by the competitiveness of the local authority. In Panel A we show the local authority level characteristics as well as student level characteristics within each local authority. In Panel B we show the school level characteristics within each Local Authority. Both Panels $\mathrm{B}$ and $\mathrm{C}$ include selective schools/students who attend selective schools in the computations. 


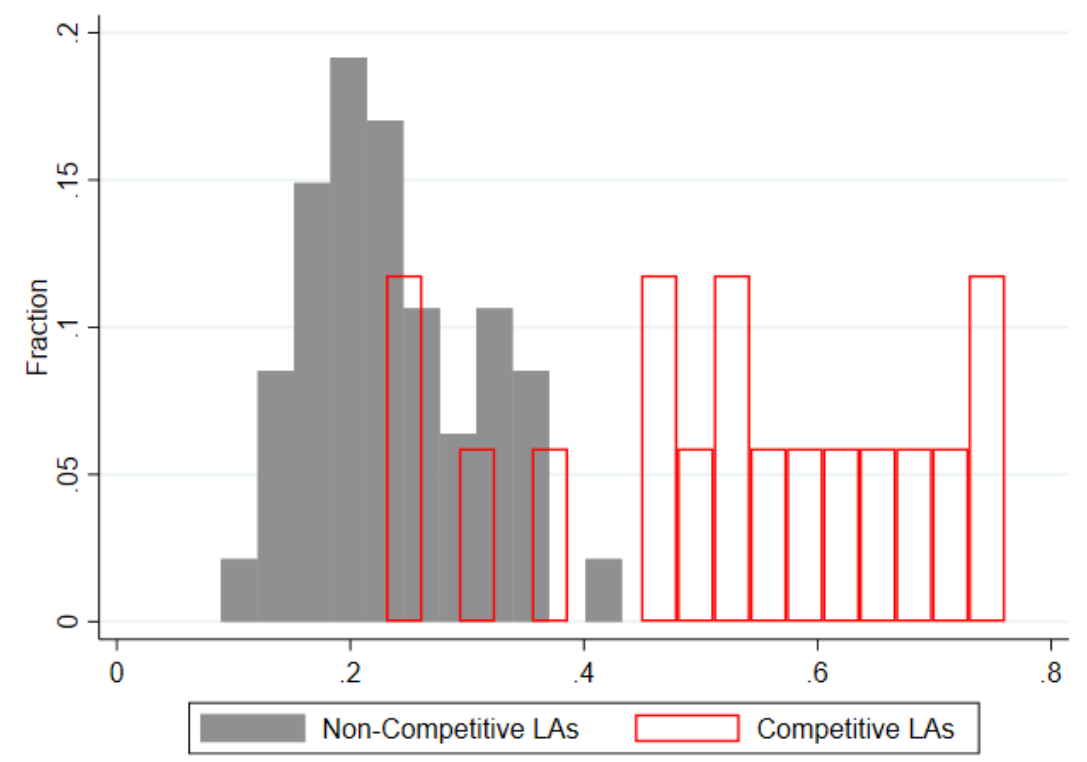

Figure 4: Distribution of Standard Deviation of School KS2 Test Scores

Notes: This figure shows the within-local authority standard deviation of the school KS2 scores. Non-competitive local authorities are denoted in gray bars and competitive local authorities are denoted in red outlined bars.

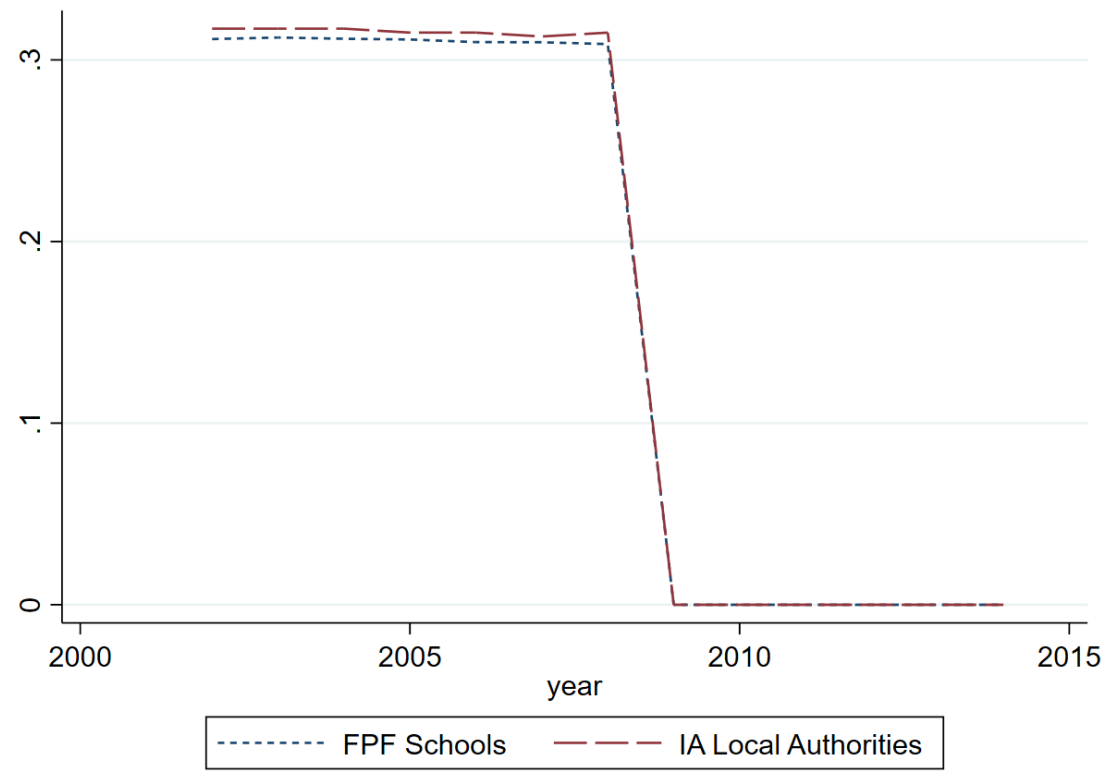

Figure 5: Effect of the FPF Ban on FPF Usage

Notes: This Figure reports the share of local authorities (dashed line) that use the IA mechanism and the share of schools (dotted line) that use the FPF admission criterion over time. 
(a) Competitive IA and DA Local Authorities

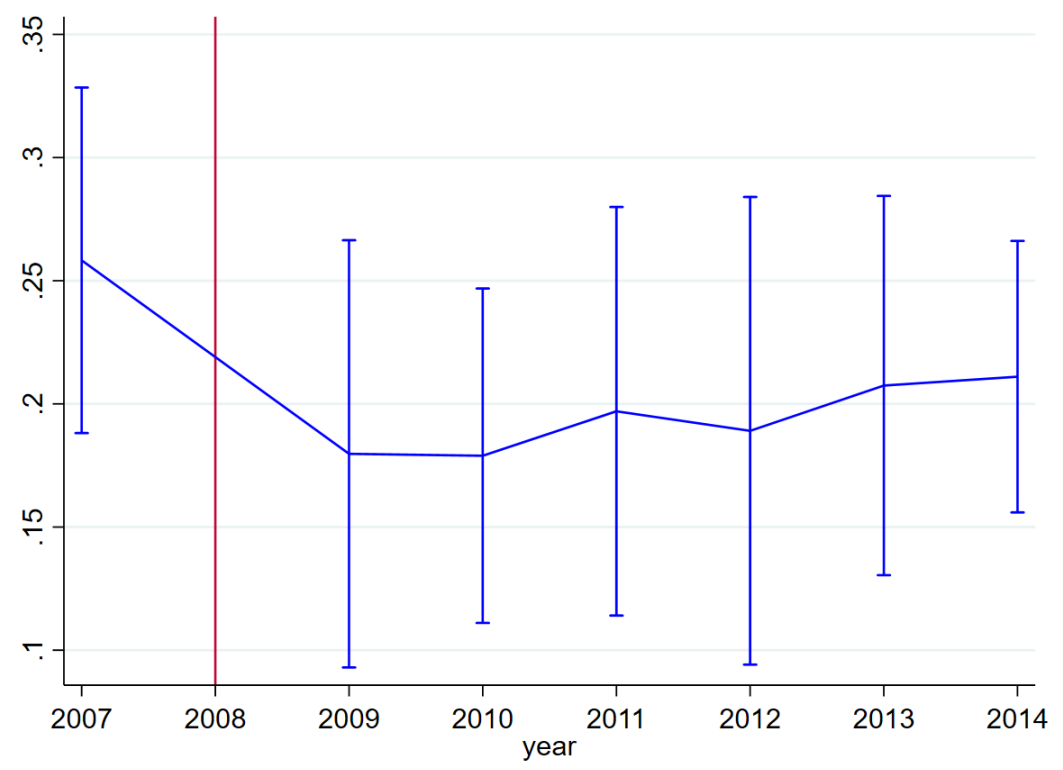

(b) Non-Competitive IA and DA Local Authorities

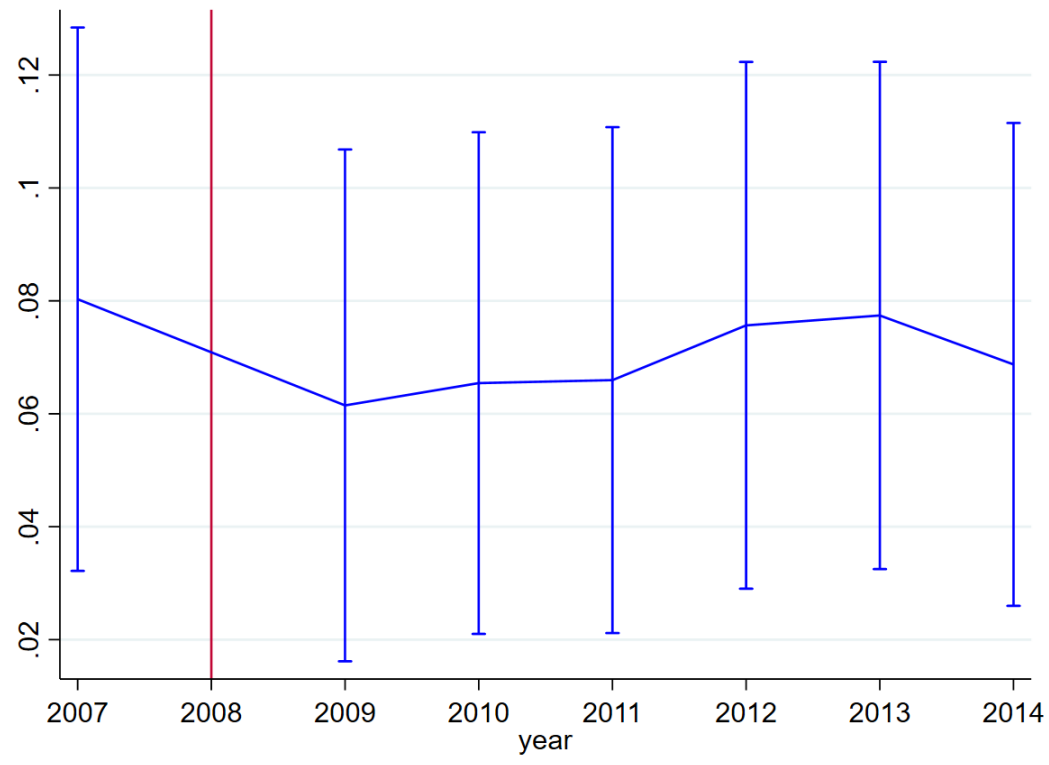

Figure 6: First Choice Accommodation

Notes: This figure reports the $\beta_{t}$ coefficients from the following event-study regression: $y_{i t}=\sum_{t \in \mathcal{T}} \beta_{t} I A_{i} \cdot T_{t}+X_{i}^{\prime} \delta+\varepsilon_{i t}$ where $y_{i t}$ is the proportion of students in local authority $i$ in year $t$ receiving their first choice, $\mathcal{T}$ is the set of years that have first choice data from 2007 onwards, $I A_{i}$ is a dummy variable that is equal to one for IA local authorities, $T_{t}$ is an indicator for the year $t, X_{i}$ is a vector of local authority level controls, and $\varepsilon_{i t}$ is an idiosyncratic error term. The specification shown in this figure does not include any controls. Panel (a) is the regression for competitive local authorities, which are local authorities with at least one selective school (excluding two local authorities that are very large and have very few selective schools). Non-competitive local authorities are all remaining local authorities. We show the $95 \%$ confidence interval of all coefficients. We cluster standard errors at the local authority level. 
Table 4: Effect of the Transition from IA to DA on High-SES and Low-SES Students

\begin{tabular}{|c|c|c|c|c|c|c|}
\hline & $\begin{array}{c}\text { School } \\
\text { Value-Added } \\
\end{array}$ & $\begin{array}{c}\text { Peers' Baseline } \\
\text { Scores }\end{array}$ & $\begin{array}{l}\text { Share of } \\
\text { Low-SES }\end{array}$ & $\begin{array}{l}\text { Attends } \\
\text { Selective } \\
\end{array}$ & $\begin{array}{l}\text { Attends B25 } \\
\text { School }\end{array}$ & $\begin{array}{c}\text { Student KS3 } \\
\text { Score }\end{array}$ \\
\hline & $(1)$ & $(2)$ & $(3)$ & $(4)$ & $(5)$ & $(6)$ \\
\hline \multicolumn{7}{|c|}{ Panel A. All IA and DA Local Authorities } \\
\hline Post-Reform X IA LA & $\begin{array}{c}0.003 \\
(0.006)\end{array}$ & $\begin{array}{c}-0.023^{*} \\
(0.014)\end{array}$ & $\begin{array}{c}0.006 \\
(0.006)\end{array}$ & $\begin{array}{r}-0.022^{*} \\
(0.013)\end{array}$ & $\begin{array}{c}-0.010^{* *} \\
(0.005)\end{array}$ & $\begin{array}{l}-0.006 \\
(0.012)\end{array}$ \\
\hline \multirow[t]{2}{*}{ Post-Reform X IA LA X Low-SES } & $-0.008^{*}$ & $-0.029^{* *}$ & $0.016^{*}$ & -0.011 & 0.002 & -0.007 \\
\hline & $(0.005)$ & $(0.012)$ & $(0.009)$ & $(0.007)$ & $(0.010)$ & $(0.008)$ \\
\hline Scaled Effect (D-in-D) & $.60 \%$ & $-41.8 \%$ & $4.3 \%$ & $-17.9 \%$ & $-5.4 \%$ & $-1.6 \%$ \\
\hline Scaled Effect (D-in-D-in-D) & $-1.7 \%$ & $-53 \%$ & $10.2 \%$ & $-8.7 \%$ & $1.2 \%$ & $-1.8 \%$ \\
\hline \multirow[t]{2}{*}{ Observations } & $2,149,304$ & $2,155,216$ & $2,155,569$ & $2,155,569$ & $2,149,235$ & $1,541,279$ \\
\hline & \multicolumn{6}{|c|}{ Panel B. Competitive IA and DA Local Authorities } \\
\hline Post-Reform X IA LA & $0.008^{* *}$ & -0.018 & 0.004 & 0.001 & $-0.014^{* *}$ & -0.010 \\
\hline & $(0.004)$ & $(0.018)$ & $(0.007)$ & $(0.007)$ & $(0.007)$ & $(0.042)$ \\
\hline \multirow[t]{2}{*}{ Post-Reform X IA LA X Low-SES } & $-0.013^{* *}$ & $-0.072^{* * *}$ & $0.031^{* * *}$ & $-0.026^{* * *}$ & 0.017 & 0.011 \\
\hline & $(0.005)$ & $(0.011)$ & $(0.010)$ & $(0.006)$ & $(0.021)$ & $(0.020)$ \\
\hline Scaled Effect (D-in-D) & $1.6 \%$ & $-13.6 \%$ & $2.8 \%$ & $.3 \%$ & $-7.3 \%$ & $-2.3 \%$ \\
\hline Scaled Effect (D-in-D-in-D) & $-2.8 \%$ & $-53 \%$ & $20 \%$ & $-8.1 \%$ & $8.8 \%$ & $2.5 \%$ \\
\hline Observations & 710,668 & 710,668 & $2,155,569$ & 710,668 & 710,668 & 498,603 \\
\hline
\end{tabular}

Notes: This table reports the results from Equation (1), which estimates the differential effect of the FPF ban for high- and low-SES students (in a triple difference spirit). We let a student-level outcome $Y_{l t i}$ be a function of a dummy variable indicating whether the local authority is using the FPF admission criteria before the ban $I A_{l}$, a dummy variable equal to one for the post-reform years Post $t_{t}$, a dummy variable equal to one for lowSES students lowSES $S_{i}$, the interaction between the IA local authority indicator and post-reform indicator $I A_{l} \cdot P o s t_{t}$, and an interaction between that FSM variable and the $I A_{l}$. Post $t_{t}$ interaction. The control variable $X_{l t}$ includes a vector of LA-level control variables for (i) the average share of each school type, (ii) the share of schools that use each admission criterion, and (iii) the number of schools that students can rank on their list. The vector $X_{l t}$ also includes two additional interaction terms: Post $t_{t} \cdot l o w S E S_{i}$ and $I A_{l} \cdot l o w S E S_{i}$. We cluster standard errors at the local authority level in all regressions. The outcome in column (1) is the shrunken value-added measure of the school that student $i$ attends. The outcome in column (2) is the average KS2 score of all current year 7 students at the school student $i$ attends. We call this the a student's peers' baseline score. The outcome in column (3) is the proportion of low-SES peers at the school student $i$ attends. The outcome in column (4) is an indicator of whether the student attends a selective school. The outcome in column (5) is an indicator of whether a student attends a school with an average KS2 score in the bottom $25 \%$ of the local authority. Finally, the outcome in column (6) is an indicator of whether student $i$ achieved level 6 in both their English and Mathematics KS3 assessment, which is the standard expectation. All regressions include students attending non-selective and selective schools. *** denote significance at the 1 percent level, ${ }^{* *}$ significance at the 5 percent level, and ${ }^{*}$ significance at the 10 percent level. 
All IA and DA Local Authorities

Competitive IA and DA Local Authorities

Panel A. Peers' Baseline Scores
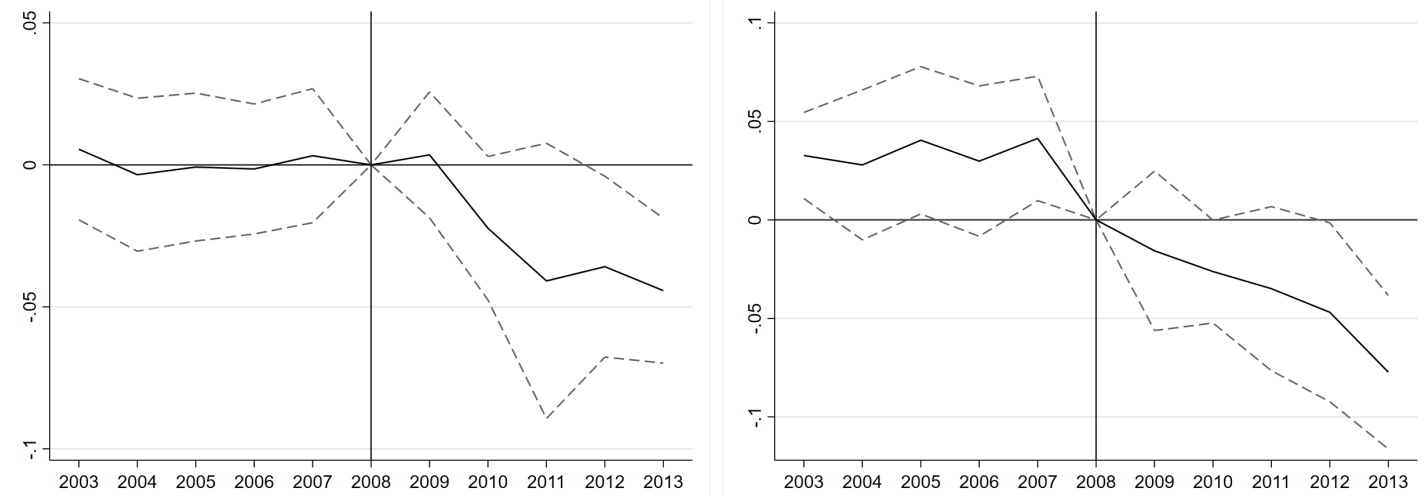

Panel B. Share of Low-SES Peers
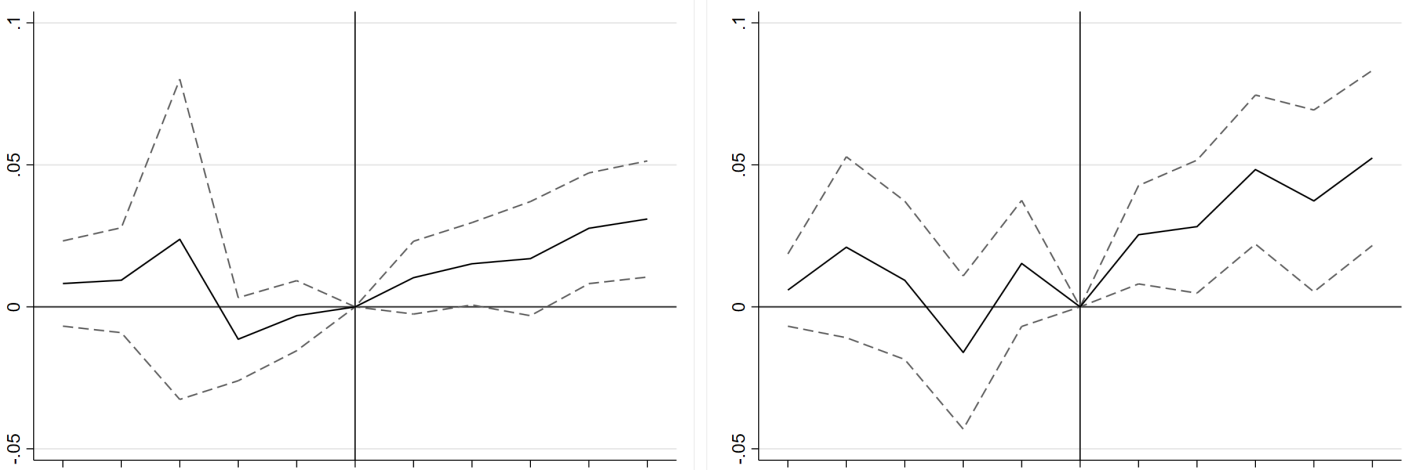

$\begin{array}{llllllllll}2003 & 2004 & 2005 & 2006 & 2007 & 2008 & 2009 & 2010 & 2011 & 2012 \quad 2013\end{array}$

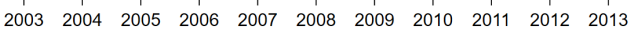

Panel C. School Value-Added
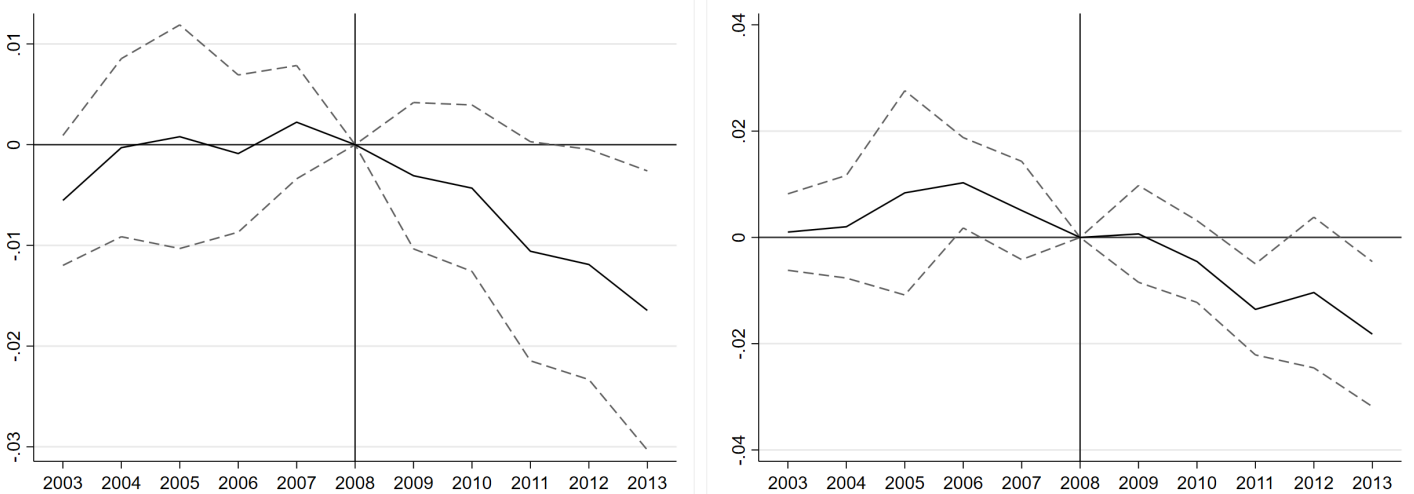

Figure 7: Event-Study - Change in Low-SES Students Peers' Characteristics

Notes: This figure provides a graphical visualization of pre-trends in outcomes by reporting coefficients (and $95 \%$ confidence intervals) from an event-study version of Equation (1) in which we replace the dummy variable equal to one for the post-reform years by a dummy for each year Yeart $_{t}$ (excluding 2008, the reference year, whose coefficient is set to zero). The coefficients we plot are the coefficient of the $I A_{l} \cdot Y$ eart $\cdot F S M_{i}$ interaction terms which indicate whether the change in student-level outcome in IA local authorities compared to the change in outcomes in DA local authorities was more pronounced for low-SES students than for high-SES students. Each regression contains the same set of controls as Equation (1), i.e a vector of LA-level control variables for the average share of each school type, the share of schools that use each admission criterion, and the number of schools that students can rank on their list. The left column are the event studies for all IA and DA local authorities and the right column are the event studies for the competitive IA and DA local authorities, which are the local authorities with at least one selective school (excluding two large local authorities with very few selective schools). 


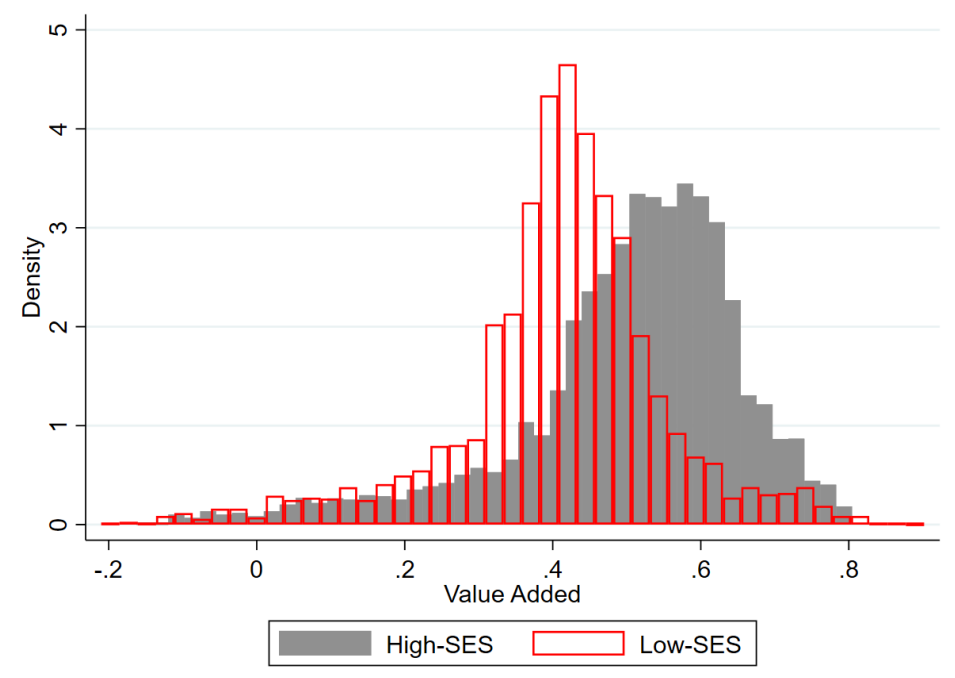

Figure 8: Heterogeneous Value-Added

Notes: This figure shows the distribution of schools' heterogeneous value-added by SES. The gray bars represent the VA distribution for high-SES students and red outlined bars represent the VA distribution low-SES students. Appendix B provides a detailed presentation of the regression used. Our VA measure captures the contribution of a school to a standard performance metric: a student's likelihood of obtaining level 2 qualifications in at least five KS4 exams including English and Mathematics. We regress this KS4 outcome (five years after enrollment in secondary school) on KS2 test scores (taken just before enrollment in secondary school), a vector of other student characteristics, a vector of time-varying school characteristics, and a vector of school fixed effects. To measure the heterogenous effect, we interact the vector of school fixed effects with a dummy variable equal to 1 for low-SES students and 0 for high-SES students.

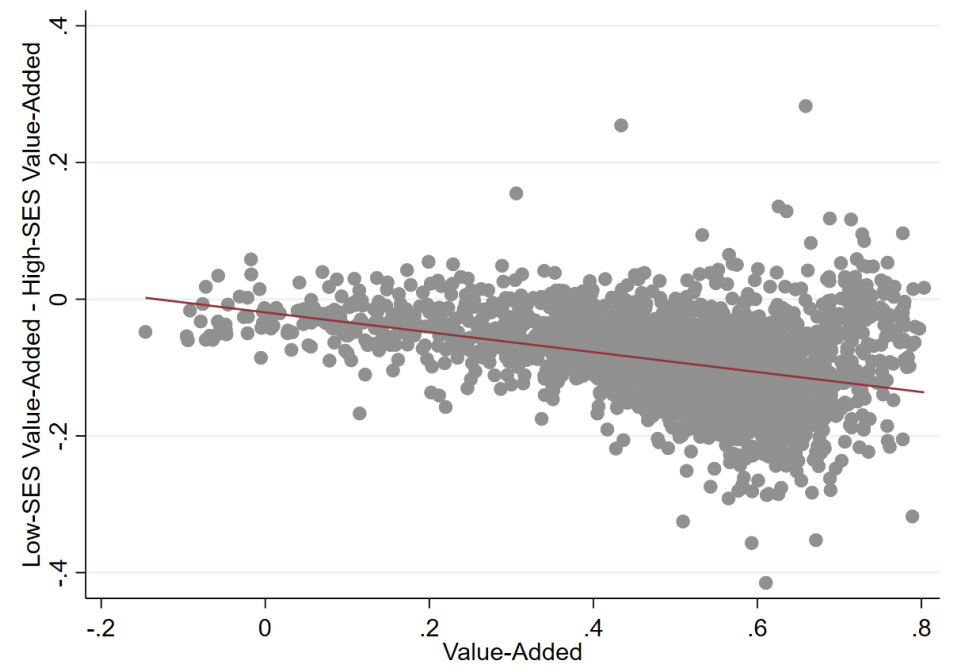

Figure 9: Difference Between Low-SES and High-SES Students' VA Along the VA Distribution

Notes: This figure shows the scatterplot and regression line of the school value-added measure on the $\mathrm{x}$-axis and the difference between the low-SES and high-SES specific school value-added on the y-axis. The slope of the line of best fit is -0.146 . 


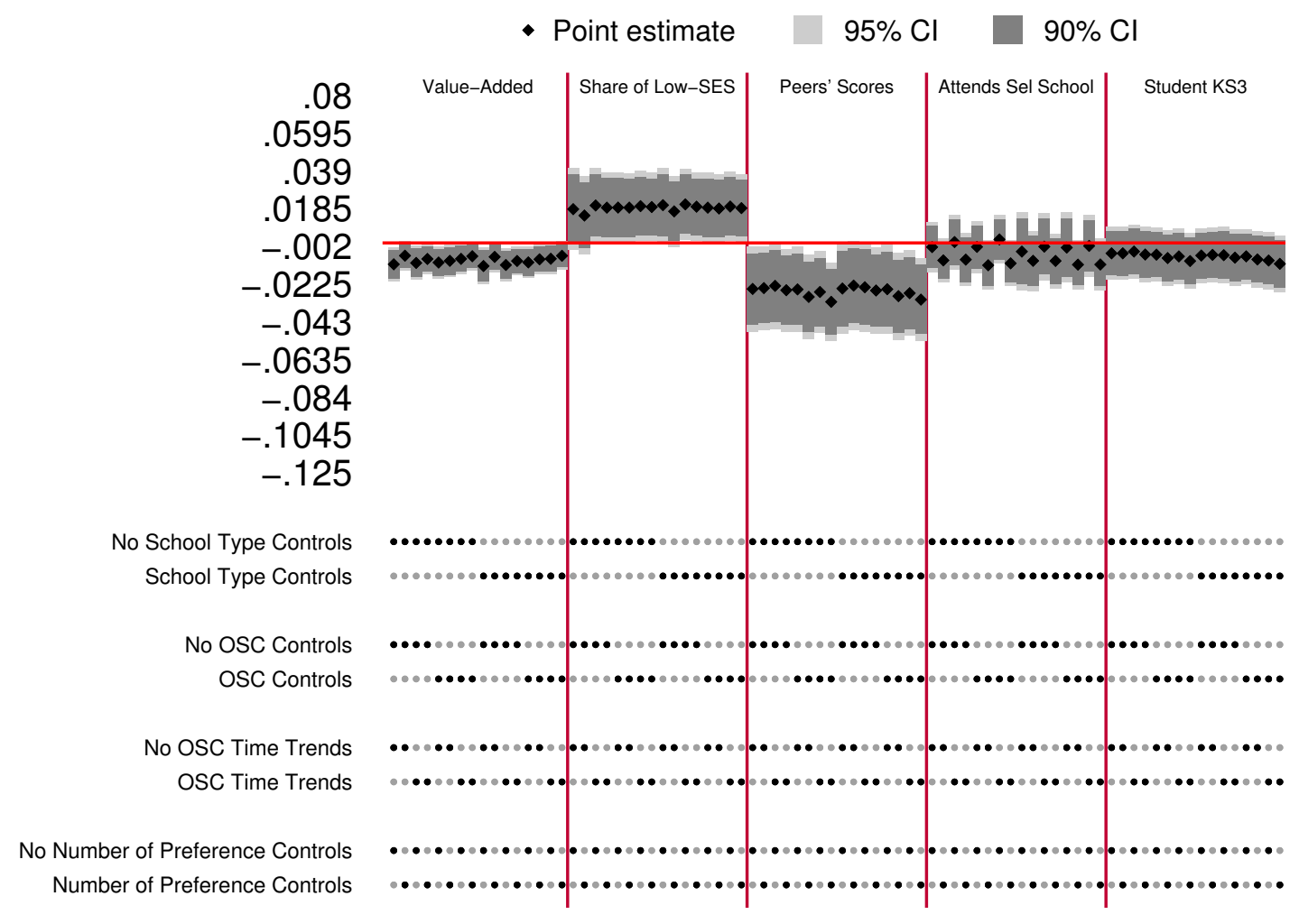

Figure 10: Robustness Checks for the Effect of the IA Ban

Notes: This figure presents robustness checks for the effect of the IA ban on the following outcomes separated by red bars: the school value-added (labelled as "Value-Added"), the share of lowSES peers (labelled as "Share of Low-SES"), peers' baseline score (labelled as "Peers' Scores"), probability of attending a selective school (labelled as "Attends Sel School"), and students' KS3 score (labelled as "Student KS3"). The four panels report whether we include (i) a set of controls for the share of schools of each type in each local authority, (ii) a set of controls for the share of schools that use each admission criterion in each local authority, (iii) time-trends for the share of schools that use each admission criterion, and (iv) controls for the number of preferences the local authority permits. 


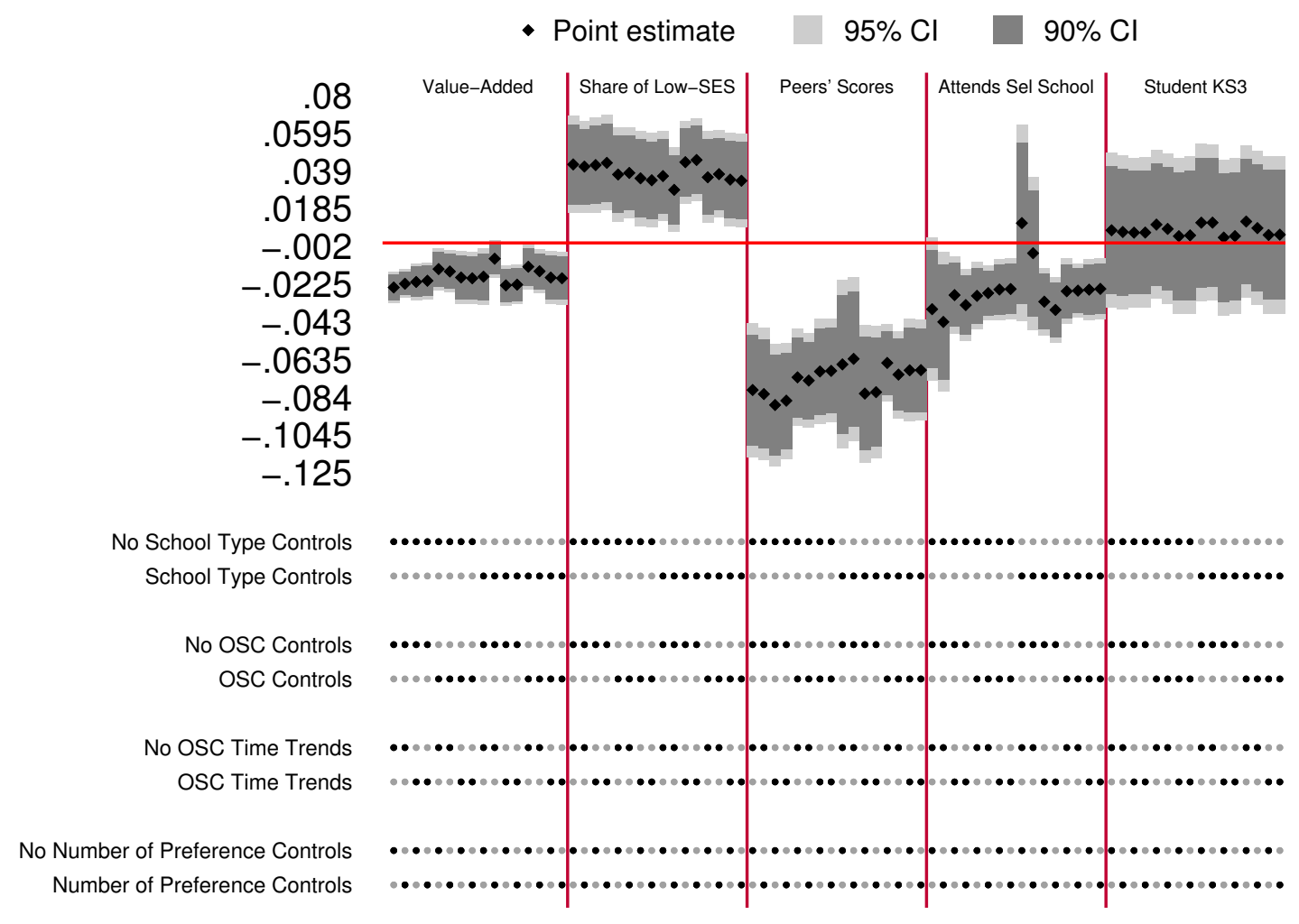

Figure 11: Robustness Checks for the Effect of the IA Ban (Competitive Local Authorities Only)

Notes: This figure presents robustness checks for the effect of the IA ban on the following outcomes separated by red bars: the school value-added (labelled as "Value-Added"), the share of lowSES peers (labelled as "Share of Low-SES"), peers' baseline score (labelled as "Peers' Scores"), probability of attending a selective school (labelled as "Attends Sel School"), and students' KS3 score (labelled as "Student KS3"). The four panels report whether we include (i) a set of controls for the share of schools of each type in each local authority, (ii) a set of controls for the share of schools that use each admission criterion in each local authority, (iii) time-trends for the share of schools that use each admission criterion, and (iv) controls for the number of preferences the local authority permits. Only competitive local authorities are shown in this figure. 
(a) \% Low-SES Students

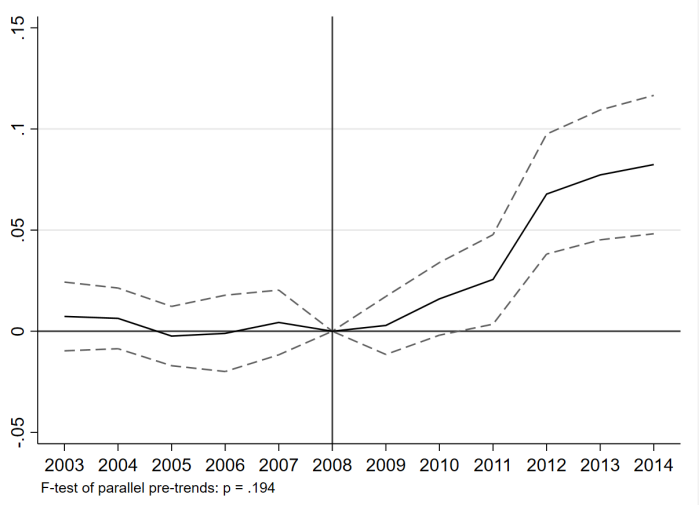

(c) \% Students with Bottom $25 \%$ KS2 Score

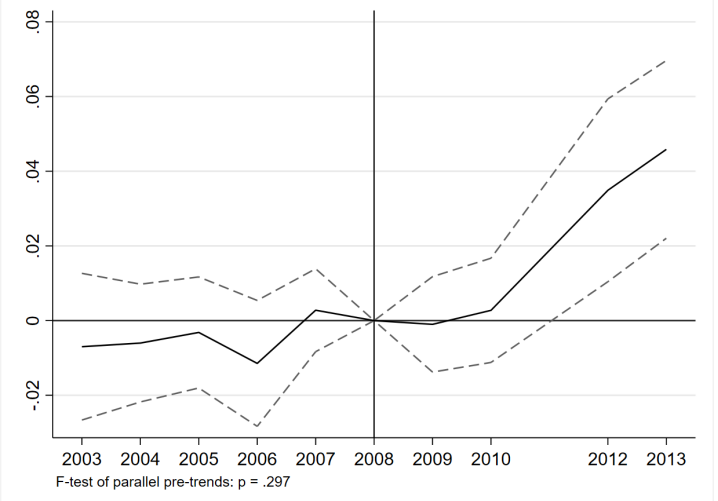

(b) $\%$ Students with Bottom $10 \%$ KS2 Score

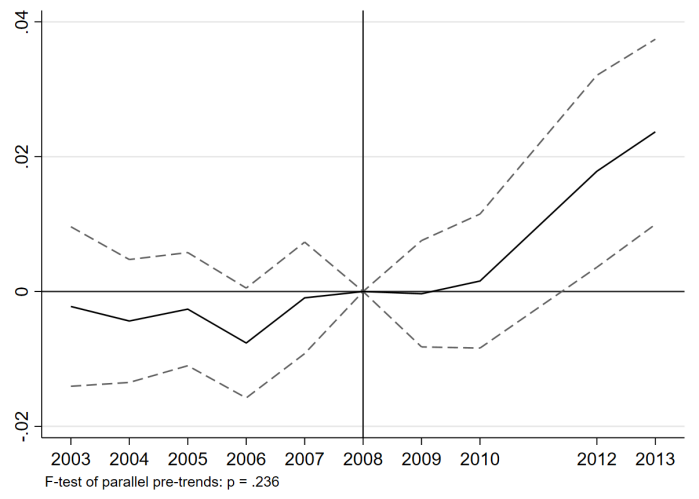

(d) \% Students with Top $25 \%$ KS2 Score

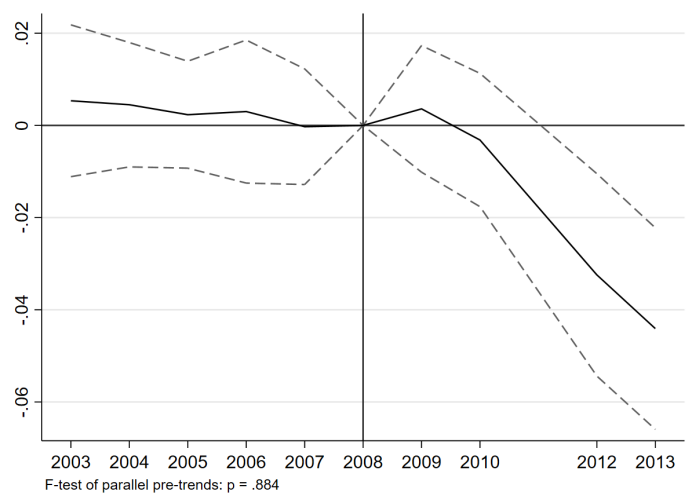

(e) \% Students with Top $10 \%$ KS2 Score

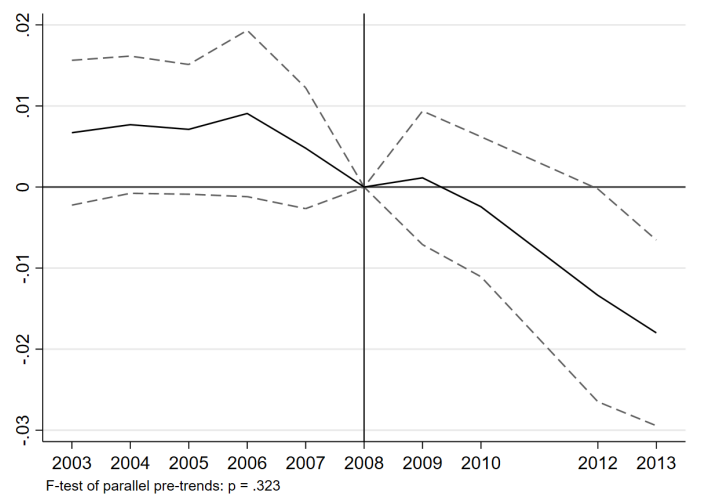

\section{Figure 12: Event-Study Effect of the FPF Ban on FPF Schools' Composition (Relative to EP)}

Notes: This figure provides a graphical visualization of pre-trends in outcomes by reporting coefficients (and 95\% confidence intervals) from an event-study version of Equation (2) in which we replace the dummy variable equal to one for the post-reform years by a dummy for each year Yeart (excluding 2008, the reference year, whose coefficient is set to zero). The coefficients we plot are the coefficients of the $F P F_{s} \cdot Y e a r_{t}$ interaction terms which capture the change in outcome in FPF schools compared to the change in EP schools. Each regression contains the same set of controls as the ones in Equation (2), i.e controls for school-level characteristics including school type, and each admission criterion used by schools. We complement each regression with a formal F-test of whether the coefficients of the FPF-by-year effects are jointly equal to zero in the pre-reform years. The p-values of the test are reported in the bottom-left side of each graph. We report results for five school-level outcome variables: the share of Free School Meal recipients, the share of students whose KS2 test score is below the 90th and 75th percentiles of their cohort distribution, and the share of students whose KS2 test score is above the 25th and 10th percentiles. 
Table 5: Effect of the FPF Ban on School Composition

\begin{tabular}{lccccc}
\hline & Low & \multicolumn{4}{c}{ Student Test Score Percentile } \\
\cline { 3 - 6 } & SES & Bottom 10 & Bottom 25 & Top 25 & Top 10 \\
& $(1)$ & $(2)$ & $(3)$ & $(4)$ & $(5)$ \\
\hline \multirow{3}{*}{ FPF X Post-Reform } & $0.039^{* * *}$ & $0.014^{* * *}$ & $0.025^{* * *}$ & $-0.022^{* * *}$ & $-0.015^{* * *}$ \\
& $(0.010)$ & $(0.004)$ & $(0.008)$ & $(0.007)$ & $(0.004)$ \\
FPF & -0.026 & -0.005 & -0.011 & 0.020 & $0.014^{* *}$ \\
Post-Reform & $(0.022)$ & $(0.007)$ & $(0.013)$ & $(0.013)$ & $(0.007)$ \\
Constant & 0.009 & -0.003 & -0.005 & 0.003 & 0.001 \\
& $(0.006)$ & $(0.003)$ & $(0.005)$ & $(0.004)$ & $(0.002)$ \\
Scaled Effect & $0.323^{* * *}$ & $0.216^{* * *}$ & $0.418^{* * *}$ & $0.096^{* * *}$ & 0.016 \\
\hline Observations & $(0.032)$ & $(0.014)$ & $(0.044)$ & $(0.029)$ & $(0.016)$ \\
R-squared & $21.5 \%$ & $13.3 \%$ & $9.8 \%$ & $-8.7 \%$ & $-14.4 \%$ \\
\hline \hline
\end{tabular}

Notes: This table reports DiD estimates of the effect of preventing schools from using the first preference first admission criterion. The DiD specification we use let a school-level outcome $\left(Y_{s t}\right)$ be a function of a dummy variable indicating whether a school is using the FPF admission criteria before the ban $\left(F P F_{s}\right)$, a dummy variable equal to one for the post-reform years $\left(\right.$ Post $\left._{t}\right)$, and the interaction between FPF and

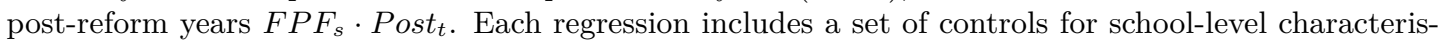
tics including school type, and each admission criterion used by schools. We cluster standard errors at the local authority level. We use five outcome variables: in each school, we compute the share of students who receive Free School Meal (FSM) who are also classified as low-SES students, as well as the share whose KS2 test score is below the 90th and 75th percentiles of their cohort distribution, and the share of students whose KS2 test score is above the $25 \mathrm{th}$ and 10 th percentiles. $* * *$ denote significance at the 1 percent level, ${ }^{* *}$ significance at the 5 percent level, and ${ }^{*}$ significance at the 10 percent level. 


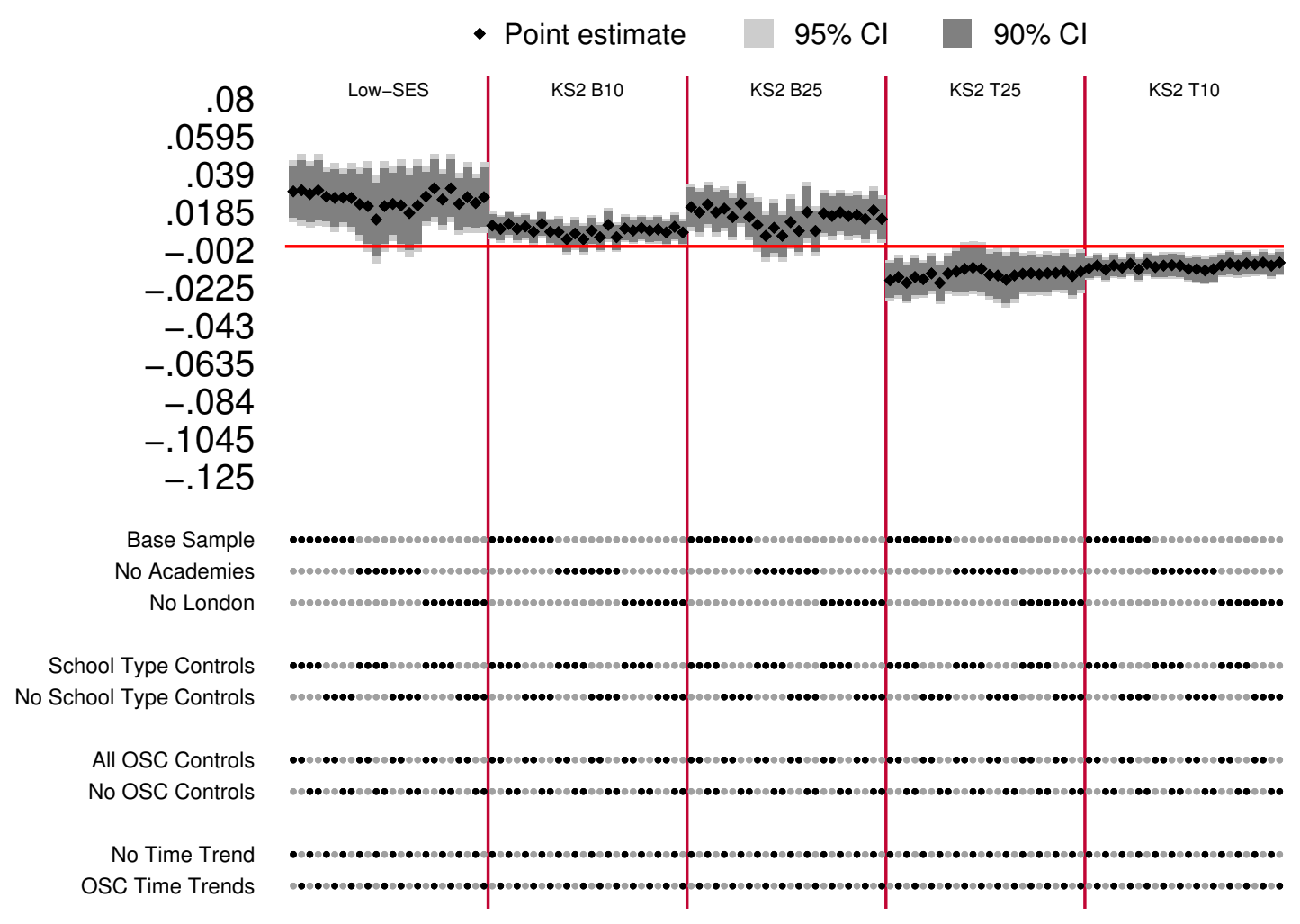

Figure 13: Robustness Checks for the Effect of the FPF Ban on FPF School Composition

Notes: This figure presents robustness checks for the effect of the FPF ban on FPF school composition. At the top of the figure we have the outcomes, which are separated by red bars, and are in order: the share of low-SES year 7 students (labelled as "Low-SES"), the share of year 7 students with a KS2 score in the bottom $10 \%$ of their cohort (labelled as "KS2 B10"), the share of year 7 students with a KS2 score in the bottom $25 \%$ of their cohort (labelled as "KS2 B25"), the share of year 7 students with a KS2 score in the top $25 \%$ of their cohort (labelled as "KS2 T25"), and the share of year 7 students with a KS2 score in the top $10 \%$ of their cohort (labelled as "KS2 T10"). Figure A.4 shows a detailed version of this Figure, outcome by outcome. The bottom part explains what sample and specification are used. The top panel reports the three samples used as alternatives to the main sample we use throughout the analysis (labelled as "Base Sample"): a sample that does not contain academy schools (labelled as "No Academies"), and a sample that excludes students from the local authorities in London (labelled as "No London"). The bottom three panels report whether we include (i) a set of controls for each school type, (ii) a set of controls for each admission criterion used by schools, and (iii) time-trends for each admission criterion. 


\section{References}

Aaronson, Daniel, Lisa Barrow, and William Sander. 2007. "Teachers and Student Achievement in the Chicago Public High Schools." Journal of Labor Economics, 25(1): 95-135.

Abdulkadiroǧlu, Atila, and Tayfun Sönmez. 2003. "School Choice: A Mechanism Design Approach." American Economic Review, 93(3): 729-747.

Abdulkadiroğlu, Atila, Parag A. Pathak, Alvin E. Roth, and Tayfun Sönmez. 2006. "Changing the Boston School Choice Mechanism : Strategy-proofness as Equal Access." NBER Working Paper 11965.

Abdulkadiroğlu, Atila, Parag A. Pathak, Jonathan Schellenberg, and Christopher R. Walters. 2020. "Do Parents Value School Effectiveness?" American Economic Review, 110(5): 1502-1539.

Abdulkadiroǧlu, Atila, Yeon Koo Che, and Yosuke Yasuda. 2011. "Resolving Conflicting Preferences in School Choice: The "Boston Mechanism" Reconsidered." American Economic Review, 101(1): 399-410.

Agarwal, Nikhil, and Paulo Somaini. 2018. "Demand Analysis Using Strategic Reports: An Application to a School Choice Mechanism." Econometrica, 86(2): 391-444.

Angrist, Joshua, Peter Hull, Parag A. Pathak, and Christopher R. Walters. 2020. "Simple and Credible Value-Added Estimation Using Centralized School Assignment." NBER Working Paper 28241.

Athey, Susan, and Guido W. Imbens. Forthcoming. "Design-based analysis in Difference-In-Differences settings with staggered adoption." Journal of Econometrics.

Bayer, Patrick, Fernando Ferreira, and Robert McMillan. 2007. "A Unified Framework for Measuring Preferences for Schools and Neighborhoods." Journal of Political Economy, 115(4): 588-638.

Bergman, Peter, and Isaac McFarlin. 2018. "Education for All? A Nationwide Audit Study of School Choice." NBER Working Paper 25396.

Black, Sandra E. 1999. "Do Better Schools Matter? Parental Valuation of Elementary Education." Quarterly Journal of Economics, 114(2): 577-599.

Bo, Inacio, and Rustamdjan Hakimov. 2020. "Iterative Versus Standard Deferred Acceptance: Experimental Evidence." The Economic Journal, 130(626): 356-392.

Borusyak, Kirill, and Xavier Jaravel. 2018. "Revisiting Event Study Designs." SSRN Working Paper 2826228.

Braun, Sebastian, Nadja Dwenger, and Dorothea Kübler. 2010. "Telling the Truth May Not Pay Off: An Empirical Study of Centralized University Admissions in Germany." B.E. Journal of Economic Analysis and Policy, 10(1).

Burgess, Simon, Ellen Greaves, Anna Vignoles, and Deborah Wilson. 2015. "What Parents Want: School Preferences and School Choice." Economic Journal, 125(587): 1262-1289.

Calsamiglia, Caterina, and Maia Güell. 2018. "Priorities in School Choice: The Case of the Boston Mechanism in Barcelona." Journal of Public Economics, 163: 20-36.

Calsamiglia, Caterina, Chao Fu, and Maia Güell. 2020. "Structural Estimation of a Model of School Choices: The Boston Mechanism versus Its Alternatives." Journal of Political Economy, 128(2): 642-680.

Calsamiglia, Caterina, Guillaume Haeringer, and Flip Klijn. 2011. "A Comment on "School Choice: An Experimental Study"." Journal of Economic Theory, 146(1): 392-396.

Carrell, Scott E., Bruce I. Sacerdote, and James E. West. 2013. "From Natural Variation to Optimal Policy? The Importance of Endogenous Peer Group Formation." Econometrica, 81(3): 855-882.

Carter, Graham. 2006. "The New School Admissions Code - Preference Arrangements." CSN conference.

Carter, Graham, Parag A. Pathak, and Camille Terrier. 2020. "Matching practices for Primary and Secondary Schools - England." Matching in Practice Country Profile 30.

CCAS Project. 2021. "CCAS Project."

Chandra, Amitabh, Amy Finkelstein, Adam Sacarny, and Chad Syverson. 2016. "Health Care Exceptionalism? Performance and Allocation in the US Health Care Sector." American Economic Review, 106(8): 2110-2144.

Chen, Yan, and Onur Kesten. 2017. "Chinese College Admissions and School Choice Reforms: A Theoretical Analysis." Journal of Political Economy, 125(1): 99-139.

Chen, Yan, and Onur Kesten. 2019. "Chinese College Admissions and School Choice Reforms: An Experimental Study." Games and Economic Behavior, 115: 83-100.

Chen, Yan, and Tayfun Sönmez. 2006. "School Choice: An Experimental Study." Journal of Economic Theory, 127(1): 202-231. 
Chen, Yan, Ming Jiang, and Onur Kesten. 2020. "An Empirical Evaluation of Chinese College Admissions Reforms Through a Natural Experiment." Proceedings of the National Academy of Sciences, 117(50): 31696-31705.

Chetty, Raj, John N. Friedman, and Jonah E. Rockoff. 2014. "Measuring the Impacts of Teachers I: Evaluating Bias in Teacher Value-Added Estimates." American Economic Review, 104(9): 2593-2632.

Coldron, John, Tanner, Emily, Finch, Steve, Shipton, Lucy, Wolstenholme, Claire, Willis, Ben, Demack, Sean, and Stiell, Bernadette. 2008. Secondary School Admissions. Annesley, Nottingham:DfES Publications.

DeArmond, Michael, Ashley Jochim, and Robin Lake. 2014. "Making School Choice Work." Center on Reinventing Public Education.

de Chaisemartin, Clément, and Xavier D'Haultfouille. 2020. "Two-Way Fixed Effects Estimators with Heterogeneous Treatment Effects." American Economic Review, 110(9): 2964-2996.

Dee, Thomas S. 2004. "Teachers, Race, and Student Achievement in a Randomized Experiment." Review of Economics and Statistics, 86(1): 195-210.

de Haan, Monique, Pieter A. Gautier, Hessel Oosterbeek, and Bas van der Klaauw. 2018. "The Performance of School Assignment Mechanisms in Practice." IZA Discussion Paper 9118.

Deming, David J., Justine S. Hastings, Thomas J. Kane, and Douglas O. Staiger. 2014. "School Choice, School Quality, and Postsecondary Attainment." American Economic Review, 104(3): 991-1013.

Ding, Tingting, and Andrew Schotter. 2019. "Learning and Mechanism Design: An Experimental Test of School Matching Mechanisms with Intergenerational Advice." Economic Journal, 129(623): 2779-2804.

Dur, Umut, Robert G. Hammond, and Thayer Morrill. 2018. "Identifying The Harm of Manipulable School-Choice Mechanisms." American Economic Journal: Economic Policy, 10(1): 187-213.

Ergin, Haluk, and Tayfun Sönmez. 2006. "Games of School Choice Under the Boston Mechanism." Journal of Public Economics, 90(1-2): 215-237.

Eyles, Andrew, and Stephen Machin. 2019. "The Introduction of Academy Schools to England's Education." Journal of the European Economic Association, 17(4): 1107-1146.

Eyles, Andrew, Stephen Machin, and Sandra McNally. 2017. "Unexpected School Reform: Academisation of Primary Schools in England." Journal of Public Economics, 155: 108-121.

Featherstone, Clayton R., and Muriel Niederle. 2016. "Boston Versus Deferred Acceptance in an Interim Setting: An Experimental Investigation." Games and Economic Behavior, 100: 353-375.

Goodman-Bacon, Andrew. Forthcoming. "Difference-in-Differences with Variation in Treatment Timing." Journal of Econometrics.

Greaves, Ellen, Iftikhar Hussain, Birgitta Rabe, and Imran Rasul. 2021. "Parental Responses to Information About School Quality: Evidence from Linked Survey and Administrative Data." CEPR Discussion Paper 16406.

Haeringer, Guillaume, and Flip Klijn. 2009. "Constrained School Choice." Journal of Economic Theory, 144(5): 1921-1947.

Hakimov, Rustamdjan, and Dorothea Kubler. 2021. "Experiments on Centralized School Choice and College Admissions: A Survey." Experimental Economics, 24(2): 434-488.

Hastings, Justine S., and Jeffrey M. Weinstein. 2008. "Information, School Choice, and Academic Achievement: Evidence from Two Experiments." Quarterly Journal of Economics, 123(4): 1373-1414.

Hastings, Justine S, Thomas J Kane, and Douglas O Staiger. 2009. "Heterogeneous Preferences and the Efficacy of Public School Choice." NBER Working Paper 12415.

He, Yinghua. 2017. "Gaming the Boston School Choice Mechanism in Beijing." TSE Working Paper.

Hofflinger, Alvaro, Denisse Gelber, and Santiago Tellez Cañas. 2020. "School Choice and Parents' Preferences for School Attributes in Chile." Economics of Education Review, 74: 101946.

Hussain, Iftikhar. 2009. "Essays in Household Economics and Economics of Education." PhD Thesis, University College London.

Hussain, Iftikhar. 2015. "Subjective Performance Evaluation in the Public Sector Evidence from School Inspection." Journal of Human Resources, 50(1): 189-221.

Hussain, Iftikhar. 2020. "Housing Market and School Choice Response to School Quality Information Shocks." Unpublished manuscript.

Hwang, Sam Il Myoung. 2017. "How Does Heterogeneity In Beliefs Affect Students In the Boston Mechanism?" Working Paper. 
Kane, Thomas J., and Douglas O. Staiger. 2002. "The Promise and Pitfalls of Using Imprecise School Accountability Measures." Journal of Economic Perspectives, 16(4): 91-114.

Kane, Thomas J., Daniel F. Mccaffrey, Trey Miller, and Douglas O. Staiger. 2013. "Have We Identified Effective Teachers? Validating Measures of Effective Teaching using Random Assignment." Research Paper. MET Project. Bill \& Melinda Gates Foundation.

Kapor, Adam J., Christopher A. Neilson, and Seth D. Zimmerman. 2020. "Heterogeneous beliefs and school choice mechanisms." American Economic Review, 110(5): 1274-1315.

Koedel, Cory. 2009. "An Empirical Analysis of Teacher Spillover Effects in Secondary School." Economics of Education Review, 28(6): 682-692.

Koedel, Cory, Kata Mihaly, and Jonah E. Rockoff. 2015. "Value-Added Modeling: A Review." Economics of Education Review, 47: 180-195.

Miralles, Antonio. 2009. "School Choice: The Case for the Boston Mechanism." Working Paper.

Morris, Carl N. 1983. "Parametric Empirical Bayes Inference: Theory and Applications." Journal of the American Statistical Association, 78(381): 47-55.

Pais, Joana, and Ágnes Pintér. 2008. "School Choice and Information: An Experimental Study on Matching Mechanisms." Games and Economic Behavior, 64(1): 303-328.

Pathak, Parag A. 2016. "What Really Matters in Designing School Choice Mechanisms." in Advanced in Economics and Econometrics, 11th World Congress of the Econometric Society, eds. Larry Samuelson, Cambridge University Press.

Pathak, Parag A., and Tayfun Sönmez. 2008. "Leveling the Playing Field: Sincere and Sophisticated Players in the Boston Mechanism." American Economic Review, 98(4): 1636-1652.

Pathak, Parag A., and Tayfun Sönmez. 2013. "School admissions Reform in Chicago and England: Comparing Mechanisms by Their Vulnerability to Manipulation." American Economic Review, 103(1): 80106.

Song, Yan, Kentaro Tomoeda, and Xiaoyu Xia. 2020. "Sophistication and Cautiousness in College Applications." SSRN Working Paper 3711118.

Sun, Liyang, and Sarah Abraham. Forthcoming. "Estimating Dynamic Treatment Effects in Event Studies with Heterogeneous Treatment Effects." Journal of Econometrics.

Troyan, Peter. 2012. "Comparing School Choice Mechanisms by Interim and Ex-Ante Welfare." Games and Economic Behavior, 75(2): 936-947. 


\section{A Additional Figures and Tables}

\begin{tabular}{|c|c|c|c|}
\hline 17 & Year 13 & \multirow{2}{*}{ Key Stage 5} & \multirow{7}{*}{ SECONDARY } \\
\hline 16 & Year 12 & & \\
\hline 15 & Year 11 & \multirow{2}{*}{ Key Stage 4} & \\
\hline 14 & Year 10 & & \\
\hline 13 & Year 9 & \multirow{3}{*}{ Key Stage 3} & \\
\hline 12 & Year 8 & & \\
\hline 11 & Year 7 & & \\
\hline 10 & Year 6 & \multirow{4}{*}{ Key Stage 2} & \multirow{7}{*}{ PRIMARY } \\
\hline 9 & Year 5 & & \\
\hline 8 & Year 4 & & \\
\hline 7 & Year 3 & & \\
\hline 6 & Year 2 & \multirow{2}{*}{ Key Stage 1} & \\
\hline 5 & Year 1 & & \\
\hline 4 & Reception & \multirow{2}{*}{$\begin{array}{c}\text { Foundation } \\
\text { stage }\end{array}$} & \\
\hline 3 & Nursery & & NURSERY \\
\hline AGE & YEAR & STAGE & SCHOOLS \\
\hline
\end{tabular}

Figure A.1: British Education System

Notes: This figure presents the British education system, which is divided into primary education (from ages 5 to 10 ) and secondary education (from ages 11 to 16). Primary education corresponds to Key Stage 1 and 2, while secondary education corresponds to Key Stage 3 and 4, and 5. In this paper, we focus on admissions to secondary schools in England at age 11. 


\begin{tabular}{|c|c|c|}
\hline Criteria & 2003 code & 2007 code \\
\hline $\begin{array}{l}\text { First } \\
\text { Preference } \\
\text { First }\end{array}$ & NO REFERENCE & $\begin{array}{l}2.13 \text { In setting oversubscription criteria the admission authorities for all maintained schools } \\
\text { must not give priority to children according to the order of other schools named as } \\
\text { preferences by their parents, including 'first preference first' arrangements. }\end{array}$ \\
\hline $\begin{array}{l}\text { Parental } \\
\text { commitment }\end{array}$ & NO REFERENCE & $\begin{array}{l}2.13 \text { In setting oversubscription criteria the admission authorities for all maintained schools } \\
\text { must not give priority to children according to their parents' willingness to give } \\
\text { practical support to the ethos of the school or to support the school financially or in some } \\
\text { other way. }\end{array}$ \\
\hline $\begin{array}{l}\text { Children of } \\
\text { associated } \\
\text { adults }\end{array}$ & NO REFERENCE & $\begin{array}{l}2.13 \text { In setting oversubscription criteria the admission authorities for all maintained schools } \\
\text { must not give priority to children whose parents are current or former staff or } \\
\text { governors or who have another connection to the school. }\end{array}$ \\
\hline $\begin{array}{l}\text { Children in } \\
\text { care }\end{array}$ & $\begin{array}{l}\text { 3.14 Children in public care are a disadvantaged group who } \\
\text { have very low average levels of attainment, often related to } \\
\text { frequent changes of school because their care placements } \\
\text { change. It is recommended that all admission authorities } \\
\text { give these children top priority in their oversubscription } \\
\text { criteria. Schools designated by the Department as having a } \\
\text { religious character may give priority to looked after children } \\
\text { of their faith over those children belonging to other faiths. } \\
\text { Schools will then also be able to offer places that become } \\
\text { available in the school year to these children first over others } \\
\text { on the waiting list, if one is maintained, to ensure that they are } \\
\text { quickly placed in a school to meet their needs. }\end{array}$ & $\begin{array}{l}2.7 \text { Children in care are among the most vulnerable children in society and it is of paramount } \\
\text { importance that a school place is found that is in the best interests of the child as quickly as } \\
\text { possible. All admission authorities must give highest priority in their oversubscription } \\
\text { criteria to these children as required by the Education (Admission of Looked after } \\
\text { Children) (England) Regulations } 2006 \text {. } \\
\text { The practical effect of this is that in a school's published admission arrangements the first } \\
\text { and highest oversubscription criterion must be in respect of these children. }\end{array}$ \\
\hline Siblings & $\begin{array}{l}\text { 3.5 Commonly used and acceptable criteria include sibling } \\
\text { links, distance from the school, ease of access by public } \\
\text { transport, medical or social grounds (with an explanation of } \\
\text { what evidence is required and how this will be assessed), } \\
\text { catchment areas, transfer from named feeder primary schools } \\
\text { and whether the child is in public care. }\end{array}$ & $\begin{array}{l}\text { Siblings of children who are still at the school } \\
2.17 \text { Many parents will want their children to attend the same school and most } \\
\text { admission authorities recognize this and give priority in admissions to siblings. This is } \\
\text { generally good practice, with the limited exceptions set out below in the case of the small } \\
\text { number of partially selective schools which select more than } 10 \% \text { of their intake by aptitude } \\
\text { or ability (see paragraph } 2.20 \text { ), and at those designated grammar schools that rank children } \\
\text { according to their performance in a test and allocate places to those who score the highest } \\
\text { (see paragraph } 2.13(\mathrm{n}) \text { ). Schools that use any form of selection or banding and test } \\
\text { children must observe the provision at paragraph } 2.89 \text {. [ } 2.89 \text {. Admission authorities must not } \\
\text { adjust the score achieved by any child in a test in order to take account of oversubscription } \\
\text { criteria, such as having a sibling at the school.] } \\
\text { Giving priority to siblings particularly supports families with young children of primary } \\
\text { school age who may not be able to travel independently. Admission authorities should also } \\
\text { consider carefully how other relatives, including those adopted or others living permanently } \\
\text { in the household will be treated if a sibling criterion is adopted, and must make this clear in } \\
\text { information provided to parents including how terms such as step-children will be defined. } \\
\text { Siblings at secondary schools and schools that select } 10 \% \text { or less by ability or aptitude } \\
2.19 \text { At secondary school age, children are usually more independent [than at primary } \\
\text { schools] but many parents will still want their children to attend the same schools. Giving }\end{array}$ \\
\hline
\end{tabular}

Figure A.2: Changes in Oversubscription Criteria Between the 2003 and 2007 School Admissions Codes 


\begin{tabular}{|c|c|c|}
\hline Criteria & 2003 code & 2007 code \\
\hline & & $\begin{array}{l}\text { priority to siblings at secondary schools that have no more than } 10 \% \text { selection by } \\
\text { ability or aptitude is acceptable and can be good practice. } \\
\text { Siblings at secondary schools that select more than } 10 \% \text { of their intake by ability or } \\
\text { aptitude } \\
2.20 \text { A number of secondary schools are permitted under section } 100 \text { of the School } \\
\text { Standards and Framework Act } 1998 \text { to use pre-existing partial selection by ability or } \\
\text { aptitude and a number of these admit substantially more than } 10 \% \text { of their intake in this } \\
\text { way. Some of these schools give priority for their nonselective places to siblings of children } \\
\text { already at the school - whether or not those older siblings secured selective or non-selective } \\
\text { places. This reduces the number of non-selective places available to children who do not } \\
\text { have siblings at the school. The Government believes that this may lead to the school's } \\
\text { intake including a disproportionately high number of children who would have passed the } \\
\text { selection test, as some younger siblings would be likely to have passed the selection test if } \\
\text { they had taken it. At the same time, the chance for children who would not have passed the } \\
\text { test to gain a place at the school would be correspondingly reduced. It is often the case that } \\
\text { children admitted by selection are drawn from a much wider area than those who are not and } \\
\text { this reduces the number of non-selective places for children who live closer to the school. } \\
\text { Where there are a number of partially selective schools in an area this problem is } \\
\text { exacerbated. } \\
\text { Former siblings } \\
2.13 \text { In setting oversubscription criteria the admission authorities for all maintained schools } \\
\text { must not allocate places at a school on the basis that a sibling or other relative is a } \\
\text { former pupil, including siblings who were on roll at the time of application but will have } \\
\text { left by the time the child starts school. }\end{array}$ \\
\hline $\begin{array}{l}\text { Medical/social } \\
\text { needs }\end{array}$ & $\begin{array}{l}\text { 3.5 Commonly used and acceptable criteria include sibling } \\
\text { links, distance from the school, ease of access by public } \\
\text { transport, medical or social grounds (with an explanation of } \\
\text { what evidence is required and how this will be assessed), } \\
\text { catchment areas, transfer from named feeder primary schools } \\
\text { and whether the child is in public care. }\end{array}$ & $\begin{array}{l}\text { 2.24 If admission authorities propose to give higher priority to children for social or medical } \\
\text { reasons they must ensure that in doing so they are not failing to comply with paragraph } \\
2.13(\mathrm{~g}) \text { of this Code, which prohibits the use of oversubscription criteria that discriminate } \\
\text { against or disadvantage children because of their special educational needs or disabilities. } \\
2.25 \text { Admission authorities must not use this criterion to give a child a lower priority in } \\
\text { obtaining a place at the school, but it is acceptable to give higher priority to children or } \\
\text { families where there is a social or medical need (for example where one or both parents or } \\
\text { the child has a disability that may make travel to a school further away more difficult). }\end{array}$ \\
\hline Catchment & $\begin{array}{l}\text { 3.5 Commonly used and acceptable criteria include sibling } \\
\text { links, distance from the school, ease of access by public } \\
\text { transport, medical or social grounds (with an explanation of } \\
\text { what evidence is required and how this will be assessed), } \\
\text { catchment areas, transfer from named feeder primary schools } \\
\text { and whether the child is in public care. }\end{array}$ & $\begin{array}{l}2.35 \text { The } 1997 \text { Rotherham } 40 \text { Judgment confirmed that there is nothing unlawful in the } \\
\text { principle of admission authorities operating catchment areas as part of their } \\
\text { oversubscription criteria and thereby giving priority to local children whose parents } \\
\text { have expressed a preference for the school. However, admission authorities must not } \\
\text { guarantee places to parents in a local catchment area, in case the pattern of preferences } \\
\text { expressed does not allow this guarantee to be met. In drawing up catchment areas, admission } \\
\text { authorities should ensure that they reflect the diversity of the community served by the } \\
\text { school, and must not exclude particular housing estates or addresses in a way that might }\end{array}$ \\
\hline
\end{tabular}




\begin{tabular}{|c|c|c|}
\hline Criteria & 2003 code & 2007 code \\
\hline & & $\begin{array}{l}\text { disadvantage particular social groups. A catchment area does not prevent parents expressing } \\
\text { a preference for the school if they do not live in the area. } \\
\text { 2.36 Local authorities and admission authorities must not suggest that parents are required to } \\
\text { express a preference for the school in whose catchment area they live, or that they have been } \\
\text { allocated a place at that school before they have expressed a preference. Local authorities } \\
\text { must be clear that parents have a statutory right to express a preference for any school they } \\
\text { choose, although they should explain the possible consequences of not expressing a } \\
\text { preference for a school in whose catchment area they live. } \\
\text { 2.37 Some schools have adopted inner and outer catchment areas and these work well for } \\
\text { some specialist schools in particular by extending choice to more parents. These work by } \\
\text { giving priority for a specified number of places in the inner catchment area and the } \\
\text { remaining places in the outer area. } \\
\text { 2.38 Some schools establish a number of small catchment areas some of which are some } \\
\text { distance from school. This practice can exclude some families and if used along with certain } \\
\text { other criteria such as partial selection by ability or aptitude or siblings can substantially limit } \\
\text { the number of places for families living nearer the school. If using catchment areas in this } \\
\text { way admission } \\
\text { authorities should take into account the possible effect of their other oversubscription criteria } \\
\text { and the admission arrangements at other schools in the area in limiting access to the school. } \\
\text { 2.39 For children of UK Service personnel and other Crown Servants admission authorities } \\
\text { must treat a family returning to their area as meeting the residency criteria for that catchment } \\
\text { area even if no house is currently owned in that area once proof of the posting has been } \\
\text { provided. } \\
\text { 2.40 Where catchment areas or distance from the school are used as oversubscription } \\
\text { criteria, admission authorities should provide a map of the areas, and indicate how far } \\
\text { parents within those areas have succeeded in getting places in the past, and whether that is } \\
\text { likely to be a guide for the future. Catchment areas must not be set after applications have } \\
\text { been made. }\end{array}$ \\
\hline Feeder schools & $\begin{array}{l}\text { 3.5 Commonly used and acceptable criteria include sibling } \\
\text { links, distance from the school, ease of access by public } \\
\text { transport, medical or social grounds (with an explanation of } \\
\text { what evidence is required and how this will be assessed), } \\
\text { catchment areas, transfer from named feeder primary } \\
\text { schools and whether the child is in public care. }\end{array}$ & $\begin{array}{l}2.66 \text { The use of named feeder [primary] schools allows local continuity and can support } \\
\text { good curriculum and geographical links between phases in an area. Admission authorities } \\
\text { must ensure that such arrangements do not disadvantage children from more deprived } \\
\text { areas, for example they must not include only feeder primaries that serve more } \\
\text { advantaged groups and leave out schools that are a similar distance from the school } \\
\text { but serve less advantaged groups. }\end{array}$ \\
\hline $\begin{array}{l}\text { Special } \\
\text { Education } \\
\text { Needs }\end{array}$ & $\begin{array}{l}\text { Children with special educational needs and banding } \\
2.84 \text { Children with special educational needs can be included } \\
\text { in banding arrangements, that is they can be allocated to the }\end{array}$ & $\begin{array}{l}\text { 2.6 All governing bodies are required by section } 324 \text { of the Education Act } 1996 \text { to } \\
\text { admit to the school a child with a statement of special education needs that names the } \\
\text { school. This is not an oversubscription criterion. Schools must admit such children } \\
\text { whether they have places or not. }\end{array}$ \\
\hline
\end{tabular}




\begin{tabular}{|c|c|c|}
\hline Criteria & 2003 code & 2007 code \\
\hline & $\begin{array}{l}\text { band appropriate to their ability, but schools must not refuse } \\
\text { to admit a child with a statement that names the school. }\end{array}$ & \\
\hline Faith related & $\begin{array}{l}\text { 3.9 Schools designated by the Department as having a } \\
\text { religious character may give preference in their admission } \\
\text { arrangements to members of a particular faith or } \\
\text { denomination (as may be required by their Trust Deed), } \\
\text { providing this does not conflict with other legislation, such as } \\
\text { race relations legislation. Where they do, their admission } \\
\text { arrangements should make clear whether a statement of } \\
\text { religious affiliation or commitment would be sufficient; } \\
\text { whether it is to be 'tested' for admission purposes and if so, } \\
\text { how; and what, if any, references would be required from the } \\
\text { family's priest, Minister or other religious leader and how they } \\
\text { will be used to decide on the application. } \\
\text { 3.10 Faith schools can contribute to community cohesion by } \\
\text { having admission arrangements that are inclusive of other } \\
\text { faiths and of all elements of the population of their local area. } \\
\text { Some faith schools already achieve inclusiveness by } \\
\text { designating a proportion of places for which children of their } \\
\text { own faith or denomination will be given priority, and the } \\
\text { remainder as community or open places for which local } \\
\text { children will be given priority. Note: this is quite different } \\
\text { from 'quotas' which would reserve places solely for particular } \\
\text { groups, and would mean leaving places empty if not enough } \\
\text { members of those groups apply. With the repeal by the } \\
\text { Education Act } 2002 \text { of section } 91 \text { of the School Standards and } \\
\text { Framework Act } 1998 \text {, it is no longer possible for foundation } \\
\text { and aided schools with a religious character to agree special } \\
\text { arrangements with their LEA by which they can keep places } \\
\text { empty if they do not have enough applications from their } \\
\text { particular faith or denomination. Where evidence of } \\
\text { commitment to another faith (or denomination) is required, the } \\
\text { guidance in paragraph } 3.9 \text { applies. } \\
\text { 3.11 The governing bodies of Church of England schools } \\
\text { that are their own admission authorities must consult their } \\
\text { local Diocesan Board about the admission arrangements they } \\
\text { are proposing to have for their schools before they go out to } \\
\text { statutory consultation with other admission authorities, and } \\
\text { they must have regard to the Board's advice. }\end{array}$ & 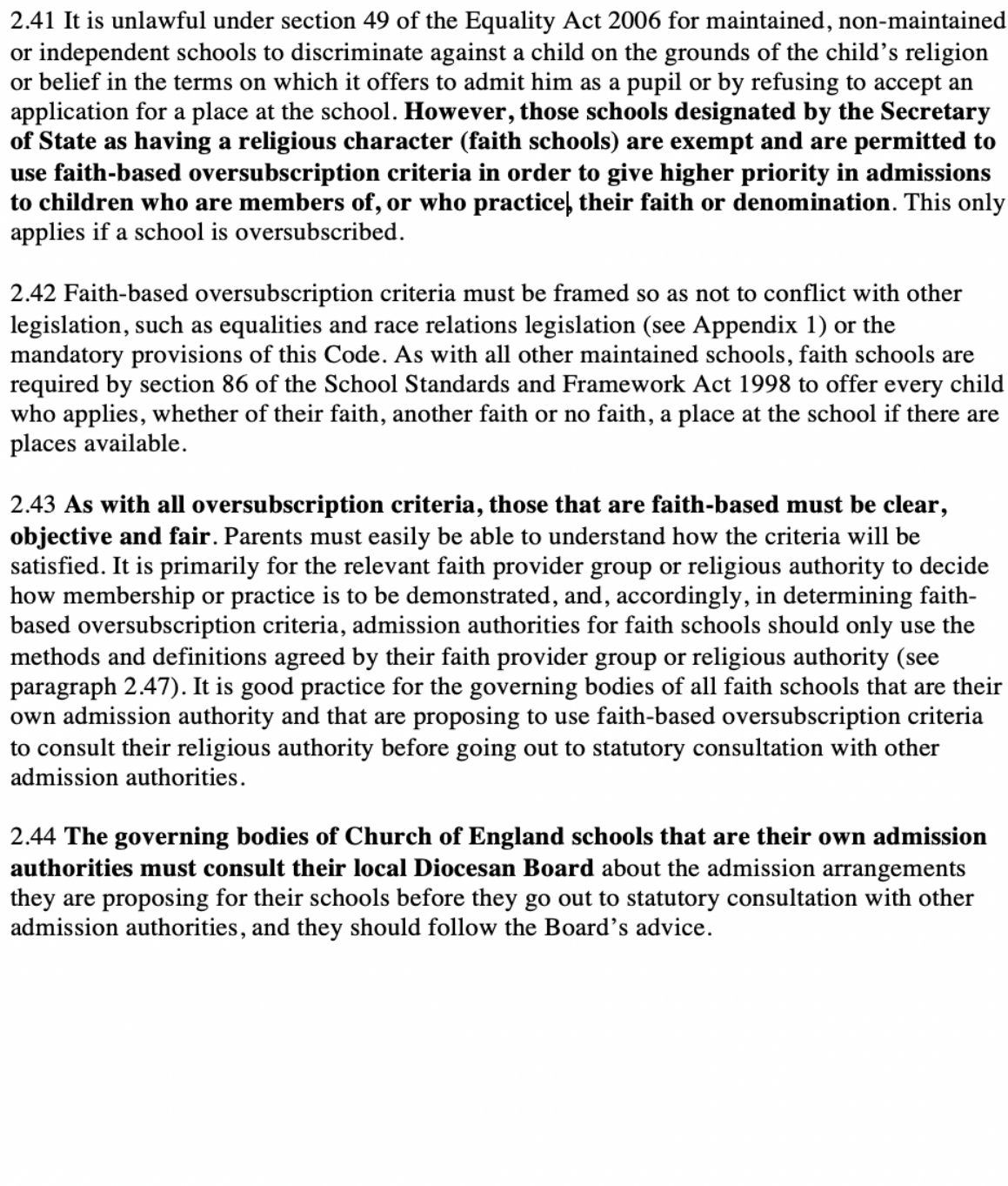 \\
\hline
\end{tabular}


(a) Competitive IA and DA Local Authorities

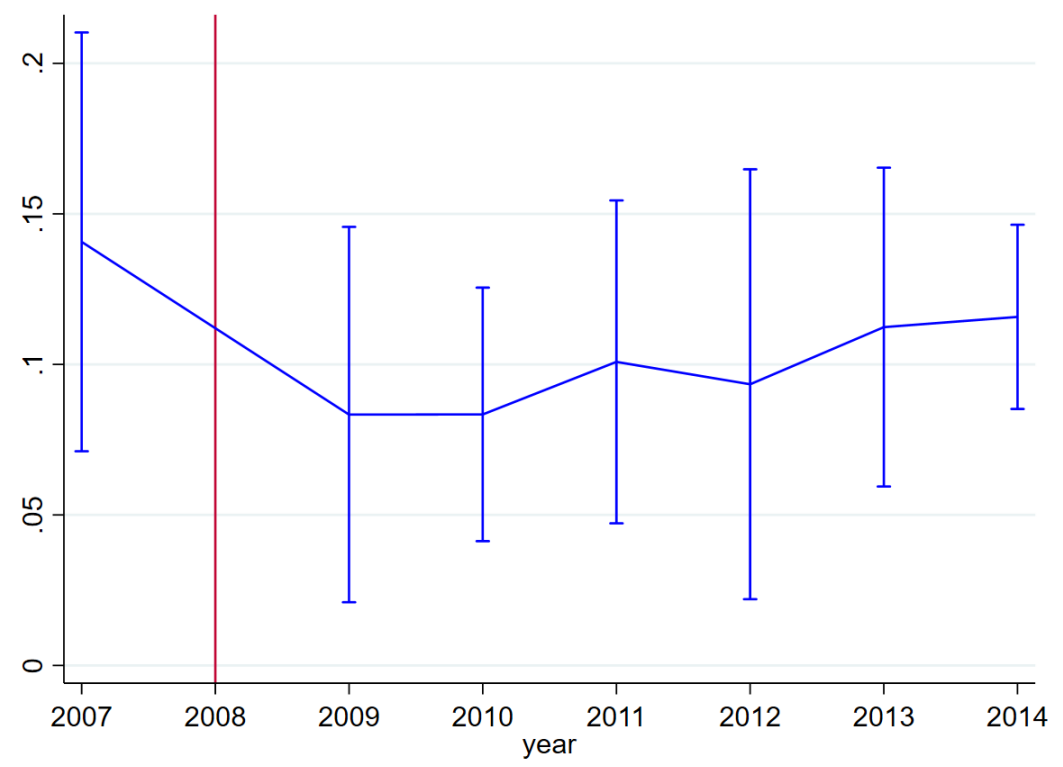

(b) Non-Competitive IA and DA Local Authorities

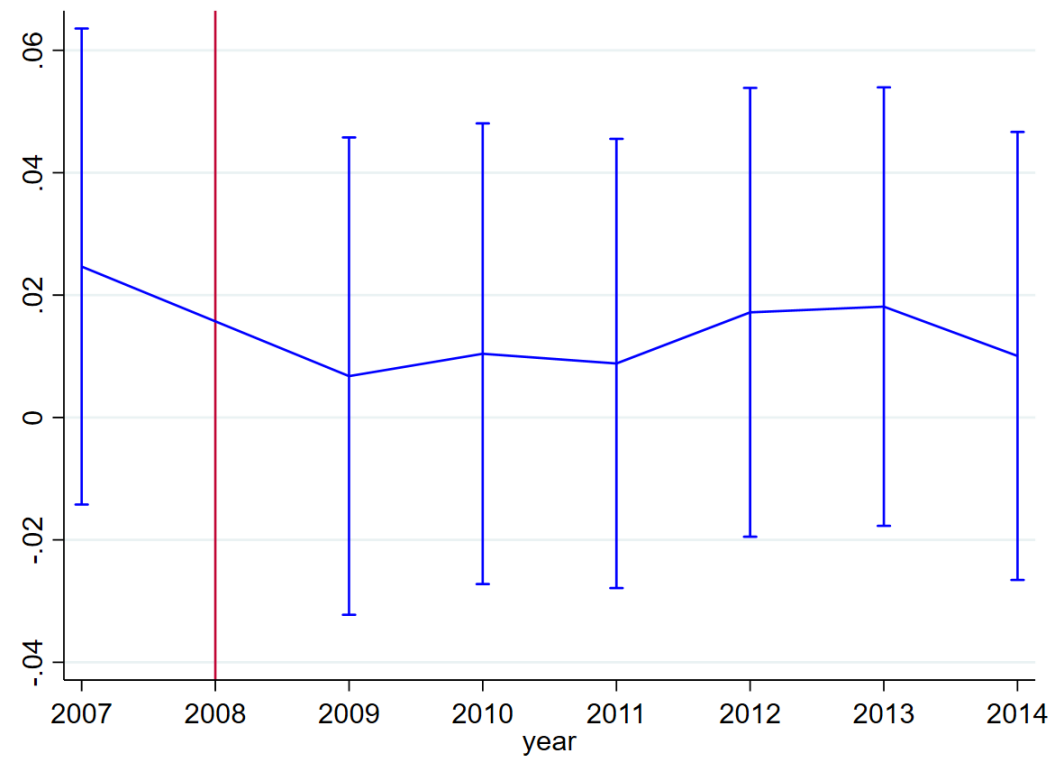

Figure A.3: First Choice Accommodation (with Preference Controls)

Notes: This figure reports the $\beta_{t}$ coefficients from the following regression: $y_{i t}=\sum_{t \in \mathcal{T}} \beta_{t} I A_{i} \cdot T_{t}+X_{i}^{\prime} \delta+\varepsilon_{i t}$ where $y_{i t}$ is the proportion of students in local authority $i$ in year $t$ receiving their first choice, $\mathcal{T}$ is the set of years that have first choice data from 2007 onwards, $I A_{i}$ is a dummy variable that is equal to one for IA local authorities, $T_{t}$ is an indicator for the year $t, X_{i}$ is a vector of local authority level controls, and $\varepsilon_{i t}$ is an idiosyncratic error term. The specification shown in this figure controls for the number of preferences in the local authority. Panel (a) is the regression for competitive local authorities, which have a share of selective schools in the top quartile of all local authorities. Non-competitive local authorities are all remaining local authorities. We show the $95 \%$ confidence interval of all coefficients. We cluster standard errors at the local authority level. 
(a) Low-SES

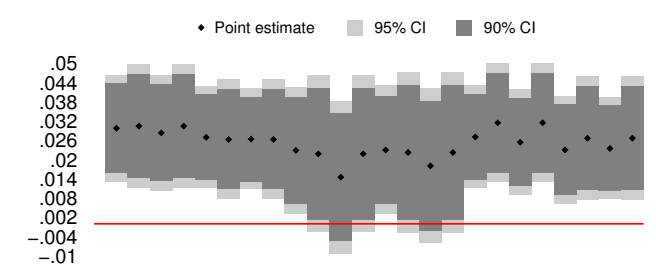

$$
\begin{aligned}
& \text { Base Sample } \\
& \text { No Academies } \\
& \text { No Londor }
\end{aligned}
$$

School Type Controls
No School Type Controls$$
\text { All osc Controls } \ldots \ldots \ldots \ldots \ldots
$$

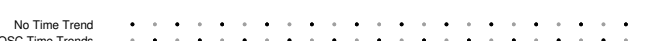

(c) KS2 B25

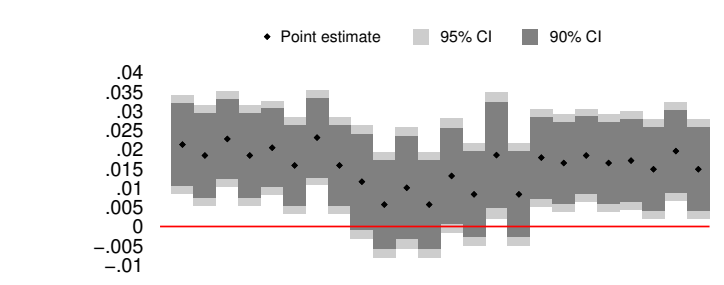

(b) KS2 B10

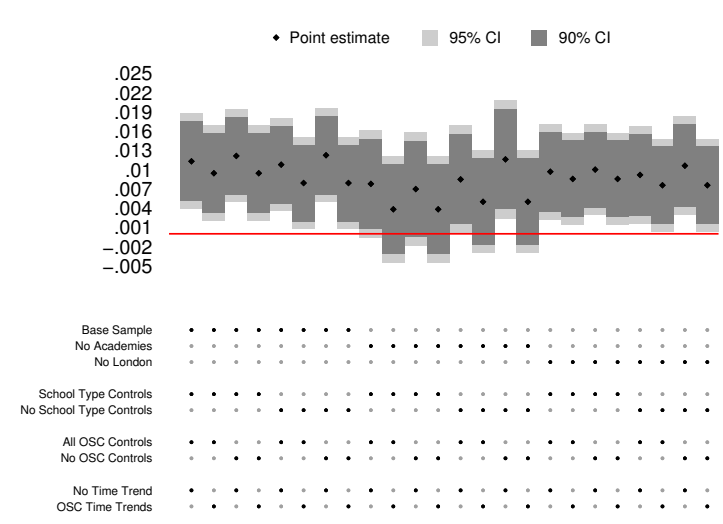

(d) KS2 T25

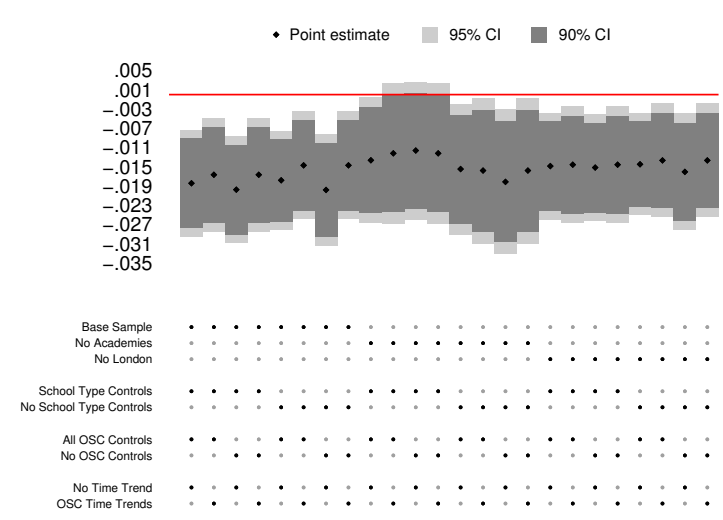

(e) KS2 T10

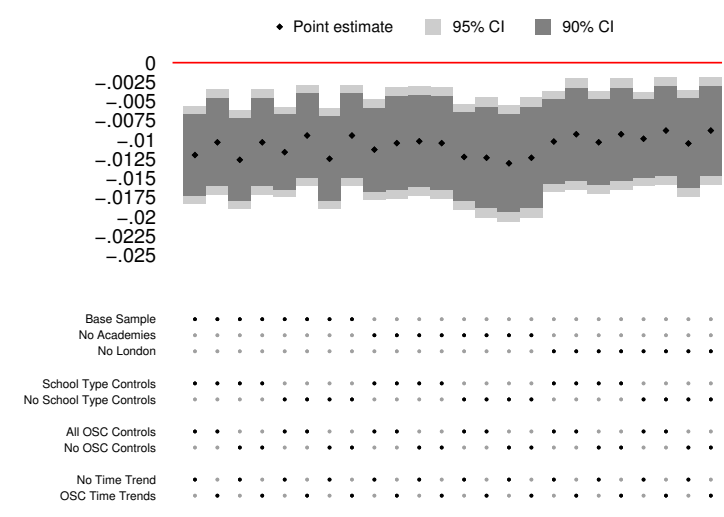

Figure A.4: Effect of the FPF Ban on FPF Schools' Composition (Relative to EP)

Notes: This figure presents a detailed version, outcome by outcome, of the robustness checks for the effect of the FPF ban on school composition presented in Figure 13. See Figure 13 for more details. 


\section{B Value-Added Computation}

We compute a school's value-added using the following specification that is similar to what is outlined in Koedel, Mihaly and Rockoff (2015)

$$
y_{i s t}=X_{i s t}^{\prime} \beta+Z_{s t}^{\prime} \gamma+\theta_{s}+\varepsilon_{i s t},
$$

where $y_{\text {ist }}$ is a dummy variable that measures whether year 7 student $i$ who attends school $s$ in year $t$ has level 2 qualifications in at least five GCSE exams including English and Mathematics ${ }^{57}$, $X_{i s t}$ is a vector of student characteristics (the student's KS2 score, gender, race, and free school meal eligibility), $Z_{s t}$ is a vector of time-varying school characteristics (the average KS2 scores of the school's current intake, the school's racial and gender composition, and the proportion of the school's year 7 students who qualify for a free school meal), $\theta_{s}$ is school $s$ 's fixed effect, and $\varepsilon_{i s t}$ is an idiosyncratic error term. The student's KS2 score acts as a proxy for the lagged test score of student $i$ as students take the GCSE tests after the KS2 test. These controls are consistent with those used in past studies (e.g. Aaronson, Barrow and Sander, 2007; Kane et al., 2013; Chetty, Friedman and Rockoff, 2014; Koedel, 2009). We can interpret a school's value-added as the contribution to a student's likelihood of obtaining level 2 qualifications in at least five GCSE exams including English and Mathematics.

To account for noise in the fixed effects estimates (Kane and Staiger, 2002), we construct an empirical Bayes estimate of the school's value-added. We follow the general procedure of Koedel, Mihaly and Rockoff (2015). The shrunken value-added estimate is given by:

$$
\hat{\theta}_{s}^{E B}=\alpha_{s} \hat{\theta}_{s}+\left(1-\alpha_{s}\right) \bar{\theta}
$$

In Equation (B.2), $\hat{\theta}_{s}$ is the fixed effect estimate for school $s$ obtained from estimating Equation (B.1), $\bar{\theta}$ is the average of all schools' value-added weighted by the number of students, and $\alpha_{s}=$ $\frac{\hat{\sigma}^{2}}{\hat{\sigma}^{2}+\hat{\lambda}}$, where $\hat{\sigma}^{2}$ is the estimate for the variance of the school fixed effects and $\hat{\lambda}$ is the estimate of the variance of the estimate of $\hat{\theta}_{s}$. To compute $\hat{\lambda}$ we take the square of the standard error of $\hat{\theta}_{s}$. We employ the software developed by Chandra et al. (2016), who follow the procedure of Morris (1983) to compute $\hat{\sigma}^{2}$ and ultimately to compute the shrunk estimates of value-added. Figure B.1 plots the distribution of the value-added estimates with and without shrinkage.

Heterogenous value-added for high-SES and low-SES students. To obtain the estimates for the heterogeneous school value-added by SES we estimate the following:

$$
y_{i s t}=X_{i s t}^{\prime} \beta+Z_{s t}^{\prime} \gamma+\theta_{s}+\kappa_{s} L o w S E S_{i s t}+\varepsilon_{i s t} .
$$

The notation of Equation (B.3) follows that of Equation of (B.1) with the addition of LowSES ${ }_{i s t}$ which is an indicator that is equal to 1 when a student is low-SES and 0 when the student is high-SES. The new term $\kappa_{s}$ LowSES $S_{i s t}$ is an interaction between the school's fixed effect and the student's low-SES indicator. Thus the estimated value-added of school $s$ is $\hat{\theta}_{s}$ for high-SES students and $\hat{\theta}_{s}+\hat{\kappa}_{s}$ for low-SES students. ${ }^{58}$ As previously, we compute shrunk estimates following Equation (B.2) for the entire sample of value-added estimates.

\footnotetext{
${ }^{57}$ Achieving level 2 in five subjects including English and Mathematics is a standard performance metric used to asses both students sucess and school performance. This indicator is reported in schools performance tables published by the Department for Education.

${ }^{58}$ The specification is similar to the approach Dee (2004) uses.
} 


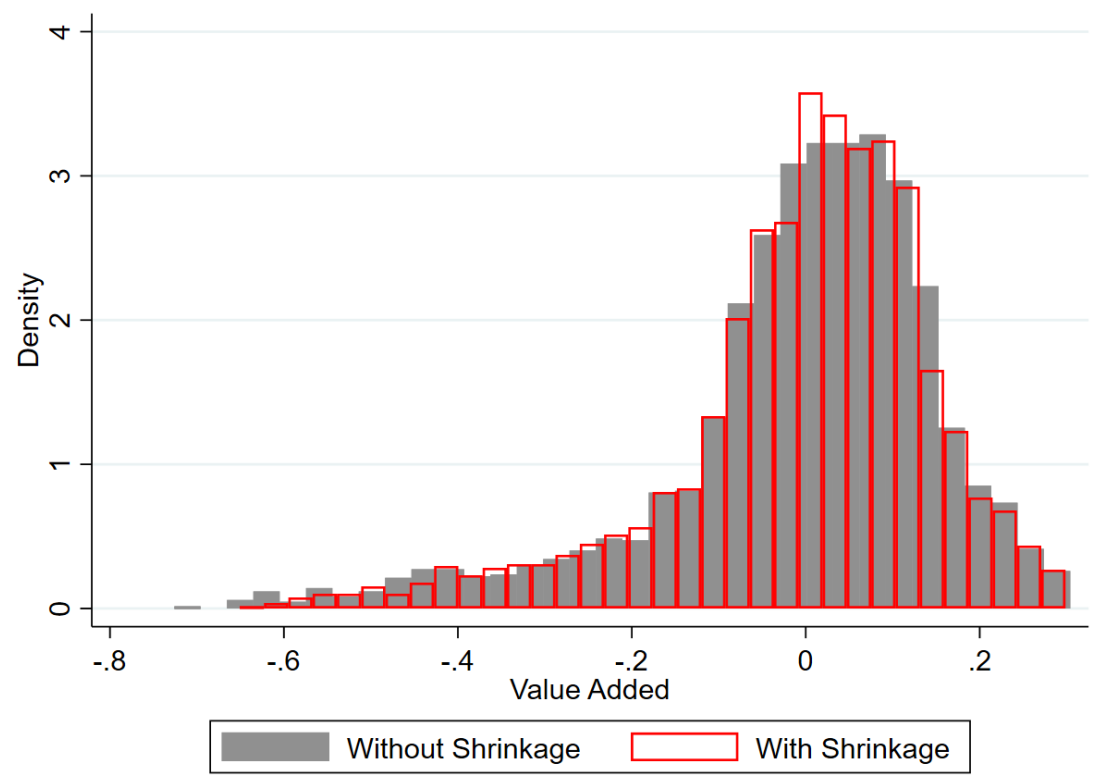

Figure B.1: Distribution of School Value-Added (with and without Shrinkage)

Notes: The gray bars denote the value-added estimates without shrinkage and the red outlined bars denote the value-added estimates with shrinkage. The standard deviation is 0.15 and 0.16 with and without shrinkage, respectively.

Table B.1: Correlation Between School Value-Added and Schools' Characteristics Pre-Reform

\begin{tabular}{lcccc}
\hline & $\begin{array}{c}\text { School KS2 } \\
(1)\end{array}$ & $\begin{array}{c}\text { School KS3 } \\
(2)\end{array}$ & $\begin{array}{c}\text { School FSM } \\
(3)\end{array}$ & $\begin{array}{c}\text { Selective } \\
(4)\end{array}$ \\
\hline \multirow{3}{*}{ Covariance } & $0.218^{* * *}$ & $0.357^{* * *}$ & $-0.743^{* * *}$ & $0.078^{* * *}$ \\
& $(0.003)$ & $(0.004)$ & $(0.006)$ & $(0.003)$ \\
Constant & $0.497^{* * *}$ & $0.380^{* * *}$ & $0.625^{* * *}$ & $0.491^{* * *}$ \\
& $(0.001)$ & $(0.002)$ & $(0.001)$ & $(0.001)$ \\
Observations & 16,532 & 19,167 & 19,247 & 19,248 \\
R-squared & 0.313 & 0.251 & 0.482 & 0.027 \\
\hline
\end{tabular}

Notes: This table contains the regression outcomes by regressing the school value-added measure (with shrinkage) onto various school characteristics. The characteristics are: (1) the average KS2 score of the current intake of year 7 students at school $s$, (2) the average KS3 achievement of the current intake of year 7 students at school $s$, (3) the proportion of students who qualify for a free school meal (low-SES) at school $s$, and (4) a dummy variable of whether school $s$ is selective. *** denote significance at the 1 percent level, ${ }^{* *}$ significance at the 5 percent level, and ${ }^{*}$ significance at the 10 percent level. 